SF

951

DI27 


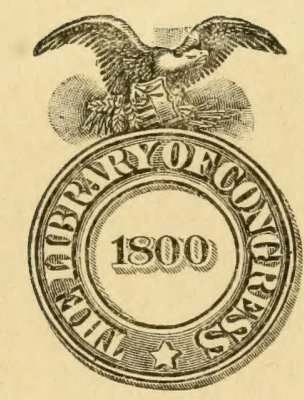






\section{PRACTICAL TREATISE}

ON THE MOST OBVIOUS

\section{DISEASES PECULIAR TO HORSES;}

TOGETHER WITH DIRECTIONS FOR

\section{THEIR MOST RATIONAL TREATMENT;}

CONTAINING, ALSO,

SOME VALUABLE INFORMATION ON THE ART OF SHOEING HORSES.

\section{BY GEORGE H. DADD, V. S.,}

Author of "Anatomy and Physiology of the Horse," "Modern Horse Doctor," etc., etc., and Principal of the Veterinary School of Chicago.

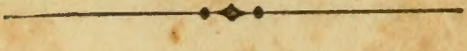

CHICA GO:

PUBLISHED BY LORD \& SMITH.

S. C. GRIGGS \& CO.

NEW YORK:

BLAKEMAN \& MASON; C. M. SAXTON. 
Entered according to the ACt OF Congress, in the Yehr 1868, BY GEO. H. DADD, V.S.,

IN the Clere's Office of the District Court of the United States, for the NORTHERN District OF ILLinoIs.

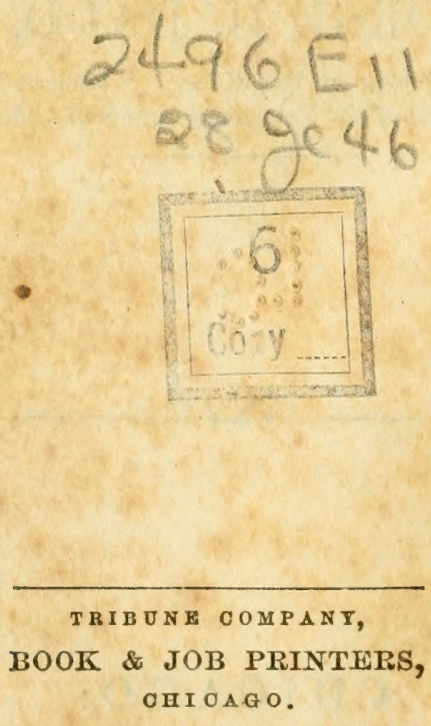

LrMAN \& ZeEsz, Stereotypers, 47 Clark street, Chicago. 


\section{P R E F A C E,}

THE object of the author in preparing this work, is to meet a great emergency, which all persons interested in the welfare of the Horse, acknowledge to exist.

For example, many works on the treatment of equine affections are too voluminous for practical use among those, who, from sheer necessity, are compelled to try their skill as amateur physicians, in view of restoring to usefulness a siok or disabled animal.

I find that in the hour of need, or when a horse is suddenly attacked with a dangerous malady, and appears to suffer tormenting pains, and no surgeon at hand, humanity prompts the owner to seek for some information that may enable him to prevent the destruction of his property; under such circumstances he cannot spare the time to sit down and read a lengthy article; his object is to ascertain, without delay, the nature of the disease and its treatment.

Since the commencement of our present national troubles, the spread of disease is alarmingly on the increase, from the fact that thousands of diseased animals have been disposed of and distributed all over the country, carrying with them the propagating germs of infection; and many of these animals have proved a sore pest, and dear purchases, althongh they may have cost but a trifle. In the same ratio, therefore, as disease multiplies, so also will be the desire 
for practioal information on the naturo of the same. For these, and other reasons which might be alluded to, thore exists a necessity for a work of this kind.

In the composition of the work I have endeavored to be as brief and practical as possible. I have also, for the reader's instruction, introduced a number of cases which have occurred in my own practice, which may aid the practitioner in treating others. GEO. H. DADD, V. S. 


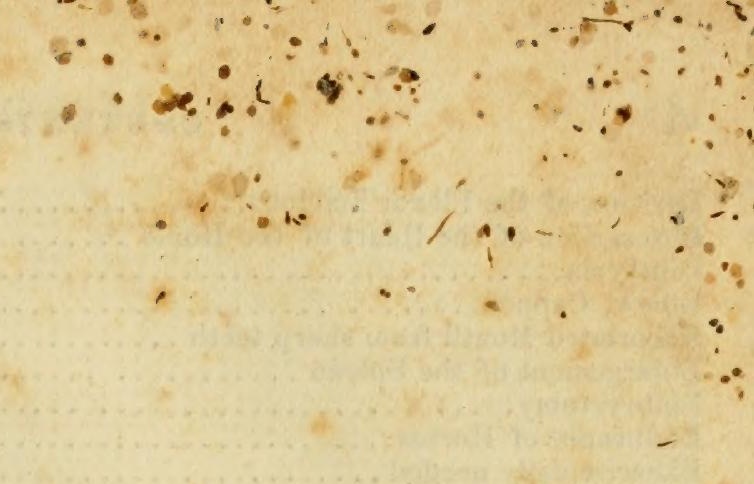

\section{CONTENTS.}

PAGR

Abdominal Dropsy..................................... 13

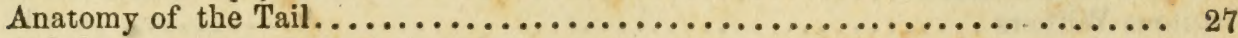

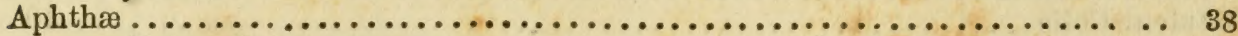

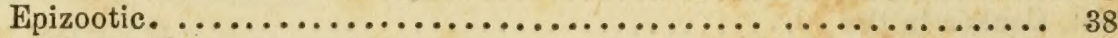

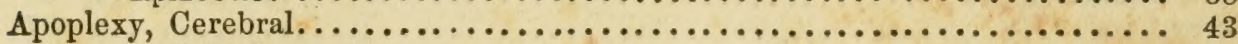

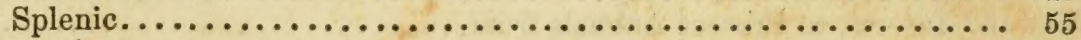

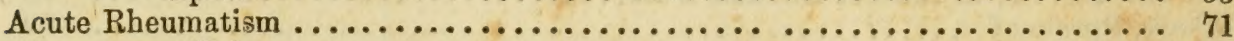

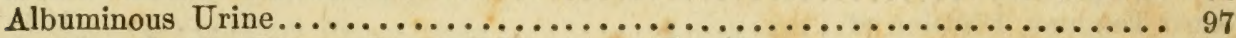

Antidote for the Bite or Sting of Venomous Reptiles................ 99

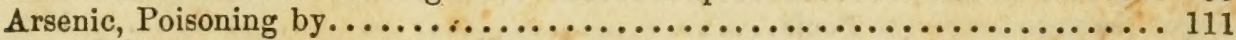

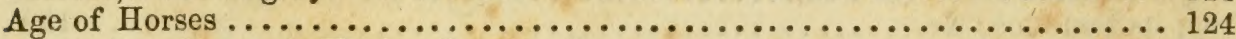

"American Magnetic Equine Powders" .......................... 142

"American Magnetic Equine Liniment"......................... 142

"American Magnetic Equine Lotion".......................... 142

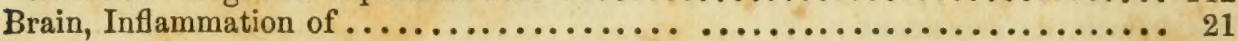

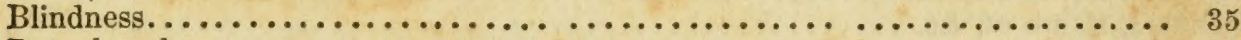

Bronchocele ........................................ 41

Bruise of the Sole......................................... 41

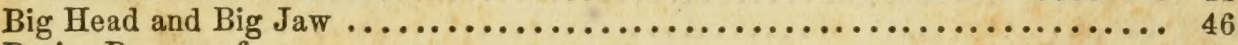

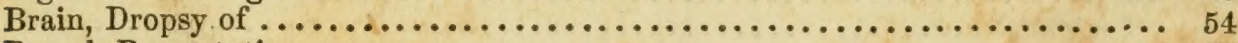

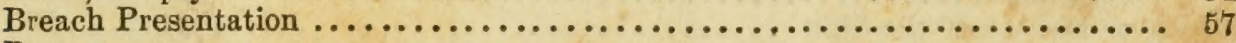

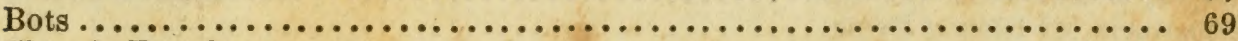

Chronic Founder .................................... 14

Capped Hock ....................................... 15

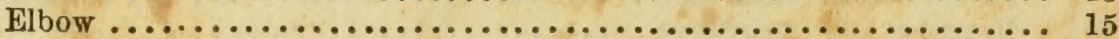

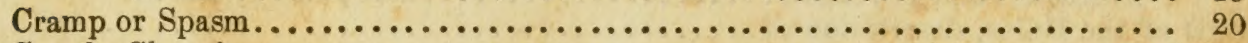

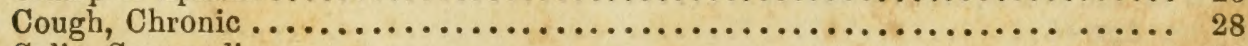

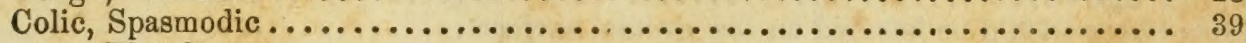

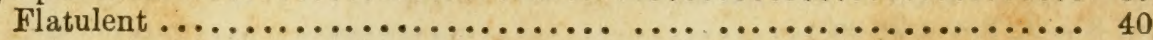

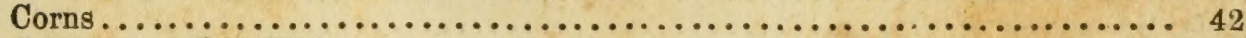

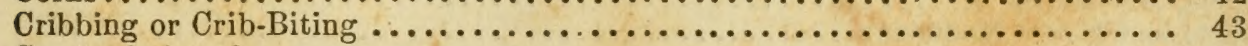

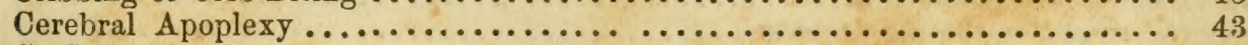

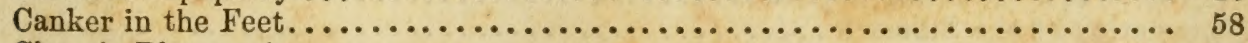

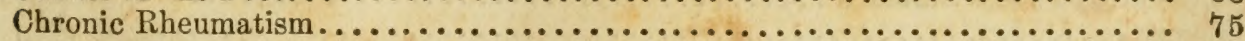

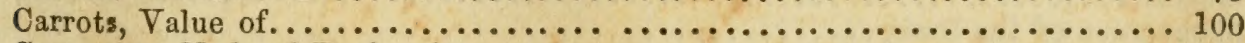

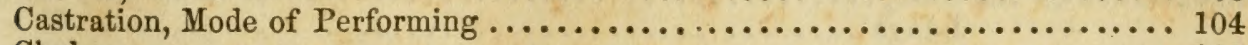

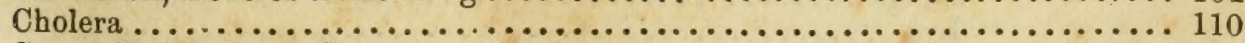

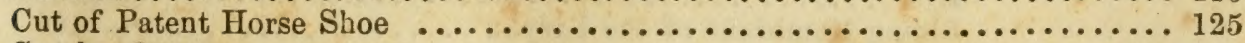

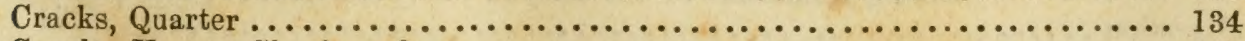

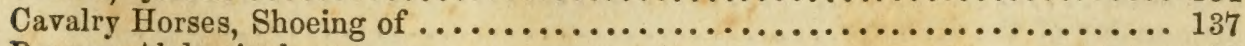

Dropsy, Abdominal ................................... 13

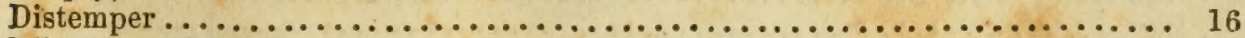

Dilatation of the Pupil..................................... 32

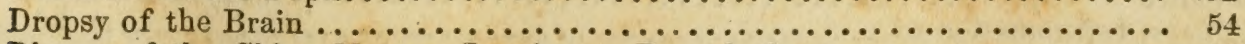

Disease of the Skin-Mange-Lousiness-Remedy for same............ 68

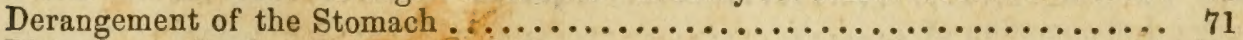

Diabetes, or Profuse Discharge of Urine....................... 97

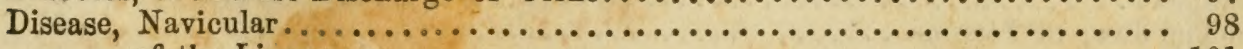

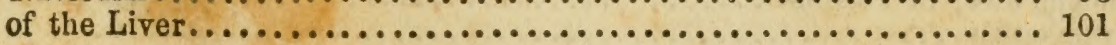


Remarks on the Application of Hot Shoes....................... 131

Stables, Importance of Ventilating ......................... 9

Social Science, its Relation to Veterinary Science.................. 11

Stomach, Inflammation of ................................. 13

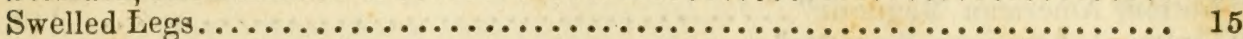

Scrotal Hernia, Reduction of. ............................ 18

Spasm, or Cramp................................... 20

String Halt....................................... 20

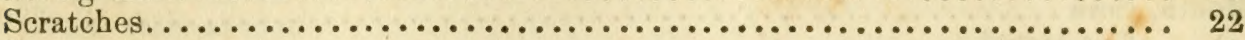

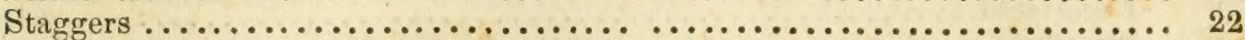

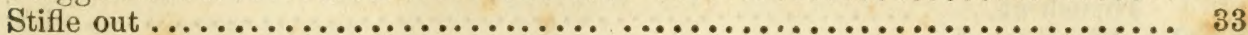

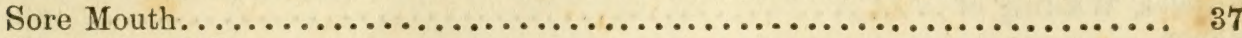

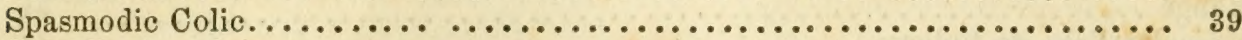

Sole, Bruise of ....................................... 41

Spleen, Enlargement of................................ 45

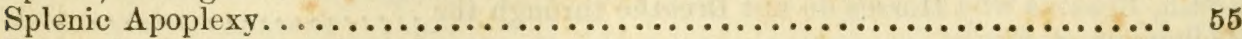

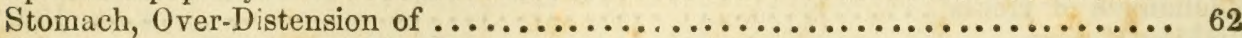

Sweeney, or Wasting of Muscles............................ 63

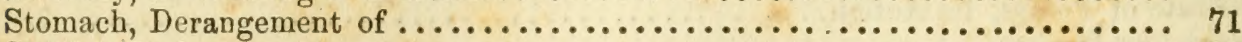

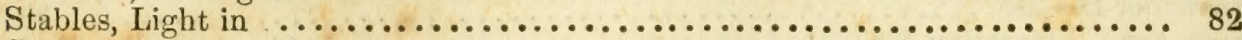

Splent, its Nature, \&c. . . . . . . . . . . . . . . . . . . . . . . . . . 92

Spavin, its Nature, \&c............................... 93

Suppression of Urine ................................... 97

Sprain of the Fetlock................................ 99

Structure and Function of the Liver......................... 101

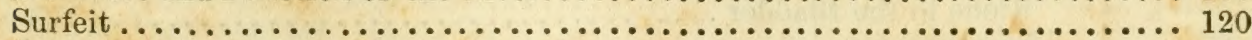

Shoeing Horses, Rules for............................... 128

Cavalry Horses.................................. 137

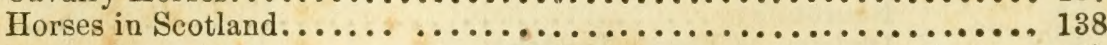

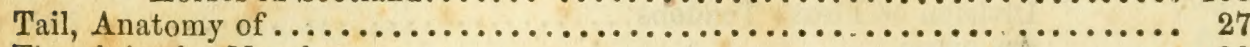

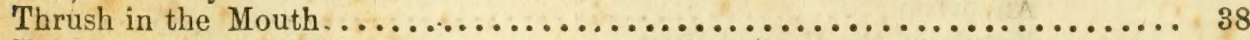

Tetanus, or Locked Jaw................................ 51

Typhoid Pneumonia .................................. 53

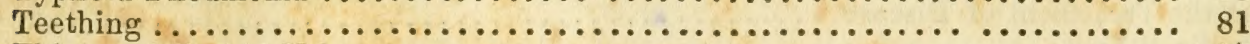

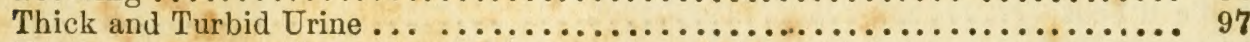

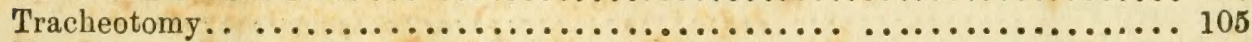

The Bite or Sting of Venomous Reptiles........................... 11 ?

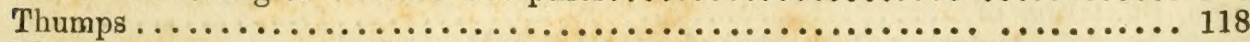

Theory and Practice of Shoeing Horses in Scotland ................ 138

Umbilical Hernia. ...................................... 58

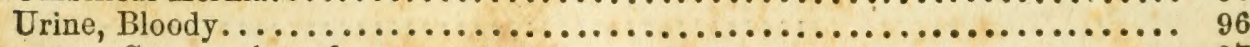

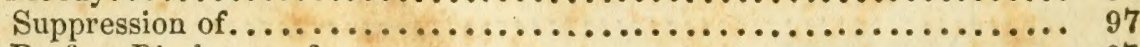

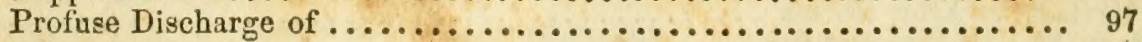

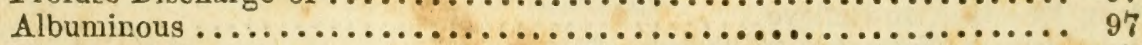

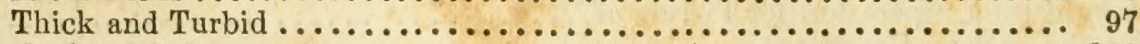

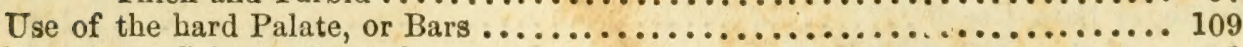

Veterinary Science, Remarks on. ........................... 11

Veterinary Midwifery, Case of............................ 57

Value of Carrots ....................................... 100

Veterinary Seience, How to Inaugurate it in the U. S. Army............. 115

Withers, Fistulous....................................... 29

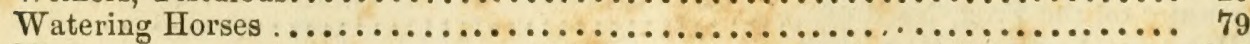

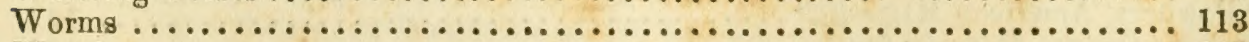

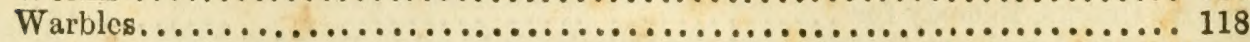




\title{
IMPORTANCE OF VENTILATING STABLES,
}

\author{
IN VIEW OF PREVENTING DISEASE.
}

"Prevention is better than Cure."

IT was the intention of the Creator, that all animals, so long as they were permitted to exercise their natural instincts, and thus comply with the requirements of physiology-the science of lifeshould enjoy health and long life. Hence a great amount of disease and death results from the evils of domestication.

One of the conditions which physiology imposes, in order that a horse shall enjoy health, is, that the atmosphere at all times, and under all circumstances, shall be uncontaminated, so that the blood shall be decarbonized and purified of the defiling elements acquired in the course of circulation.

Let the reader understand that the lungs are something like a sponge, elastic, composed of a myriad of cells. In the former, however, these cells have a vast internal surface, communicating with each other up to their common origin, the bronchial tubes and windpipe. On their internal surface we find a delicate yet highly important membrane permeable to the atmosphere; in extent, it is supposed to occupy a square surface equal to that of the external body. In contact with this membrane comes the atmosphere. If pure, zephyrlike, it fans into healthful blaze the flame of life, upheaving from the living Vesuvius arid lava, in the form of corbonic acid gas, almost as destructive to animality as that issuing from its great prototype proves to vegetation. The stable atmosphere being pure, and the lungs in working order, the blood is well arterialized, capable of supplying the waste of the animal machine, and renovating its tissues.

On the other hand, should the atmosphere be impure, it fails to vitalize the blood; the latter is unfit for the purpose of nutrition, and may be considered a non-supporter of vitality. Hence the need of pure air, the breath of life.

But are horses always furnished with pure air? Let the owners of unventilated, crowded, filthy, down-cellar and low-roofed stables answer.

Let those who have stables in the region of swamps, sewers, and stagnant pools of water answer.

In such locations disease and death run riot, and the noble companion of man, instead of being within the ramparts of the science of life, is on the margin of death's domain. II may exist for seve- 
the glandered matter, coming in contact with an abraded, or absorbing spot, on any part of a man's body, will surely cause him to die the most horrible of all deaths; and the same remarks apply to the disease known as "malignant farcy."

I might enumerate many other forms of disease which are communicable from the superior order of animality to the inferior, and vice versa, but the above must suffice, in view of attracting attention to the value and importance of the subject. In regard to the origin of diseases, it is known to the profession that the diseases of men and animals are often due to similar causes; that the evils of domestication which operate to develop disease in animals, are as notorious as the evils of civilization, which induce unnecessary disease and premature death among members of the human family; therefore, our science does bear an intimate relation to social science, and it appears to me that no scientific mind can fail to appreciate the advantages to be derived from a more extended knowledge of the. fundamental principles of veterinary science.

Let husbandmen and stock raisers of this country put their shoulders to the wheel, in view of establishing veterinary schools and colleges throughout the length and breadth of our immense agricultural domain; and soon we can boast of having a class of Veterinary Surgeons, educated on American soil, conversant with the diseases incidental to the live stock of America; in that event, we can do our own "Doctoring," without foreign interference.

I am not disposed to find fanlt, nor scold about the itirerant veterinary practice which prevails in this locality, for I am aware that all try to do the best they can for the relief of the inferior orders of creation; the fault is not with the practitioners, but with the people who have failed to furnish the means of education. 


\title{
NATURE OF DISEASE
}

\author{
$\triangle M B D$ \\ METHODS OF TREATMENT.
}

\section{INFLAMMATION OF THE STOMACH.}

CAUSE.-Improper food, and poisons which irritate the vascular coat of the stomach; the disease often runs into the gastro-enteritis, which signifies inflammation of the stomach and bowels.

Symptors.-The animal is very restless and ungovernable, and appears to be in excessive pain, the pulse is wiry, and the patient refuses both food and water, knowing, probably, that if anything be taken into the stomach it will only add to the torment.

Treatment.-Give the animal, every four hours, one pint of linseed tea, into which stir one drachm of nitrate of potass. Should it be discovered that the animal has been poisoned, give half a pint of linseed oil, and the same quantity of lime-water; mix, and give as a drench every four hours, until the animal is better, or the bowels respond to the medicine. The patient should be lightly fed, and during convalescence should have a few doses of an infusion of chamomiles.

\section{ABDOMINAL DROPSY.}

CAUSE.-Effusion of serum into the abdominal cavity. It often is the result of an acute disease of the peritoneum.

Srmptoms.-Dropsical swellings in the sheath and limbs; the abdomen is enlarged; the appetite is not good, and the animal is thirsty. Let one person strike the walls of the abdomen with his hand, while another rests his hand on the opposite side; at the moment of striking, the person on the opposite side will feel a fluctuating movement, demonstrating the presence of water within the abdomen. The external symptoms show unthriftiness and debility.

Treatment.-The disease being of a prostrating character, the patient's strength must be sustained; give one drachm of ginger, and the same quantity of golden seal, and twenty grains of iodide of potass, night and morning, in a few oats or shorts, and rub the external swellings once, daily, with oil of cedar. 


\section{FOUNDER. (ACUTE LAMINITIS.)}

The term founcler signifies "ruin;" because a horse in a foundered condition is, while the disease lasts, a ruined animal. The discase is known to professional men as Laminitis, (inflammation of the vascular parts of the foot.) During the progress of the disease, $\Delta T R O P H Y$, Or wasting of the muscles of the shoulders, occurs, and some persons are then disposed to call the malady "chest founder," but the original seat of the malady was in the foot; the wasting of the muscles ocrurs in consequence of a want of physiological action of the same.

This disease, in its acute form, comes on very suddenly, and may be occasioned by severe work, overfeeaing, or imbibing cold water when the animal is in a state of perspiration; it often has a metastatic origin, that is, translation of disease from the lungs to the feet.

Symptoss. - The most reliable symptoms are, a hard, strong and wiry pulse, unnatural heat about the feet; the animal appears to suffer much pain, and is continually shifting his position and sending his foot forwards; sometimes, in view of obtaining relief, he lies down, but is uneasy and breathes quick. The position which the animal assumes, and the unnatural heat of the hoofs, point out clearly the true character of the affection.

Treatment of Acute Founder. - The feet should be kept constantly moist with cold water, and four drachms of nitrate of potass may be given, twice, daily, in a little water; but should the animal labor under a gorged state of the stomach, administer tonics and stimulants in view of arousing the digestive function, so that the food may be digested, and thus pass out of the stomach.

A few doses of nitrate of potass will soon decrease the action of the heart, and lessen the inflammatory action of the feet.

\section{CHRONIC FOUNDER.}

Chronic Founder is usually the result of organic foot disease, and a permanent cure is almost a matter of impossibility; the only thing we can do, is to mitigate the sufferings of the animal, by applying lubricating and counter-irritating liniments to the feet and limbs, and by having the feet properly prepared and shod, and allowing the subject to spend his time in the pasture. (See article "Sweeney.") Some persons contend there are many kinds of founder, but the facts are, founder is not the disease; the wiry shoulders and hollowness in front of the chest, are mere effects arising from protracted disease and pain in the fore feet-chronic foot lameness. 


\section{CAPPED HOCK.}

Capped Hock consists of a soft enlargement at the point of the hock or bone, known as the os calcis; the enlargement is usually occasioned by a bruise or some injury done to the parts.

Tranturent.-Rub the parts twice daily with some stimulating liniment,* and let the animal have regular daily exercise.

\section{CAPPED ELBOW.}

Capped Elbow is similar to Capped Hock; it arises from the same cause and requires the same treatment.

\section{PUMICED FOOT.}

Syarptours.-Convex sole and descent of sole; he travels as though he was afraid to put his foot fairly on the ground.

Treatment.-A run at grass.

\section{PUNCTURE OF THE SOLE OF THE FOOT.}

Horses' feet very often get punctured in consequence of picking up a nail when traveling on the road; at other times horses' feet get punctured in consequence of the smith accidentally driving a nail in a wrong direction; sometimes very little injury results, but often locked jaw ensues.

Treatment.-Enlarge the orifice so as to allow of the escape of any matter that may form within the hoof; then apply a plaster composed of equal parts of brown sugar and soap-or dress with Lord \& Smith's Magnetic Lotion, and apply leather under the foot, between the shoe and sole. When all symptoms of lameness have subsided, the leather may be removed. It is important that the orifice, made by the puncturing nail, should be enlarged, otherwise the matter will burrow and form a quittor.

\section{SWELLED LEGS.}

Swolled legs are occasioned by what is known as local dropsy; some horses seem to possess a peculiar predisposition, and whenever they get sick, or stand a few days in the stable, their hind legs swell.

\footnotetext{
* The Magnetic Liniment manufactured by Messrs. Lord \& Smith, No. 23 Lake street, Chicago, I have found very efficacious.
} 
The swelling arises from the presence of serum or water within the cellular tissue of the parts.

Treatment.-Should the swelled legs be the result of a prostrating disease, tonics and diuretics are indicated; give two drachms of powdered goldenseal every morning, and three drachms of nitrate? of potass every night, to be mixed with the food, and let the animal have daily exercise.

In obstinate cases it will be necessary to apply daily a p tion of the following:

Mix.

Spirits of Camphor. .............6 ounces.

Vinegar...................... 1 quart.

Or use Lord \& Smith's Magnetic Liniment.

\section{INFLUENZA AND DISTEMPER.}

Such affections as the above named, are apt to mak their appearance in the spring, and are most preval nt in stables that are not ventilated; such affections are very apt to extend from the mucous surfaces of the nostrils, to the throat and interior of the air cells of the lungs; usually, however, the throat is the seat of sor n ss and exudation; while in some cases that have lately occurred in this city, a verу profuse discharge from both nostrils was observed, which ended in a critical outburst of an abscess between the angles of the lower jaw. In two cases that have lately come under my observation, the disease ended in pleurisy, and effusion of serum into the cavity of the chest, which was attended with dropsical swellings of the legs and external parts of the chest.

When distemper occurs in the system of an animal debilitated by previous disease, or one of a morbid or scrofulous diathesis, a profuse and protracted nasal gleet remains, and this is accompanied by tumefaction of the thyroid glands in the region of the throat. The purulent discharge from the nostrils, need not occasion any anxiety on the part of the owner of the horse or the medical attendant, for, as it increases in quantity, the other observable symptoms of the malady grow milder; in fact, the discharge may be considered an effort, on the part of nature, to rid the system of morbific matter, and any attempts by injudicious treatment to arrest this salutary discharge may effect a translation of disease, which often ends in death. Death may, however, be occasioned by the re-absorption of the morbid nasal discharge; under such circumstances, the nasal membrane takes on a livid aspect, and streaks or spots of extravasated blood are observed; the membranes of the eyes assume a dark red color, the pulse becomes indistinct; cold sweats bedew the body; the patient becomes emaciated, loses his appetite, and, soon after, his life. In a few solitary cases a partial recovery takes place-death refuses to receive a victim - the animal lives to be the subject of confirmed heaves or broken wind.

As regards the Contagious or Infectious Elmment of Dis- 
TEMPER - Should I contend that "Distemper" was contagious and infectious, probably the bulk of evidence would be on my side; in fact, I was formerly led to believe that, either by infection or contagion, distemper was propagated from the system of one animal to that of another; but experience, which is generally the only true guide, has of late years led me to think differently, yet I am well aware that even at the present day, in spite of the ever accumulative knowledge of pathology, both the negative and affirmative of this proposition may be logically maintained.

Because a number of horses are attacked with distemper, in this or that stable, is not positive proof in evidence of its contagious or infectious element, because the season of the year may have more to do with its production than some people are aware of. It is well known that influenza or distemper is more frequently encountered in spring, than in antumn; more in autumn, in some countries, than in summer, and in winter more rarely than in either of the other quarters of the year.

Then again, influenza may make its appearance at a certain stable, and rapidly spread, so that a great proportion of its occupants are affected with unmistakable symptoms of the malady; but this proves nothing in favor of the theory of the contagionists, for the same cause which operated to develop the malady in the system of one animal, was operative (if operative at all) in the systems of the others.

In view of maintaining my argument, I offer the following pertinent case: Mr. Harbin, an extensive dealer in horses, informs me that he once purchased a number of horses for a southern market, and knowing that all horses at some period of their existence ought, or must, have an attack of distemper, he was desirous of getting his animals through the scrape ere he delivered them to his friends; and in view of delivering them in good condition, he purposely ex. posed them, by purchasing a horse affected with distemper; and notwithstanding his efforts to communicate the disease, the animals improved in condition, and not one of them appeared sick until a long time afterwards when they were landed in a southern port, and even then he disposed of the whole lot, having but one sick patient on his hands; the sickness being contracted after arriving south.

Treatarent of Distemper. - The animal should be placed in a comfortable location, where he can breathe pure air, and be free from annoyance of every kind; should the weather be chilly, the body may be lightly elothed, and the lower part of the limbs bandaged with flannel. It is very important that the surface of the body be kept warm, for when cold, the equilibrium of the circulation is disturbed, the blood then localizes itself about the internal organs, and produces congestion; a condition very unfavorable, in view of the speedy restoration of the sick creature.

It should be understood by every husbandman that this affection is of a prostrating nature, that the object of the treatment of the malady is to husband the animal powers-keep the horse alive while the disease runs its course-and preserve the tone of the system by administering tonics and diffusive stimulants; a few doses of golden seal and ginger, accompanied by a rational allowance of scalded oats, 
small quantities of hay, and water enough, are generally all that is needed by way of treatment. And if this course be pursued, the animal will recover, very little the worse for having had the distemper. A mild form of this disease is often made to assume a typhoid or putrid type simply from meddlesome medication and overdosing; with agents which depress the vital powers, and by bleeding.

No matter what may be the stage in which we find the disease, the treatment must be life-sustaining; no kind of treatment which contemplates a depression of vitality is at all admissible. This is my experience after a practice of very many years-and the most intelligent and liberal-minded physicians of the present day depend more on nature than art, in the treatment of distemper.

Should swellings appear under the chest and limbs, the proposed plan of treatment is not to be materially altered, only add to the golden seal and ginger a little iodide of potass; this agent is a glandular stimulant, and augments the function of the absorbents which take up the fluid and thus reduce the swellings, which are of a dropsical character. The proportions of the above agents are as follows :

Golden Seal, powdered............2 ounces.

Ginger, "

Iodide of Potass" $\quad$.............3 drachms.

Mix, and divide into twelve parts, and give one night and morning in food or gruel.

It may happen that the animal is unable to swallow, in consequence of soreness of throat, as the saying is ; in such case we merely apply some stimulating application to the region of the throat, and wait awhile; soon the soreness subsides, and the patient can then swallow all he needs and as much as nature requires.

The best stimulating application for the throat is

Cod Liver Oil.................4 ounces.

Tincture of Capsicum...............1 ounce.

Another perhaps equally as good:

Olive Oil.....................6 ounces.

Spirits of Hartshorn.............. ounces.

A portion of either of the above preparations may be rubbed into the thyriod region twice daily. Under the above mode of treatment $I$ have found that recovery is not only soon accomplished but perfect.

\section{REDUCTION OF SCROTAL HERNIA.*}

The best method of reducing scrotal hernia in the uncastrated colt, is to cast the horse by means of the hobbles, and when on its back, the animal is to be kept in that position, while, by means of

* Hernia is from a Greek word which signifies a breach, from Its protrusion out of its place-a rupture. When the hernia tumor is easily put back into the abdomen, it is called reducible hernia. The symptoms of a reducible hernia are not very violent; the hor'se will paw with his fore extremities, hangs his head, looks silently at his flank, and appears to suffer fiom constant, yet not very active pain; on the affected side the scrotal bag will appear cold. 
the band and fingers, the bowel is kneaded back again into the abdominal cavity. Should the bowel or intestine not return readily, a tackle, double and single block with a small rope, must be fixed to $\pi$ beam above the posterior part of the animal; then hook the single block into the hind hobbles, and raise the posterior parts from the ground; this sends the contents of the abdomen forwards, towards the diaphragm, and the imprisoned intestine usually recedes into proper position. Should the bowel not return, after a fair trial, the animal may be rtherized; while administering the sether, however, the patient should be released from the tackle, and hoisted again when in a state of $x$ therization; after this the hernia is easily reduced.

Should, however, the case be a bad one, in consequence of a lapse of considerable time since the period of the accident, or from the presence of a portion of bowel distended with gas, forming a tumor of considerable magnitude, the operator must proceed to open the scrotum and tunica vaginalis, and should a portion of bowel present itself, much distended with gas, the bowel may be punctured in several places with the point of a fine needle; these punctures will allow the gas to escape, and the volume of the intestine is so reduced that it usually returns, without any trouble, into its proper cavity. Having reluced the hernia, the wooden clamps are to be placed on the sprermatic cord and secured; the testicle is then to be severed from the cord.

A case may now and then occur, which precludes the possibility of a return of the intestine, after the above fashion, in consequence of a thickened state of the walls of the gut; in such a case we have to enlarge the inguinal ring with a probe-pointed bistourie, and after the bowel has returned into the abdomen, castration must be performed as just described.

Shall we remove both testicles? I usually invite the owner of the horse to decide this question; at the same time inform him that the animal, unless a very valuable one, had better be completely emasculated. The loss of one testicle will not very seriously impair his powers as a sire of progeny ; therefore, if the subject of this loss be of gond blood or stock, it is better to let the unaffected testicle remain, for, as the old saying is, "blood will tell."

\section{ON THE TREATMENT OF FEVERS.}

\section{"FEVERS GENERALLY TEND TO THEIR OWN CURE."}

Mann, and several other authors of the modern school, contend, that "The principal treatment that is necessary in disorders of this kind, is, to let nature have 'fair play.' If the purest air is supplied, the most perfect cleanliness is scrupulously observed, and nothing is given or done that can continue the oppression of the system, nature snon rights herself.' The excretory organs, step by step, expel the offending matter from the blood, and the balance of health is gradually restored. The low diet, the quiet, and other waluable measures directed by medical science, all have the object 
in view, in the first place, of removing or withholding such influence as would oppose nature in its beneficent work; and, in the second place, of aiding its operations, so far as this can be done, by artificial appliances. Every one ought to understand this, in order that he may be prepared to yield intelligent and effieient obedience to medical suggestions and directions, in case of being placed in positions in which such may be required."

The above are very excellent directions, and if fully carried out in the treatment of the various diseases of the inferior orders of creation, would probably save the lives of many valuable animals that are constantly dying from the practice of a system of meddlesome medication, and from the unwarrantable use of drugs that are either injurious or actively poisonous in their character.

\section{CRAMP OR SPASM.}

Cramp, as it occurs in horses, is usually confined to the muscles and tendons which flex the limb. The following case will illustrate iny treatment:

Case of Cramp, or Spasar.-I was requested, a short time ago, to visit a horse, said to be the subject of "stifle lameness." The patient, a gray gelding, aged eight years, was put up at the stable, on the evening preceding my visit, apparently in perfect health ; early in the morning, ere I was called, the "feeder" observed that the horse was incapable of moving the near hind limb, and it appeared to be, as I was informed, "as s'tiff as a crowbar."

On making an examination of the body of the animal, he appeared to be in perfect health; yet he was unable to raise the limb, in the slightest degree, from the stable floor. The case was accordingly diagnosed as cramp of the flexors.

Treatarent. - The body and lower parts of the limbs were clothed with blankets and flannel bandages, and the affected limb was diligently rubbed for half an bour with a portion of the following liniment:

Oil of Cedar................... ounce.

Sulphuric Ather .................. ounces.

Proof Spirit.................. pint.

In the course of a few hours after the first application, the difficulty had entirely disappeared.

The owner informed me that the horse had, on the day prior to the attack, been exposed to a cold and continuous rain storm, and probably this operated as the exciting cause of the spasm.

\section{STRINGHALT.}

Stringhalt is probably a disease of the nervous system, and seems to affect the muscles of the hind extremities through the 
nerves of involuntary motion. Persons who have dissected animals which were once the subjects of stringhalt, declare that they found pressure on the posterior portion of the spinal column.

I have noticed that many horses, the subjects of commencing spavin, have stringhalt when they start. This may be occasioned by irritation on the nerve which passes over the hock.

Medicine has but little if any power over this disease, yet, if the reader wishes to try the effects of the same, I would advise the use of stimulating liniment, to be applied over the region of the back, and inside of the thighs, and let the animal have a couple of drachms of asafoetida every day for a week or more. Most veterinary surgeons contend that stringhalt is incurable. In France the action of a stringhalt horse is (on the dancing-master principle) considered rather graceful than otherwise; so that if any of the readers of this work happen to have a horse the subject of stringhalt which they cannot cure, they had better ship him to France.

\section{MEGRIMS.}

Megrims, in the horse, is supposed to be analogous to epilepsy in man. A horse the subject of this affection is apt to appear dull and stupid when at work, and will, at a later period in the stage of the malady, be seized with a sudden fit, and drop down in the shafts; at other times will gallop forwards and run head foremost into any obstacle which happens to be in his way; he soon after goes into convulsions and becomes insensible.

A horse subject to this malady is never safe to drive, and consequently is almost worthless; indeed, when attacked, his recovery is never certain, for he often dies in convulsions.

Treatment.-Bathe the head constantly with cold water, and apply spirits of ammonia to his nostrils; should the case be a curable one, the animal will soon rise, when he must be led, cautiously, to the stable. Then administer the following:

Powdered Golden Seal..............1 ounce.

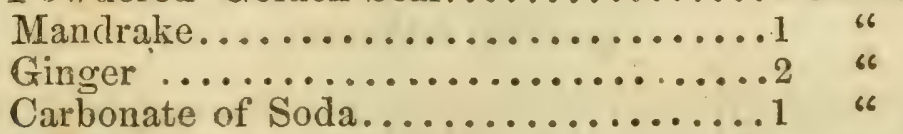

Divide into ten parts, and give one, night and morning, in a few oats.

\section{INFLAMMATION OF THE BRAIN.}

Animals most subject to this affection, have a short thick neck and bulky forehead; the disease is one of the most formidable with which we have to contend, as it often ends in fienzy; sometimes, however, dropsy of the brain sets in, at others, rupture of a blood vessel takes place-in either case, death is very, apt to ensue. 
Srmptors. - The animal soems to have no control over itself, and will dask about in the most violent manner, and disregards all the owner's commands; the membranns of the eyes are very lighly injected, and the pulse is full and active. In short, the animal xppears in a state of madness.

Trentment.-The only way in which we can be of any service, in a case of this character, is to use the lancet freely until the patient is prostrated, then give half an ounce of pulverized nitre, and ten grains of aconite root every half hour, until symptoms of improvement take place; in the meantime, injections, composed of hot water, soap and salt, should be thrown into the rectum. Tonics should be resorted to, as soon as the patient shows symptoms of weakness.

\section{STAGGERS.}

The usual forms of staggers which occur arnong horses in this part of the country, are Stomach Staggers and Sleepy Staggers; in the first case, the animal is usually the subject of over disterition of the stomach, and, when urged to move, staggers like a drunken man; in the latter case, the function of the stomach is paralyzed, and the animal is somnolent or sleepy.

The usual exciting causes of such affections are, overfeeding and want of proper exercise, yet it may arise fiom hard work when the animal is the subject of an over-distended stomach.

Trentment.-Both the above affections may betreated as follows: Give the patient six ounces of table salt, one ounce of ginger, in half a pint of lot water. Then dissolve half a pound of Glauber salts in hot water and throw the same into the rectum. In the course of a couple of hours the dose may be repeated. The diet should consist of sloppy bran mashes, well seasoned with salt.

\section{GREASE:}

In olden times, Grease or Scratches, and crackeả heels, were not only very prevalent but very formidable affections. Before veterinary surgions were employed in the British army, many thousands of valuable horses were condemnerl as useless for aetive service in consequence of the prevalenee of that loathsome affection known as inveterate Grease; but now in consequence of the presence of veterinary surgeons and the consequent improved system of management in eamp and stable, Grease is almost miknown. Most veterinary writers contend that Grease almost always arises firom improper nanagemert of the horse, yet I have seen it occur in horses that were well cared for and properly treated. The truth is, some horses are predisposed to affections of the skin of the heels and the sebaceous glands of the same, and although cleanliness and good management may stave of as attack for a long while, yet when the 
system abounds in morbific matter the same is very apt to gravitate towards the heels-1hey being most remote from the contre of circtilation-inducing inflammation of the skin of the heels, distension of the sebaceous glands, and a stinking and unhealthy deposit on the surface, and a purulent discharge through ulcerated cracks: this constitutes Grease.

It is contended by Mr. Blain and others, that "Grease has local weakness for a cause. As fluids press, not in proportion to their diameter, but to the height of their column, the venous blood must find some difficulty in its ascent. Debility is therefore more felt in the distended vessels remote from the influence of the heart, under which circumstance the effects productive of Grease necessarily ensue."

Some horses are constantly the subjects of swelled legs, and if the heels happen to be accidentally abraded, the latter often operates as the exciting cause of a very formidable affection of the heels. Associated with the swelled legs is a scurfiness of the skin beneath the fetlock; these conditions, together with the fact that the animal is of the lymphatic temperament, (gray color,) are sure indications that a predisposition to maladies of the above character is present. Having such horses under our care, the chicf object should be to ward off an attack, by dietetic and hygienic measures; too much washing of the heels without drying them by rubbing, is just about as bad as if the filth was allowed to remain; the practice chills the part by a process of slow evaporation, and the result is local congestion, \&c.

I propose to illustrate, for the benefit of the reader, the treatment of Grease :

July 15th. Was requested to see a gray gelding, the property of the Transfer Company of St. Louis. On arrival I found him to be a large, flabbily organized creature, having a large amount of loose tissue under the skin. I found that there was a bad odor arising firom some ulcerations and exudations about the heels and sides of the same; intermediate of the ulcers were dry horny scabs, the hair about the parts pointing straight out; the heel was excessively tender, quite vascular, and blood escaped from its vessels. The moment a hand was placed upon the locality, the animal would catch up the limb and appear to suffer much pain.

Treatarent.-In the first place I had the parts well cleansed with soap and water ; then after wiping the parts dry, they were wetted three times daily with a portion of the following solution:

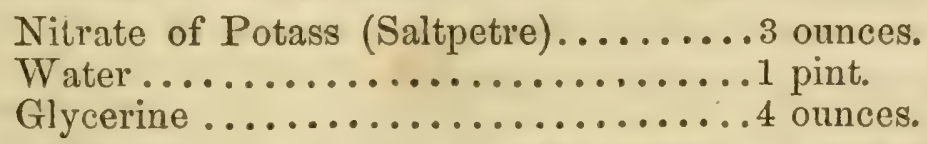

Every time the solution was applied, the parts were dusted with pulverized charcoal; this charcoal completely covering the abraded parts, and bcing a good antiseptic, had a very excellent effect in excluding atmospheric air and in correcting the fetid odor.

I administered as an alterative to correct the morbid habit, twenty grains of iodide of potass; four drachms of sulphur; two drachms of powdered sassafras bark; one drachm of gentian; these were 
mixed in food, and the same quantity was given during a period of four days, and the dressings were also continued.

On the fifth day the animal had very much improved, stood fair on the foot, and seemed to suffer but very little pain; the limb was somewhat swollen, partly from want of use, and other'wise from a slight effusion into the cellular tissue. I discontinued the medicine and ordered the following mixture to be applied twice daily :*

$$
\begin{aligned}
& \text { Pyroligneous Acid, } \\
& \text { Coal Oil, }
\end{aligned}
$$

After each application the charcoal was reapplied.

At the end of about fifteen days the animal was well, with the exception of some enlargenent and induration which time alone could remedy.

This plan of treatment would probably prove successful in all curable cases of Grease, Cracked Heels, Scratches, \&c., and I advise the reader to try it whenever such cases occur; the patient, how ever, should be kept on a light diet-green feed in summer and carrots in winter-and a moderate supply of oats and hay.

\section{MYALGIA.}

Myalgia signifies muscular pain and stiffiness.

St. Louis, July 26. I was this day called to examine a colt, the property of Mr. P., of this city. The owner informed me the colt was put in a flour wagon with a pair of mules, this being the first time he ever was driven; he was worked hard all that day, and on being taken out, and while he was under great heat, and completely tired out, was allowed to drink freely of water. The next morning my attention being called to him, I proceeded to examine him.

I found the pulse small and wiry, and in a state of exhaustion. Respirations somewhat accelerated upon backing him ont of the stall; he moved very stiff and with difficulty, seemingly in considerable pain. The back was arched, bringing the feet in close proximity; these were very hot, the animal being very unwilling to move.

Dingnosis.-Myalgia, or muscular pain.

Treatarent.-Gave by drench :

Iodide Potass................ drachms.

Tincture of Golden Seal .......... "6

Rubbed his legs with the following:

$\left.\begin{array}{l}\text { Indian Hemp, } \\ \text { Chloroform, }\end{array}\right\}$ equal parts.

July $2 \%$. Called argain to see the patient and found him somewhat improved, and not in so much pain. The stiffuess had in considerable degree disappeared. Ordered his legs to be rubbed wi.h the same 
preparation which was applied yesterday morning, then gave, by drench :

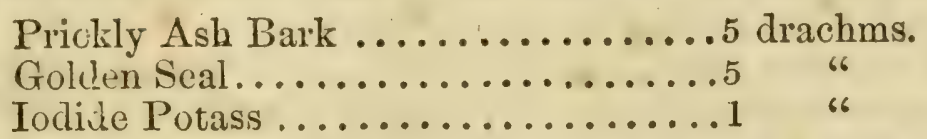

July 28. Called to see my patient this morning, and found him rapidly improving. His waik was much firmer and his general appearance livelier. I did not consider his legs needed any further medical application, but I gave a drench composed of-

Golden Seal ..................

July 29. I found such a decided improvement this morning that I felt it necessary to suspend further medical treatment, and informed the owner that by turning him out to grass he would ultimately recover.

RemanKs.-Myalgia is a very prevalent disease among horses, yet it is often confounded with pleurodyna, founder, rheumatism, \&c. In view of griving the reader some idea of the cause and nature of Myal,ria, I propose to make a few extracts from a lecture lately delivered by 'Thomas Inman, M.D., of the Royal Infirmary, Liverpool:

"My attention has been drawn very forcibly, of late, to the subject of the muscles, and the frequency with which they are painfully affected in the human subject. It is clear that they are affected much in the same way in the horse and other animals.

"If any man undergoes an excessive amount of physical exertion, and especially if he be unaccustomed to it, or if he has been the victim of cramp, we know that on the next day he complains of stiffness and soreness in those parts of the body which have been most exercised. Experience tells us that this stiffness lasts for about four or five days, but that it goes off on the first day as the individual is again warmed to his work, and comes on again as soon as he is cool.

"There is every reason to believe that excessive or long protracted exertion will produce a bad effect upon a healthy and strong muscle; it is equally certain that a similar result will be produced in a weakly and unhealthy muscle by a very slight exertion, because that exertion, though seemingly small, is excessive.

"If any man or horse die of tetanus, we may ascertain readily the physical efiects produced on their muscles, by excessive and prolonged involuntary contraction. The muscles of a tetanic patient are pale looking, fishy, bloodless, spotted, \&c.

"From the foregoing partisulars it is evident that the muscles, in their entirety, were frequently the seats of very severe sufiering; and experience showed that myalgic affections were far more common than had been supposed. But many patients had muscular pains from doing the very same things that others had done without experiencing anything disagreable, and many had myalgia from continuing to perform actions which they had been accustomed to do all their lives. This had to be accounted for.

"A short consideration sufliced to state the matter thus: If an individual, whose muscles are strong, experience stiffiness, pain and 
sorcness, from doing double an amount of ordinary work, another, whose muscles are only of half the average strength, will have a similar result from doing his ordinary work.

"The deduction, then, was inevitable, that myalgic pains would be common and severe in direct proportion to the patient's debility. But it is still necessary to demonstrate, that the muscles of various indiriluals had varying powers; and still more important was it to show that those of the same individual varied in power according to circumstances."

By trials of strength, \&c., the Lecturer showed, very conclusively, the facts sought for.

\section{PRICKING OR NICKING HORSES' TAILS.}

Nicking Monses. - The English method of nicking horses is, insteall of inserting a knife and mating a subcutaneous section of the muscles of the tail, linown as the depressors, to make three straight incisions at equal distanees right across the tail; by this method the muscies of the tail are effectually or completely divided. The first incision is usually made about two inches from the root of the tail, and the other two at equal distances from the first, in a direction towards the end of the tail.

The tail is then kept perpendicular, in the usual manner, by pullies. It is said that by this method a more graceful curvature of the tail is secured, which I believe is a fact; yet the operation is anything but pleasant to the horse. It is one of the fashionable barbarisms of civilization.

The English method of nicking, although the most unsightly and barbarous, is 'still the safest, as there is less liability to locked jaw. It is well known that loeked jaw more frequently ensues from a punctured wound, than a clean cut or incision. Yet when nicking or prieling after the American fashion, if care be taken to make the orifice through the skin suficiently large, so that the pus, afterward secreted, may escape, I think there is no danger. The danger arises fiom imprisonment of pus by closure of the orifice in the skin. In healthy subjects the orifice made through the skin will often unite, in the course of a few hours; then, should morbid matter accumulate within the substance of the tail, it burrows, forms an abscess, or else beeomes absorbed, producing locked jaw. Therefore I would adrise persons having pricked or nicked horses under their care, to pay strict attention to such, and see that the orifices are kept open, which rnay easily be done by oceasionally inserting the point of a penknife. The skin should be the last place to heal. The healing process must be perfected in the interior first, and lastly the skin. Should fungus or "proud flesh" appear, apply powdered blood-root, burnt alum, or red precipitate.

When an abscess forms at the base of the tail after pricking, apply a ponltice of flaxseed; and when the tail is much inflamed and swollen, it should be bathed frequently with acetic acid one part, water seven parts; mix.

When horses are nicked in warm weather, the tail should be moistened with tincture of aloes; this will keep off the flies. 
l'ersons who are not experts in the art of pricking, are apt to wound, and sometimes completely sever the coccygeal arteries, thereby causing an unnecessary and dangerous hemorrhage. In such cases, I should advise the operator to crowd into the orifice a small piece of dry sponge; this will arrest the hemorrhage, and at the same time keep the divided ends of the muscles apart, so that they cannot reunite; hence it is not necessary to put the tail into pulliss for some hours, or until bleeding has ceased; when this is the case, the sponge may be removed by means of a small pair of forceps.

The suceess in securing what is denominated a fashionable tail, depends altogether on the skill of the operator, who must make a complete division of the muscles beneath the tail only, whose action is to comp"ess and depress that useful appendage; for should the incision be made too high on the side of the tail, the curvators may be partly or wholly severed; then the tail will ultimately diverge laterally, or in stable language it will be said, "that the horse cloes not carry lis tail straight." To remedy this, the curvator on the opposite side must be divided; then the tail has to be forcibly drawn and kept in an opposite direction from the curved side, so as to prevent the muscle from reuniting. In the course of a short time, granulations are thrown out from the surface of the divided ends of the muscle; it then acquires length, and thus the tail becomes straight.

Anatomy of the Tair. For the benefit of those who wish to practice the art of "nicking or pricking" understandingly, I now propose to give a brief exposition of the anatomy of the tail.

Bones of the Tuil. The bones of the tail number fifteen, sometimes sixteen, and are situated at the back of the rump bone or sacrum. They are not a continuation of the vertebral bones, but are an aripendage to the haunch bone.

The bones entire are termed coccyx (from the Greek, which signifies cretion, the bill of which bird the appendage to the sacrum, or haunch bone of man, is said to represent), and in order to prevent confusion in anatomical terms, veterinary surgeons have applied the same name to the tail bones of the horse; hence, when the terms coccygis or coccygeal are used, they have some relation to the tail. The bones are roughened on their surfaces, have depressions and cminences for the insertion of ligaments, tendons, and muscles.

Muscles of the Tail. These muscles are divisible into four pairs. They are most distinctly seen at the root of the tail, but in their course towards the end of the same they become blended one with another.

First Pair. The first pair is situated on the upper part of the tail; they are attached to the sacrum and to the bones of the tail, Their action is to raise or erect the tail.

Second Pair of Coccygeal Musiles. These are termed depressors coccyx, and are situated at the under part of the tail. They are attached to the underneath part of the sacrum, and to the same locality on the bones of the tail. They are antagonistic to the first pair, and their direct action is to depress the tail. These are the 
muscles which should be divided in the process of pricking or nicking.

Third Pair. The third pair are termed curvators coccyx. These museles are situated on the sides of the tail, between the first and second pairs. They are attached to the fourth and fifth lumbar vertebri, and to the sides or transverse processes of all the bones of the tail. Their action is to curve or flex.the tail towards the quarter and sides, and the division of one of these muscles causes permanent flexure of the tail in an opposite direction. Considering the tail as a means of defense in switching off flies, \&c., these muscles are the principal ones called into action.

Fourth Pair. The fourth pair are termed compressors coccya. They are located at the sides and root of the tail, and are inserted into the back part of the hip bones (ischinm), and into the first fire bones of the tail. The action of these muscles is to maintain the tail forcibly against the anus. In the mare these muscles protect her from ravishment.

The Arteries of the Tail are termed coccygeal arteries. Those located at the sides, are called lateral coccygeal, and the one found in the lower or inferior region, is so called-inferior coccygeal.

Nerves of the Tail. As with the muscles, so with the nervesthere are four pair of coceygeal nerves. They are not a continuation of the true spinal cord, but are given off from it. They are distributed to the muscular filaments, to the skin, and to the extremity of the tail.

\section{CHRONIC COUGH - ITS TREATMENT, \&c.}

Chronic Cough is often the result of indiscretion in the treatment of influenza, distemper, and disease of the respiratory apparatus. It usually depends on a morbid and irritable condition of the membrane, found on the interior of the respiratory passages; the cough is generally aggravated by over-exertion, especially when the roads are dusty; food of an inferior quality, and that of a musty character, has the same effect.

It is generally supposed by those persons who have not had the benefit of a medical education, that the presence of acute, or chronic cough, indicates diseased lungs, or disease in some parts of the organs of respiration; but this is not always the case, for, whenever the liver becomes diseased, the subject is very apt to be tormented with a harassing cough, which lasts as long as that organ shall be the seat of disease; howercr, there are several symptoms, to be observed in cases of functional or organic disease of the liver, which are not present in lung discase; lience there is no difficulty in the way of making a correct diagnosis, and for the benefit of the nonprofessional, I would inform them that, in all cases of liver discase, a marked yellow tinge will be observed on the visible surfaces within the mouth; the tongue slightly coated; the dung is unusually dark colored, and is voided in hardened lumps, and the urine is also of a dark yellow color. 
Treatment of Chronic Cough. - Should it appear that the cough is occasioned by irritation, or an irritable state of the lining membrane of the respiratory passages, I recommend the following:

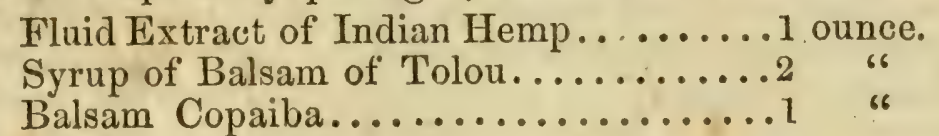

Mix.

About a table-spoonful of the above should be given twice, daily, from a small bottle.

The patient should be coaxed to drink an infusion of linseed now and then; it will lubricate the surfaces with which it comes in contact, lessen the cough, and tend to improve the condition.

Attention must be paid to the Diet. An irritable state of the mucous surfaces is apt to be aggravated by the use of hay of an inferior quality; in fact, poor hay, dusty or musty, is dear at any price, and is not, in that condition, fit for food. If the patient has been long kept on any particular kind of provender, a change becomes necessary-then such articles as linseed, sliced carrots, green feed, or oat straw, may advantagenusly be given.

Should the cough be dependent on disease of the liver, I would advise the owner of the animal to consult a veterinary surgeon.

See Magnetic Horse Powders.

\section{FISTULOUS WITHERS.}

Cause of Fistulous Withers.-Various are the canses assigned, by veterinary writers, for the origin of fistulous withers; but it may be laid fown, as a general rule, that this accidental, local affliction is occasioned by local injury inflicted by a bad-fitted collar or saddle; which, one or the other, are continually worn, and are constantly augmenting the irritation. In fitting a collar or saddle to a horse's back, or shoulders, the harness-maker should study the conformation of the parts to be fitted, so as to distribute an equal pressure on all the bearing parts. Unequal pressure is usually attended or followed by local injury, inflammatory tumor, and suppuration; and the result is "fistulous withers."

Nature of Fistulous Withers.-In the first stage a tumor, or inflammatory swelling, varying in size, is observed in the dorsal spines, just at the top of the shoulder blade; it appears hot and tender, and resembles a common boil; after a short time it suppurates, and then may be considered as a common local abscess; soon the matter accumulates, and then is apt to spread and burrow in various directions, and instances have occurred where the matter has burrowed beneath the scapula, and found its way to the point of the elbow. The fistulous condition, however, does not exist until the matter, by absorption, has created several canals, or "pipes," as they are sometimes called; the skin is then also broken, and we have a real case of fistulous withers.

Occasionally the matter becomes so acrimonious and morbid that 
it acts on the spines of the dorsal vertebre, and parts of them undergo ulceration, become detached, and finally have to be removed. In some cases of this character the stench arising from the same is almost intolerable, and at times the discharge is very copions, and in running over the shoulders denudes the parts of hair, and oceasions superficial sores. The acrimonious and morbid condition of such matter is probably owing to a bad habit of body, or vitiation of the solids and fluids, which must be corrected by tonics, alteratives, and suitable diet, ere the disease can be arrested.

Treaturent of Fistulous Wrthers.-When the small tumor (skin unbroken) is first discovered, a cold water dressing is to be applicd, by means of a bandage. I usually apply a wet sponge, and confine it to the spot with a surcingle, frequently wetting the sponge. The patient should be confined to a light diet, and receive, in the form of drench, six drachms of nitrate of potass (saltpetre.) After the lapse of twenty-four hours, should this treatment fail to reduce the tumor, and it has increased in size, it may be inferred that suppuration has commenced, and matter is forming beneath the skin. So soon as matter, or pus, can be detected (its presence may be known by the softening and fluctuation, I advise that an opening be marle into it at its lowest margin, and large enough to admit of a free and complete discharge of its contents; the cavity should be syringed out two or three times, with a small quantity of fluid extract of blood-root. It is important that this orifice should be kept open for several days, or until the discharge has about ceased. 'This is the most rational method of treating a case of this character in its early stage. The same rule applies to the treatment of all abscesses wherever situated, viz., whenever matter can be detected it should be immediately liberated, lest contiguous parts be injured.

In some cases, however, a spontaneous abscess makes its appearance in the upper region of the shoulder blade, and often both sides are the seat of the same. They cannot be traced to any local injury, for I have often known them to occur in colts that have never been harnessed; therefore I term them spontaneous. In such cases I have found it best not to be in a hurry to open them, for suppuration is generally tardy, does not do much damage, may depend on morbid habit and morbid action; which may be corrected by a few doses of iodide of potass and golden seal; the dose of the same being as follows: Iodide of potass, fluid extract of golden seal-four drachms per day. The local application in view of exciting absorption is composed of-

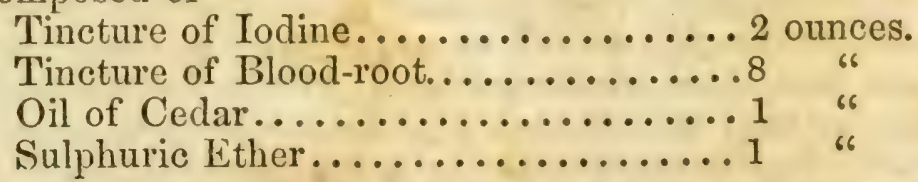

Mix, and rub into the tumefaction a portion of the above twice daily. After a few days' trial of the above, if the tumor does not decrease, but rather augments, the treatment must be discontinued; and if it be advisable to open the abseess, it can be done by means either of a lancet or seton. The after treatment consists in cleansing the parts, and in securing an open orifice at the lower part of the tumor, which will act as a drain to carry off the matter as fast as 
it is secreted. I sometimes inject, by means of a syrirge, a small quantity of pyroligneous acid daily, which acts both as an astringent and antiseptic.

In all cases of fistulous withers where the bones are involved, or fistulous pipes run in various directions, I advise the owner of the animal to secure the services of a veterinary surgeon, for it is impossible to put on paper all the information which the peculiarity or emergency of the case may require.

\section{INFLAMMATION OF THE LUNGS.}

This case will serve to illustrate my treatment.

On Sept. 20th, I was called to visit a roan gelding, the property of a gentleman of Chicago. On arriving at the place designated by the owner, I found the annimal in the following state:

Head hung down; the eyes lacking somewhat their usual brightness; respirations rapid and somew hat laborious; pulse quick and strong; membranes of the mouth and nose of a highly reddened hue; legs cold; slight cough; refused his feed, and would not lie down, his forclegs standing wide apart: these were the key-notes, and I accordingly pronounced the disease Pneumonia.

Treatment.-I consider nursing to be of very great advantage in the cure of disease, and I forthrvith ordered my patient to be placed in a clean stall, where he might have the advantage of inhaling pure air. I also had his body well clothed. His legs were freely rubbed with straw, and flannel bandages were wound around all four limbs from the hoof up to the knees.

As he was now in the acute stages of the disease, and highly inflammatory action being present, I administered by drench the following:

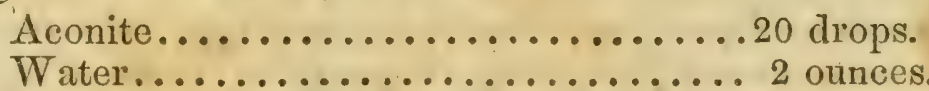

I then had a thin bran mash placed before him, and cautioned the hostler to withhold all oats and corn. Tow ards evening I gave him by drench,

Blood-root.................2 drachms.

and left him for the day.

Second Day. Called and found him in much the same state, although $I$ could perceive the respirations were not so hurried as on the day previous; but he retained the highly inflammatory state, and also had a morbid thirst for water. I placed a bucket of cold water before him, first placing in the water half an ounce of nitrate of potass. I also had his sides rubbed with

$$
\left.\begin{array}{l}
\text { Powdered Mustard, } \\
\text { Vinegar, }
\end{array}\right\} \begin{gathered}
\text { Mixed together so as to } \\
\text { form a paste. }
\end{gathered}
$$

I took off the bandages, and rubbed his legs well until I had produced an cqual circulation of the blood all over the parts.

Third Day. Found my patient with encouraging symptoms; his breathing was not so hard; pulse falling; legs not so cold, but he 
was begirning to show symptoms of debility, I therefore administered

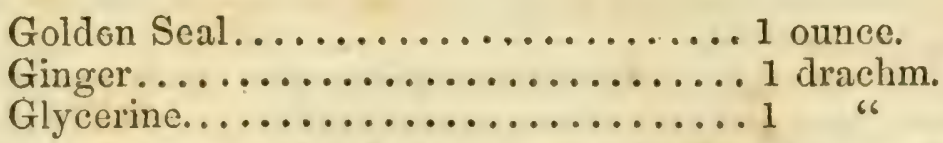

The disease was now bordering on the chronic state, and in consideration of this fact, the treatment required was tonics and those medicines in whose properties there are agents which will co-operate with nature in sustaining vitality and life. I left a dose of the following, to be given in four hours after the first dose which I had administered:

Golden Seal................. 1 ounce.

Iodide of Potass ................ 15 grains.

Blood-root.................... 1 drachm.

Fourth Day. This morning I considered my patient a far different horse from what he was when I first commenced with him. He began to show symptoms of activity; held his head more erect; his eyes appeared brighter and his legs were warmer, and his whole appearance had undergone a great change, and in a very short space of time. I gave him a tonic, namely:

Tr. Golden Seal................... ounce.

and informed the owner that $I$ would call in the morning.

Fifth Day. After examining my patient, I ordered the bandages to be taken from his limbs, and had him walked around in the open air. The owner then mentioned to me that he thought be needed no further treatment. This suggestion I complied with, and discharged the case.

This is only one of the many cases which go to show how medicines of a sanative character will act upon disease, and how few take into consideration what harm they are doing and the small amount of benefit the animal derives, when these individuals are pouring an apothecary's shop down an animal.

In the above disease of Pneumonia, care must be taken as soon the animal shows any symptoms of complaint, to place him in a dry clean stall, in which place he has the benefits derived from an unadulterated atmosphere. Whatever feed is placed before him should be of a sloppy character, such as bran mashes, \&c. And bear in mind there are but two conditions, namely-acute and chronic, and they are to be treated accordingly.

\section{GUTTA SERENA - (Dilatation of the Prpil.)}

Gutta Serena, sometimes called "amaurosis," consists of paraly. sis of the optic nerve; the diagnostic symptom, or liey note of the disease, is dilatation and fixedness of the pupil of the eye, and if a lighted candle be held to the same, it does not contract like the pupil of an eye unaffected.

The symptoms of this kind of blindness, independent of the above, are active muscular motions of the ears, and lifting the fore feet higher than usual from the ground. 
When Gutta Serena comes on in a slow and insidious manner, and has existed some time, it is sure to end in total blindness, but it is often a sympathetic affection, and subsides as soon as the disease which gave rise to it disappears. Whenever the affection is associated with other derangements, a mixture of golden seal and ginger, administered in two drachm doses once or twice daily, will afford relief.

\section{PARTIAL PARALTSIS IN MARES DURING THE PERIOD OF " HEAT" OR MENSTRUATION.}

My attention has often been called to Mares, the subjects of a sort of hysterical affection, accompanied by partial paralysis of the hind extremities. It is quite common for mares that are barren to be aflicted with this malady, for the simple reason that they are often the subjects of diseased ovaries. I once spayed a very valuable mare, a regular hysterical subject, who, during the menstrual period was uncontrollable, yet was often afflicted with partial paralysis of the hind extremities. The operation was a perfect success, and the mare was finally sold for the sum of firteen hundred dollars.

Partial paralysis, occurring in the male equine, is usually considered as incurable, and $I$ think it is from the fact that most practitioners resort to desperate means, in the use of strychnia, which, when adminstered in popular doses, is better calculated to kill than to cure; the patients often die, secundum artem, poisoned by Strychnine.

Ali curable cases of partial paralysis may be benefited by the nse of anti-spasmodics, which consist of camphor, Indian hemp, asafœida, musk or garlic; and this disease, like many others, is often self-limited. A little patience, a small quantity of anti-spasmodic medicine, given occasionally, will accomplish wonders, and often save a valuable animal, which, when otherwise treated, would be sure to die. As regards the "male," the affection is said to be the pro perty of the matured animal, very rarely affecting colts. Fast trotters, omnibus horses, and animals subjected to extreme exertion, are most liable to it. The disease in the male is supposed to be eccentric, and therefore it is difficult to say how it will terminate. It generally ruins the horse.

\section{"STIFLE OUT." - (Luxation of the Patella.)}

The Patella of the horse, or "Stifle-bone" as it is sometimes called, corresponds to the knee-pan of the man, and performs the same office. The position of the bone is at the lower part of the femur, and upper part of the tibia. The bone itself is kept in position by strong ligaments, and in consequence of the presence of a large prominence or condyle on the inner and lower part of the femur: Dislocation inwardly very rarely, if ever, takes place; the bone is, therefore, in case of luxation-stifle out--found on the outer and lower part of the thigh. 
An accident of the above named character is usually accompanied with much pain, and it is with great difficulty that the animal can be urged to leave the stall; the limb is rigid, and it is a matter of impossibility to get it off the floor, for the simple reason that the stifle is thrown off its pulley-like articulatory surface, and the action of the joint is suspended.

The liability to slifle-out, or luxation of the patella, is not so great as some persons would suppose; I have seen but very few cases of the kind. Many times have I been requested to visit horses said to have their stifle out, and on making examination have often found them subjects of cramps, or spasms, of the flexors; others have turned out to be cases of foot lameness, nail in foot, and even fracture of the pelvis.

So that the reader may not mistake a case of this character, I would inform him that the stifle is never out, unless the bone can be distinctly felt and seen, per tumor, on the outer and lower part of the thigh bone, at the same time the animal when urged to move does not raise the limb but drags it after him; this accident can easily be distinguished from a case of spasm or cramps, from the fact that when cramp sets in, the limb becomes, as it were, riveted to the floor; this condition, however, is peculiar to the cramp of the flexors, or those muscles which are concerned in bending the affected limb.

Means of Reducing Dislocation of the Patella or Stifle. The means of reducing dislocation of the patella are very simple. The patelia (stifle-bone), as I have already intimated, will be found on the outer side of the stifle joint. The person who proposes to accomplish the reduction must with his right hand (supposing the dislocation to be on the near or left limb) grasp the leg just below the hock, and gradually raise it upward and forward; the left hand should, at the same time, embrace the stifle bone, then by joint action of pressing the bone inwards, raising and extending the limb, the stifle-bone slips into its proper position, and the reluction is then effected. It will be observed that at the moment when the stifle-bone slips into its proper position, a snapping sound is heard, like that when the head of one of the shaft bones is made to slip into its socket. As a precautionary measure, it is highly necessary that assistants should support the animal, lest be fall and injure both .himself and the operator.

According to the above rule, it is a very easy matter to reduce a recent dislocation; and such requires very little after treatment, except rest, and the application, occasionally, of cold water.

When the stifle-bone has remained unreduced for many hours, it may be inferred that the ligaments, tendons, \&c., have been so long stretched or distended that they will not immediately contract, so that unless we adopt measures to prevent it, a re-dislocation is very apt to occur. To guard against this, a person has to be stationed so as tokeep a hand on the stifle-bone, at the same time the region of the stitle must be constantly bathed with some astringent. A solution of alum will answer; sometimes, however, it is necessary to shave the hair from the part and apply a strengthening plaster, composed of pitch, tar and rosin-equal parts; these are to be melted in a.tin or iron vessel, and when the mixture is sufliciently 
cool it may be spread on the region of the stifle by means of a knife or spatula; this is to be covered with a thin layer of wool or cotton batting.

In days of yore it was oustomary to apply the stifle-shoe, but I think the practice is injudicious, highly injurious, and at the present period is scarcely, if over, advocated by men who do their own thinking and practice in accordance with the principles of common sense.

\section{BLINDNESS AMONG HORSES-ITS NATURE AND SYMPTOMS.}

A great proportion of these cases of blindness are the result of over-feeling; our horses are notoriously fat, I do not mean that those now blind are in this condition, but that they were so ere blindness set in; now, their digestive organs are the seat of functional disorder; consequently they are, in this condition, more apt to lose rather than gain flesh.

It is quite a common practice among dealers to force their horses into a fat and sleek condition ere they offer them for sale. The animal undergoes the stuffing process; his stomach is converted into a grist mill ; the food (Indian corn) is rich in oxygen or fat, contains more of the fat-making principle than any other article of equine diet; and under the condition of rest, in warm city stables, adipose or firtty matter accumulates very rapidly, and is stored up in the eellular tissues, and as the fatty matter preponderates, the muscular structures degenerate.

Butchers are well acquainted with the fact that very fat carcasses contain but little meat or muscle, and even the heart of a fat animal often contains a considerable quantity of fat globules, insinuated between its muscular fibres. 'This condition impairs the heart's function, and constitutes a disease known as fatty degeneration. This is the effect which food, rich in sugar or oxygen, has on the animal economy. Now, in this land of plenty, and in this region, which is the great national bread-basket, there is danger of orerfeeding horses. In view, therefore, of preventing plethora and blindness, horse owners must dip a lighter hand into the corn bin.

Blindness occurs as follows: When blindness occurs as a functional disorder, it is often the result of a disturbed sympathetic rela. tion between the brain and the stomach; and an overworked or an over-distended stomach may not occasion any local pain, but often operates with that kind of influence on the brain which gives rise to symptoms, not stomachic, but cerebral. The brain once affected, then commences morbid action in the eye, or eyes, as the case may be, through the operation or medium of the optic nerve, which originates in the base of the brain.

It appear's to me that many of the horses daily parading our cities, blind in one or both eyes, must labor under some peculiar predisposition to derangement and diseases of the organs of vision, and whenever the ordinary exciting causes (errors in diet) are nperative for any length of time, they develop a morbid condition, 
which might otherwise have remained latent during the natural period of the awimal's life.

It is a well known law of the animal nconomy, that predispositions to various forms of disease are transmitted through the sexual conngress to offspring, and in the system of the latter may remain latent until the conditions favorable for the development of the constitutional malady are presented, which are nothing more nor less than the ordinary exciting causes of disease.

In some parts of the United States similar errors in the feeding of horses produce blind-staggers, stomach-staggers, and organic disease of the brain; this goes to show that in such cases the animals are more predisposed to cerebral disease than to disease of the organs of vision.

In view of preventing diseases of the above character, proper attention must be paid to the principles of breeding, and all animals showing the least symptoms of organic disease should be rejected. The disease itself may not be transmitted, only a predisposition thereto, and this is usually the case when only one of the parents is afflicted; when both parents are the subjects of analogous predispositions or maladies, then they appear in an augmented form in the systems of their offspring.

Whenever an animal shows the least symptoms of blindness, he should be kept on a light diet of hay and oats. Such horses can be kept in a perfectly good condition on twelve pounds of hay and five pounds of oats. This amount is all that is necessary for the preservation of the integrity of their organism; all beyond this amount is either expelled with the excrements or stored up in the cellular tissues of the body in the form of fat.

One of the principal symptoms attending incipient blindness, and one which ordinary observers might be apt to notice, is the motion of the fore limbs; it will be observed that they are raised from the gromnd to an unnecessary height, the ears, at the same time, being drawn forwards and backwards in quick succession, showing that the animal is sounding the ground orer which he travels, after the fashion of a blind man with his walking-stick, thus placing more dependence on the sense of hearing than on that of sight.

\section{OPHTHALMIA. (Inflammation of the Membranes of the Eye.)}

Simple Ophthalmia sometimes appears very suddenly, commencing with swollen eyelids, and a highly reddened state of the membranes which line the same, as well as of that which covers a portion of the cyeball; scalding tears run down the checks, and the animal aroids light. There are sereral other disenses peculiar to the eye, most of them of in organic character, and incurable, hence, I shall not trouble the reader with any remarks on such subjects.

Trentaient of Inflamation of tme Eye.-The treatment is very simple; bathe the forehead and region of the eyes very frequently with cold water, keep the patient in a dark corner of the 
stable, feed him on sloppy mashes, and give him four drachms of nitrate of potass, night and morning, for a few days.

Should the animal manifest symptoms of much pain, take one ounce of laudanum, one drachm of glycerine, and three ounces of rain water-manage to introduce a portion of the same two or three times per day within the eyelids; then dissolve half a pound of Glauber salts in two quarts of water; when dissolved, stir in about two quarts of bran; set the same before the animal and he will eat it. Should this fail, at the expiration of twelve hours, to relax the bowels, repeat the dose. This simple plan of treatment usually succeeds in restoring the healthy condition of the parts.

\section{SORE MOUTH.}

Sore mouth or excoriation is often produced by damaged fodder, such as musty clover, \&c.; at other times, the angles of the mouth become sore by an unwarrantable use of the check-rein, and from irritation produced by the bit.

Treatment.-First remove the cause, and then swab the mouth by means of a sponge, twice daily, with a portion of the following:

Powdered Alum ................. ounces.

Glycerine .....................

Water.......................... quart.

Mix.

\section{IAMPAS.}

Lampas consists of tumefaction of the palate, or bars of the mouth. Most young horses are observed to have Lampas, and some persons have an idea that it occasions loss of appetite and many other ills; but such is not the case. All that is necessary to do, is to make use of some astringent lotion, composed of alum and water, and feed a few bran mashes.

Formerly it was considered necessary to cauterize the palate, but this is an unnecessary and barbarous practice.

\section{EXCORIATED MOUTH FROM SHARP TEETH.}

Occasionally the outer edges of the grinders become sharp, from uneven wear, and produce irritation on the inner membrane of the cheeks. When the irritation is confined to one side, the head of the animal deviates from a direct line, and as the saying is, he carries his head towards his side; when both sides are affected, the animal will often drop food from his mouth, and it will be evident that the act of mastication occasions pain. The remedy is a tooth rasp: the sharp edges must be rasped smooth. 


\section{APHTHA. (Thrush in the Mouth.)}

Aphthr is a very common affection among horses in the spring and autumn; it consists of tumefaction of the tongue and lips, and the appearance of little tumors and vesicular eruptions within and around the mouth - the latter being hot and inflamed. The disease affects the general health, for the functions of the body are deranged; the animal appears dull, and will often refuse to partake of food.

Treatment.-Keep the patient on a diet of gruel, or sloppy bran mashes, and bathe the mouth several times daily with a portion of the following:

Pyroligneous Acid................. ounces.

Mix.

Water ...................... quart.

If the acid cannot be procured, substitute the following:

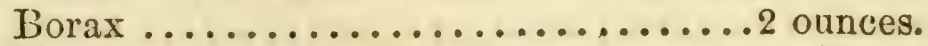

Honey ..................... gill.

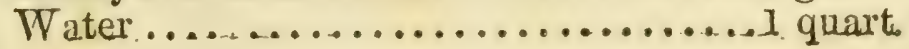

\section{EPIZOOTIC APTHA.}

"This disease is commonly known as the foot and mouth complaint. It is a febrile and highly contagious disease, readily communicable to different species of animals, and for this reason is designated a panzootic affection.

"Although it is met with in the horse, hare, pig, \&c., yet it is most commonly noticed in the ox and sheep, in which animals it occurs as a vesicular eruption, breaking out on the gums, lips, teats, and around the coronary surface of the hoof.

"In this disease the ox exhibits the following symptoms: suspension of rumination, constipation, great flow of saliva from the mouth, and severe lameness.

"Milk obtained from apthous cows should never be drunk, as it is very likely to produce a similar disease in the human subject. To prove this fact, Hertwig, together with Villain and Hann, drank the warm milk of an apthous cow, and the result was that they all became subjects of the severe inflammation of the throat, associated with vesicular eruptions. Professor Simons gave warm milk taken from an apthous cow to young pigs, and in each case aptha resulted.

"Epizootic aptha spreads amongst sheep as a consequence of actual contact with the virus, which is deposited on the pasture by one and taken up by another, either through the medium of the mouth or digits, and by this means a whole flock soon becomes affected.

"Treatmens.-Wash the mouth, lips and teats with sulphuric acid and water, half an ounce of the former to a pint of the latter, and the fect with equal parts of hydrocloric acid and water ; and administer, daily, nitrate of potash and chloride of sodium, of each three ounces. If the udder becomes affected, or induration of the teat 
supervenes, warm fomentations must be constantly applied to the vart, and a tube should be put up the teat, in order to facilitate the escape of milk."

\section{SPASMODIC COLIC, AND ITS TREATMENT.}

Spasmodic Colic is a disease of very frequent occurrence among horses, and in view of giving the readers of this work some definite ideas of its seat, nature, and treatment, I introduce the following as the result of my experience.

The appellation of colic is usua!ly given to abdominal pain, as it occurs in the intestines of horses; it is, however, a very different condition from that known as inflammation of the intestines, yet the former often merges into the latter. Spasmodic colic, therefore, consists of a morbid contraction of the muscular fibres of some part of the intestinal tube, accompanied by pain, and constitutes what is generally called "stoppage."

The small intestine is the usual seat of spasmodic colic; and dissections show irregular contractions and shortenings of the intestines, accompanied by engorgements. A few remarks on the strucsure of the intestines, will enable the reader to understand how, and by what means, the spasmodic action takes place.

The intestinal tube of the horse, which is about ninety feet in length, is composed of three coats. The first, or external, is the peritoneal; a tunic or covering, which, after having furnished a smooth, glistening lining to the interior of the whole abdominal cavity, is reflected over the intestines and gives to them a complete covering, identical with that which they are constantly in contact with. The second coat is composed of muscular fibres of two orders, one running longitudinally, the other circular. Should contraction occur in the longitudinal fibres, the bowel is proportionally shortened; when it occurs in the circular fibres, the calibre of the intestines is decreased, and sometimes in severe spasm, complete stricture of the part takes place; this I have known to continue even after death, when it was found difficult to pass a small tube through the contraction. The reader will perceive that if contraction of both these orders of fibres shonld occur, the intestines will present a knotted appearance. The third, or inner coat of the intestines, is of a villous, or rather, mucous character; its surface is adapted for secretion and absorption-thus by means of its lacteals, alimentary and other matters are imbibed or absorbed and conveyed into the general circulation. By means of an innumerable number of small glands, a fluid is secreted, which finds its way to the surface of the mucous membrane, and there operates to prevent mechanical irritation, which may follow the administration of drastic cathartics and poisons, or may result from the action of indigestible food, such as bad hay, straw, corn-stalks, \&c.

Now the question arises-by what means is spasm of the bowels produced? The ordinary cause is the application of a stimulus or agent, which calls into activity the contractile power of the involuntary muscular fibres of the intestines. It may follow the act of imbibing a quantity of cold water; or may result from the presence of 
something within the intestinal tube, there generated, such as an acid or an alkali; generated in consequence of a morbid condition of the salivail or the gastric fluids, and from the presence of worms. But spasm of the bow els is produced more easily by a poculiar stimulus conveyed through the nerves which are connected with, and supply nervous force to those muscles at the seat of spasm. I wish the reader to understand that it does not matter much whether the stimulus, which occasions the state of spasm, be applied to the external or internal surfaces; for it is well known that horses of a peeuliar nervous temporament when heated by exereise and then driven into water, will occasionally be attacked with cramp or spasm, and even locked jaw; and locked jaw is a disease of the same class and order as spasm of the bowels, only located in a different part of the body. The reason why external and internal stimuli act precisely alike to produce spasm, in the predisposed subject, is because the ultimate nerve fibres have a similar distribution on external as well as internal surfaces.

This peculiar arrangement of the nervous systern, of a two-fold character, appears to be a wise arrangement: First, it brings the psychical endowments of animals into relation with the external world and its influences; informing them, through the medium of the organs of sensation, of the changes which take place under conditions of the atmosphere known as "heat and cold"; and in their undomesticated state, the conscious, or instinctive mind receives an instructive lesson and acts accordingly, so as to guard against danger. Secondly, an impression made on the internal surtice of the intestines, reacts through its nervous and motor apparatus, precisely as if applied to the external surface of the body, and excites or arouses voluntary and involuntary action and spasm, as the case may be, purely on the principle of self-preservation, and of resisting injuries when threatened.

Treatment.-To one ounce of fluid extract of lobelia adi three drachms of sulphuric rther; mix this in a small quantity of sweetened water, and drench the patient with the same: the lobelia and xther act as anti-spasmodics, and tend to relax the spasm of the bowels.

Then take two ounces of fluid extract of lobelia, two quarts of warm water, and throw the same into the rectum by means of a syringe.

Should the above treatment not relieve the animal, I should rtherize him, and apply a stimulating liniment to the abdomen, and after the animal recovers from the effects of the xther, a few drops more of lobelia will do him no harm; yet, if he is relieved, the medicine should be dispensed with.

\section{FLATULENT COLIC.}

Flatulent Colic is the result of derangement of the digestive organs : the food, without being properly digested, runs into fermentation, and generates gas within the stomach and intestines. 
The malady is easily recognized from the fact that the abdomen is distended, and if the walls of the same be struck, a windy sound is elicited; and it will be noticed that gas escapes from the anus, and sometimes from the mouth.

The animal is usually in great pain, and will tumble about in the stable, rolling from side to side, in view of obtaining relief.

Treatment.-The principal object to be accomplished, is, first, to give tone to the stomach, and arouse the digestive function, so as to put a stop to fermentation; this accomplished, the animal is almost sure to recover.

In this view I recommend the following:

Powdered Ginger ............... ounce.

"Golden Seal................. "

Carbonate of Soda ............... drachms.

Warm Water..................... pint.

Mix; and drench the animal with the same.

The next best remedy is :

Fluid Extract of Ginger............. ounce. " " of Golden Seal.......... "6

Carbonate of Soda ................ drachms.

Warm Water ....................

Mix; and drench.

After administering the medicine, throw into the rectum enemas, composed of warm water and common salt.

In the course of a few hours the animal will get relief; if he should grow worse, repeat the dose, and lubricate the abdomen with stimulating liniment.

\section{BRONCHOCELE.}

Bronchocele is a very common affection among horses; the malady is known to veterinary surgeons as enlargement of the thyroid glands; the enlargement is sometimes the sequel of epizootic and enzootic affections, and it often accompanies the affection known as sore throat.

Treatuent.-Give the patient twenty grains of iodicle of notass daily, which may be dissolved in the water which is ofiered him, and rub the swellings daily with a small quantity of tincture of iodine, or if the Magnetic Liniment can be procured, use it.

Should the above treatment fail, give the patient a few doses of the Magnetic Horse Powders. (See Magnetic Horse Powders.)

\section{BRUISE OF THE SOLE.}

Bruise of the sole of the foot, is the consequence of the animal treading on a stone or rail iron; the result is, extravasation of blood within the articulatory surfaces of the sensitive and insensitvie lami$\mathrm{næ}$; the accident is almost always sure to result in lameness. 
Treaturent.-Keep the foot constantly wet with cold water; excuse the animal from duty, and give him a chance to breathe pure air; have patience, and the horse will soon get well.

Should the patient appear to suffer much pain, give him twenty drops of tincture of aconite every four hours, until relief is obtained; and feed him on bran mashes, allowing, at the same time, a small quantity of hay, in view of distending the stomach to a healthy capacity.

\section{CORNS IN HORSES. "No Foot no Horse."}

A horse the subject of corns is expected to have defective feet, hence the above quotation is "true as gospel."

That peculiar disease occurring within the inner quarter of the fore feet of horses, known as corn, is a very different affection from that peculiar to the feet of man. In horses, corn is neither more nor less than extravasation, which signifies escape of blood from its proper vessels into the surrounding tissues of the part. This extra. vasation or escaped blood, finally coagulates, and creates a black spot, known as the "corn-spot"; this is exposed on paring the sole at its inner quarter. All blood which escapes in this way becomes as a foreign body, yet in some parts of the system, where the ab. sorbent vessels are very numerous and active, the foreign deposit is soon removed by the ordinary process of absorption; but within the dense tissues of a horse's foot this process is tardy, sometimes im. possible, consequently, matter or pus is generated between the sensitive and non-sensitive parts, and a passage must finally be cre. ated for the liberation of the imprisoned matter; for it cannot escape through the dense structure composing the hoof itself; hence it burrows and migrates in various directions from the sole, and lastly creates an outlet at the inner and upper part of tne hoof, where the matter escapes.

Treatarent of Corn.-The only chance of relieving the animal is to remove the shoe and apply one having a slight concavity at the former seat of pressure; or if the animal has a prominent frog, the bar-shoe can be attached; previous to doing so, however, the corn. spot can be slightly pared, and whenever there appears to be any pressure on the sole at the quarters, the shoe must be removed and adapted as above. The theory, therefore, in the treatment of corn. is to secure a vacancy between the heel and the shoe.

If the horse happens to be "dead lame," and tenderness and swelling are observed at the upper part of the hoof, the part may then be punctured with a lancet; after squeezing out the imprisoned matter, the part slould be dressed, daily, with fir balsam. In some cases of suppurated corn the matter must be liberated, by making an opening through the sole of the inner quarter; this is also to be dressed with fir balsam; the shoe to remain off for a few days. 


\section{CRIBBING OR CRIB-BITING.}

"Is Cribbing a Disease?"- I answer that it is not. It is not injurious to the horse that practices it, and the Court of Appeals have pronounced in favor of its innocuousness. Cribbing comes under the denomination of a bad habit or vice, which, like other bad habits or vices, is both inherited and acquired: it prevails mostly among horses of a windy or colicky predisposition. Yet any horse with a bad example near him, in the form of a confirmed cribber, and having but little to do except to devour hay and grain, may finally become a cribber; hence, horses like men, are not benefited by keeping bad company.

I am willing to admit that cribbers are not always in the best condition, although some of them have but little to do and plenty to eat; in fact many such animals appear lank and lean, yet it will be no. ticed that they almost always have a bulky abdomen, which is generally occupied by gas; this gas is not swallowed in the act of cribbing, as many persons suppose, but is generated within the stomach and intestines, in consequence of functional derangement of the digestive organs; hence, in plain language, most cribbers may be considered as the subjects of a most prevalent and fashionable malady: known to prevail among the members of the human specics, called indigestion or dyspepsia.

The following paragraph I select from Mr. Percival's writings, which is more authoritative than anything I may possibly offer:

"In general, crib-biting ought rather to be regarded as a vice or habit than a disease; the latter I have never been able to regard it. Horses that are old crib-biters present the inconvenience of being faulty feeders-they require a great deal to satisfy them, and those which generate air in their stomachs are very subject to attacks of windy colic."

Finally, a crib-biter often grows poor, not because he is a cribber, but for the simple reason that in his dyspeptic condition the digestive organs fail to elaborate from the food the requisite amount of chyme, chyle and blood, for the renovation and growth of the animal fabric.

\section{CEREBRAL APOPLEXY.}

The following case will illustrate the pathology of the disease:

I was requested a short time ago to visit an animal the subject of cerebral apoplexy.

Position of the Anrmat. - The position very clearly indicated disease of the brain, for he stood as if in the act of forging forwards, with his head against the sides of the crib, and it was with considerable difficulty that he could be made to "back," and when once out of the ziant he manifested unsteadiness as when attacked with staggers.

Noticeable Srmptoms. - The pulse at the angle of the jaw could scarcely be felt, showing a feeble action of the heart; limbs and ears rather chilly; the nasal membranes of a leaden or bluish cast. 
On turning up one of the eyelids, it appeared highly congested, presenting a uniform brown reddish tinge, occasioned by obstruction in the capillaries and a highly carbonized state of the blood. The respirations were tubulous and slightly stertorous, which signifies that the lungs were not properly inflated, respiration being principally carried on in the passages which lead to the lungs. Stertorous signities snoring, the act of inspiration being accompanied with a sort of snoring sound.

On observing the flanks the respiration appeared labored and quickened, which led some persons present to infer that the animal had lung fever; but on applying my ear to various parts of the region of the chest, I became satisfied that the lungs were healthy, and therefore pronounced the case as one of cerebral apoplexy, as it proved to be. The flank movements, therefore, were of a purely mechanical or auxiliary character.

Prognosis.-Prognosis, which signifies foreknowledge of the course, event, or termination of disease, is sometimes impossible to foresee, and as regards this case, which appeared to be mild in the beginning, I was unwilling to predict an issue, or rather to foretell the event of the malady.

The difficulties in the way of predicting with any degree of certainty, were as follows: 1st, The animal was young and had always enjoyed perfect health, never having shown the least predisposition to disease in any form. 2nd, Two days prior to the attack, he had been driven a long distance, and on arriving at his quarters appeared merely fatigued, and the groom noticed that his excrement was coated with slime, and from these circumstances we might rationally infer that the digestive organs were deranged; hence the brain difficulty might possibly be of a sympathetic character; and if so, the patient might recover.

I therefore informed the owner of my patient, that, if the disease was mercly functional, he might expect recovery; if otherwise, the disease being organic, death would surely ensue.

Treatment and Termination of tile Case.-I administered diffusible stimulants by the mouth and rectum, applied counter irritants composed of turpentine, oil and ammonia; the limbs were rubbed with wisps of straw and then enveloped in flannel; the region of the cranium (which was very hot) was bathed with cold water. Reaction took place, and the animal appeared more lively; the surface of the body regained its normal temperature, and to all appearance the condition of the patient was many removes from that of a dying creature; but alas for human calculation! all at once he was seized with convulsions and suddenly died.

AutopsY.-On removing a triangular piece of the cranium (scull) and its membrane, the superficial vessels of the brain appeared highly congested; on puncturing the pia mater (the membranous covering proper of the brain), serum, or water, exuded, indicating dropsy of the brain, and a quantity of dark colored or highly carbonized blood escaped, showing very conclusively that the cause of his sudden death was rupture of a blood vessel in the brain. 


\section{ENLARGEMENT OF THE SPLEEN.}

A short time ago I visited a black gelding, aged nine yoars; he had shown some symptoms of illness for several days, being rather dull and weak in his legs.

On examination the following symptoms were noticed: pulse quite feeble; respiration natural; tongue coated with a brown secretion; mouth hot, and a fotid odor fiom the same is perceptible; the visible surfaces of the mouth are pale, yet have a yellow tinge; the nasal membranes are of a leaden hue; the head droops and the tips of the ears are chilly; the patient is rather unwilling to move, and when urged to do so, exhibits a staggering gait; the bowels are lax (the excrement appearing like cow manure,) and the owner of the animal informs me that the urine is scanty and dark colored.

Percussion over the region of the liver (on the right side,) elicits an unusual dull sound, indicative of a diseased liver; on percussing the left side in the region of the spleen, a solid sound is elicited, and an evident enlargement of the spleen is perceptible.

Twelve hours after this examination the animal died.

Record of the Autopsy.-On opening the abdominal cavity, the spleen was found to occupy a very large space; it was of immense proportions, and weighed nearly twelve pounds (the ordinary weight is three pounds); it presented the appearance of a spleen in the chronic stage of disease-excessively enlarged and altered in structure; it was of a pitchy black color, and was surcharged with blood.

The liver appeared to be much enlarged, hardened, and discolored, and on cutting into it, various small tubercular deposits were exposed; all the other organs appeared to be healthy. A case of this kind is always beyond the reach of art-incurable.

Remarks on the Spleen. - The spleen, known to butchers as the milt or melt, is a spongy substance, located on the left side, between the stomach and the false ribs. It presents a blue mottled appearance externally; internally, it is dark colored.

Its internal surface is concave, by which arrangement it is perfectly adapted to occupy a locality of the stomach which in form is convex.

The spleen, like other organs within the abdomen, receives a covering from the peritoneum, and when this covering is stripped off, we discover a body soft, lacerable and spongy.

It is supposed that the spleen does not perform any secretory function, and physiologists have hitherto failed in detecting any excretory vessel, or duct. In these respects it differs from all other glands of the body; in fact, having neither secretory nor excretory vessels, it cannot, with propriety, be classed as a gland.

The anatomy of the spleen is as follows: It is furnished with arteries, from the cæliac; the cæliac terminates in the splenic, and the splenic furnishes the spleen with blood (the "cæliac" arises from the abdominal aorta); and these arteries, after being dispersed within the substance of the spleen, find innumerable ramifications, and ultimately terminate in cells of a membranous character; from this 
cell arrangement springs innumerable venous radicles. The spleen being very spongy, and porous, is capable of undergoing great distension, without danger of rupture; in fact, it sometimes acquires an enormous size, without loss of continuity. The spleen is delicately organized with nerves, and presents an intricate net-work of absorbents; the nerves of the spleen are given off from the cæliac plexus.

Notwithstanding the fact that the spleen does not perform the functions just alluded to, it is a very important organ, and serves as a diverticulum to the liver; when thus employed it tends to prevent congestion of the liver.

\section{BIG-HEAD AND BIG-JAW.}

Premiminary.-The terms big-head and big-jaw are used by husbandmen and others in Ohio, and indeed throughout the great West and South, to designate a disease of the bony structure of the horse, a disease about which very little, of a reliable character, has erer been said or written. Yet the subject is one of great importance to the people of this country, for the simple reason that the evil is one of alarming proportions, and should the disease multiply in a ratio equal to that of the few past years, it will be a terrible blow to the laudable and hitherto profitable enterprise of raising colts, in sections where this disease prevails.

I do not wish to create any unnecessary alarm, but I urge the husbandmen of the South and South-West, to give this subject their earnest consideration; for the disease probably has an hereditary origin-" is inbred," and that, as the saying is, "constitutes the root of the evil," and the disease having been pronounced incurable, our only hopes of success in putting a stop to its propagation and development, is to adopt preventive measures by rejecting, as breeders, all animals-sire and dam-that show the least predisposition to or for this affection. Let the reader understand that the disease itself is incurable, in so fur as the enlargement, dilatation, and softening of the jaw bones is concerned; yct like spavin, ringbone and various other diseases, it is accompanied, in certain stages, by lameness, and our services as physicians, are only secured in view of removing this lameness, so that the animal may be enabled to perform the ordinary equine duties; this is what some persons please to term a cure, whereas, it almost always happens that some alteration in the structure of the parts remains, which actually renders the horse unsound, because he has that about him, which may from overwork, or other exciting causes, impair his usefulness.

As regards the "alarming" features of big-head or big-jaw, I would inform the reader, that almost every lame horse, examined by me during a period of six months, had either one or the other of the jaws enlarged; in some cases one angle of the lower jaw was the seat of thickening and enlargement, but among the majority both angles were affected.*

* Theso remarks do not apply to other obvious or accidental lamenessed which are also constantly occurrino: 
A short time ago, I visited, in company with a practicing veterinarian, whose attention had never been called to this affection, three horses, the subjeets of lameness, which was said to be occasioned by eating Hungarian grass: to the astonishment of the parties concerned, I demonstrated that they were all the subjects of enlargements of the lower jaws, and from the history of the cases and the character of the lameness, it was very evident, that it was of an articular character, and this is a peculiar feature of this affection. Then again the reader must bear in mind, that the jaws of animals do not dilate nor enlarge suddenly, nor make appearance all at once, like a meteor in regions of space; the affection is insidious, progresses in an almost imperceptible manner, and usually escapes the notice of those who daily have charge of and handle the animal, as the following case, which is selected from among many others, will serve to illustrate:

About eighteen months ago a gentleman purchased what then appeared as a tine family horse, a sorrel gelding, aged five years. About the beginning of March, one year after the purchase, in attempting to walk the animal from one stable to another, but a short distance off, he became suddenly lame in one of the hind limbs-low down towards the foot-and it was found almost impossible to urge him forward; finally assistance was procured, and the animal hat, literally, to be carried into a stable. My services having been secured, I visited the sufferer, and found him standing on three legs, the near hind one being placed resting on the toe; the parts around the coronet were hot, and the patient was very unwilling to have the part handled; he seemed to suffer much pain, was breathing hurriedly, and the pulsations were quick and wiry; the near approach of any person secmed to terrify the animal, and he actually urembled from fear and pain, when ordered to move. On making an examination of the jaws, I found that both angles of the lower jaw were enlarged to about two inches in thickness; this explained the nature of the sudden, and otherwise mysterious lameness; the articulating surfaces of various bones, and the bones themselves, had become diseased, as is often the case in big-jaw. The owner assured me that the horse had never before been lame, and he was rery much surprised to find the lower jaw enlarged. Here the reader will perceive that the animal had been in Mr. W.'s possession one year, had performed ordinary labor, yet was the subject of a gradual enlargement of the jaw, and a constitutional disease, which probably existed, yet in a slight degree, at the time of purchase; hence I contend that the disease in its early stages is of a hidden or insidious character, and requires some tact and knowledge of the subject in order to detect it.

NatCre of the Drsease.-Big.head and big-jaw, are but one form of disease, only located in different parts. When the upper one becomes the seat of affection, an enlargement of the facial bones will be observed, and the examiner's attention will be attracted by the unnatural appearance of the face; as the disease progresses, the face looks more like that of an elephant than of a horse, and now the disease being incurable, the subject should mercifully be put out of his misery. The enlargement of the lower jaw is discovered by manipulation. 
On removing the skin from the sides of the face of such $\Omega$ subject, and dissecting the muscles and periosteum (ecvering of bone), the bones appear to have undergone a softening process, and particles can be separated by means of the finger nails; at the same time if a transverse section of any of the shaft bones be made, they will be found to have undergone structural changes; for example, they will not only appear softened but honey-combed, and many of the laminæ and cartilaginous braces will have been decomposed or dissolved, so that the bone looks like fibrous net work. In most eases, the vacuities and canals are filled with material resembling soft cheese, which is probably fatty matter; this occasionally degenerates into pus.

Dr. Gordon forwarded me, some time ago, the head of a horse who had long been the subject of this malady. The transverse diameter of the bones of both upper and lower jaw, was very much enlarged; the periosteum was very highly organized with bloodness; the bones were softened and elastic, and could be easily cut with a knife. On submitting them to the acid test, earthy matter was found in excess, and by burning them, it was found that they contained very little animal matter; hence I was led to infer that the disease is one of mal-nutrition.

The articular surfaces of various bones, and sometimes all the bones of the body, are often ulcerated and studded with incrustations; this explains the why and wherefore of the sudden and tormenting pains which animals suffer, and goes to show how little of benefit can be expected from the ordinary treatment, which is principally directed to the enlarged jaws.

On removing these diseased cartilages from the articulating surfaces of bones, the latter are found to be affected-in fact, ulcerated. In some cases the ligaments and tendons are separated by decomposition or necrosis of bone, and the animal "breaks down," as the saying is.

The subjects of this disease sometimes show lameness in the vertebral region, and in that of the head of the thigh bone; in such cases we may safely infer that the lameness is of an articular character, and the inter.articular cartilages, as well as the surfaces of the bones, are incrustrated and ulcerated; in this condition the animal is liable to become uscless, "or break down" at any moment. The following brief case will illustrate what is meant by "breaking down:"

I was requested a short time ago by Prof. Muzzy to examine an aged gray gelding, the subject of lameness in the near lind foot; examination revealed considerable heat, tenderness and tumefaction around both the hind coronets, and both angles of the lower jaw much enlarged in their transverse diameters. I advised the owner to let the aurmal have a run at grass; accordingly he was sent into the country, about thirty miles (which was too long a journey for him); a few days afterwards Prof. Muzzy received a letter, stating that the horse's strings (tendons) became loose, that he broke down and traveled on his fetlocks, and was then dead. I infer that necrosis took place and the extensor tendons lost their attachment, which accounted for his "breaking down."

Prof: Varnell lately consulted Dr. Harley of London in reference to this formidable malady, which is said to have been almost unknown 
in England until November, 1859, when several cases occurred among some horses, the property of $\mathrm{Mr}$. Champion Calcot, near Reading. Three of this gentleman's animals had died, a fourth was not expected to live many days, and two others were laboring under the same disease, in a less acute form. The most singular feature of the disease, as it appeared on the premises of $\mathrm{Mr}$. Calcot, were, that it did not appear to owe its origin to any perceivable cause, and it was not known to be prevalent in any other part of England. Still, my opinion is that it cloes exist in that country, only not being suspected is not sought for. It prevails very extensively among horses brought to Ohio, and hundreds of horses are purchased for the American army in the course of a few months, having more or less enlargement of the lower jaw, yet I do not belive that either seller or purchaser suspects the same. This arises from a lack of knowledge on the subject, and the same remarks, so far as our ignorance of the subject is concerned, may apply to England.

In answer to questions put to Mr. Calcot on the subject of management, \&c., he contends that the affected animals had plenty of exercise; there were no chemical factories or works in the vicinity; one horse affected was purchased at a clistance, the rest had been bred on his farm; the sires and dams all appeared free from the disease, and they were not all got by the same sire; the food consisted of good grass, hay, pollard, oatmeal and roots: other horses were on the firm, fed in the same manner as the affected ones, yet they had no symptoms of the disease (perhaps they will show symptoms when the jaws shall be examined-they may have the disease, yet not be lame or apparently ailing.) Mr. Calcot never saw a case of the kind before. From the above testimony, we may infer that the causes of this affection are not yet discovered in England, but my impression is, that overfeeding has a good deal to do in the production of the malady.

It appears to me that this disease, as I have already written, is one of mal-nutrition or defective nourishment; henee, may be considered as a scorbutic affection, like that affecting the human subject, which is known to be the result of faulty nutrition, and which often results in division of bony parts which were once immorablethe epiphysis of the pelvis for example-also in the separation of cartilages from the ribs, and the shaft bones softened and ruined by caries, ulceration or death of bones.

Name of tire Disease.--Big-head and big-jaw are terma suffciently explicit in ordinary conversation; but in view of scientific inquiry it is necessary to employ terms indicative of the pathology of the disease. We cannot expect, however, to select any one name that shall apply to all the pathological conditions, during the rise, progress and termination of this peculiar malaty; the condition of the bones, are: a state of enlargement, softening, and degeneration of the same. The disease is known to veterinary surgeons as osteo-porosis.

Cause of tme Disease. - I have alrealy informed the reader that the disease may hare an herediary origin; otherwise, I cannot account for its universal prevalenee, in certain localities, under the ordinary modes of feeding and general management. I grant 
that, at first, the disease might have had an accidental or spontaneous origin, and finally become permanent and trausmissible; for example, glanders and farcy afford illustrations of a spontaneous disease becoming contagious and transmissible. There must have been a time when neither of the two latter diseases existed; hence, when the first subject became glandered he could not have taken it by infection or by contagion, but it must have had a spontaneous origin, and finally, became permanent.

I do not pretend to urge that the active disease itsclf is transmissible, yet, in certain cases, a predisposition is transforred to the progeny. This may be called the predisposing cause; the ordinary exciting causes are those which disturb and derange the digestive function. The digestive or nutritive function is deranged, both by excessive and defective functional labors, or by the animal existing on food that does not contain the necessary amount of nitrogenous or muscle-making matter. This is the case when Indian corn is used as food for a great length of time; it is hard to digest, is deficient in nitrogen, and almost always over-distends the stomach ; for, when submitted to the action of heat and the gastric fluids, it increases in bulk to about six times its original capacity. I have noticed that where much whole corn is fed, as in Obio and Indiana, the disease is most prevalent.

Associated with the predisposing and exciting causes, are others : for example, hard usage, sore abuse, and bad stable management.

This disease is rarely ever heard of in England, and this may be owing to the fact that the food there furnished to horses is rich in phosphates and nitrogen, while corn contains more of starchy matter; which, instead of furnishing material for the preparation of muscular or animal matter, merely furnishes that which is consumed in the process of respiration.

Treatment of the Disease.-The ordinary treatment, as practiced by some persons, is to bore into the jaw-bone and inject the same with some corrosive poison; others expose the jaw-bone, and saw out a section of the same; some persons blister, or apply preparations of iodine. Such treatment, I think, only tends to create unnecessary irritation and pain, and cannot possibly be of any benefit, for I contend that the disease is not local, but constitutional; and the reader will, probably, after perusing this article, come to the same conclusion.

The disease has extensive ramifications in various parts of the bony fabric, and therefore the local treatment must fail in euring the malady. Cases may arise which require surgical operations, and if so, I have no objections to offer.

I have oiten been told that horses, after having all sorts of barbarities practiced on them, have recovered; this, so far as the treatment is concerned, is in accordance with the spirit of the old error. "He got well after taking my medicine; therefore, in consequence of taking it." This is assuming a falsehood as a fact, and then giving fanciful reasons for it.

In view both of prevention and cure of this organic disease of the bones and their articulations, more is to be accomplished by regimen than by medicine. The animal should alwa!s be provided with wholesome diet, and whenercr green regetables can be ob- 
tained, they should be fed liberally, or, what is much better, provided the season permits, let the animal roam in a pasture.

Whenever I have a case of this kind under treatment, I furnish apples, beets, carrots, cabbages, or any other kind of vegetable that I can procure, and I find that such articles are usually devoured with a good relish. The object in feeding green food is to combat the scorbutic diatheses which usually exists.

The patient should also be allowed from five to seven quarts of oats per day.

When a horse with enlargement of the lower or upper jaw is suddenly attacked with acute lameness, he should be placed in a wide stall, and the parts where the lameness appears to be located, as well as the jaws, should be diligently rubbed, twice daily, with a portion of the following:

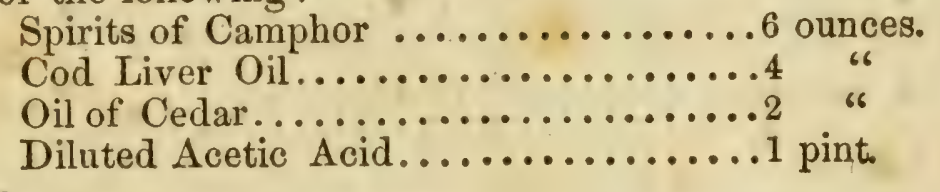

Mix.

Then procure the following:

Chlorate of Potass ............... ounces.

Powdered Ginger ................ "

"6 Gentian ................. "6

" Podophyllum............. "

" Poplar Bark.............6 "6

Mix.

Dose: one ounce night and morning, to be incorporated with the food.

This treatment usually palliates the lameness. Should it not do so, the owner must be patient and give nature time to restore the animal to comparative usefulness.

\section{TETANUS.}

Preliminary. - Two cases of Tetanus having lately occurred in my practice in the city of St. Louis, and both terminating favorably, I have thought that I could not do a better service to the readers of this work than to give them the facts. The treatment was so simple that any one might undertake the same feat, and I think that such treatment is more likely to be successful than the old-fashioned method. So far as my experience goes, I am satisfied that we are apt to do too much (over-medicate) in this, as well as in other diseases; and it often happens that the recuperative powers of nature have to contend, not only with the original malady, but also with one of a medicinal character, created by over-dosing; and perhaps this is the reason that has led some veterinary writers to contend that "tetanic affections, arising in consequence of a punctured wound, are almost always sure to prove fatal."

Nature of Tetanus. - Tetanus must not be confounded with trismus, or locked jaw, yet the former may run into the latter, and 
does really belong to the same class and order. Tetanus is charac. terized, however, by the same rigidity of various muscles of the body, yet at the same time the jaws are not locked, the animal has not lost, entirely, the power of swallowing, can drink and eat a little and take medioine; whereas, in complete locked jaw, the spasm extends to the muscles of tho plaryna, rendering it impossible, while the spasm lasts, for the patient to swallow.

Tetanus is supposed to depend on irritation, directly or indirectly, of the excito-motor system (true spinal cord.) If this be true, and I have $n o$ reason to doubt it, then all surgical operations, in view of removing the cause, are not only useless, but injurious, for the malady has migrated beyond the reach of the surgeon's kuife. I now introduce a brief report of the "cases."

Case 1. March 1, 1862, I was requested to visit a bay gelding, aged eight years, the property of C'aptain Silva. The messenger informed me that the animal was "all stiffened up." On arrival I noticed the following spmptoms: On applying my hand over the region of the neck, the muscles felt hard and rigid; the eyes had a sort of squinting appearance; the nose protruded; the ears were erect and stationary; the nostrils were expanded to their utmost capacity; the head, neck and trunk appeared quite rigid, so that it was impossible to coax or compel the animal to turn "short round," -in other words, describe a circle; the abdomen appeared "tucked up," in consequence of a rigid condition of its walls; the hind limbs were straddling, and the fore ones occupicd a forward position, anterior to the axis of the shoulder-blade; the bowels were constipated; the pulse wiry, and the respirations acelerated and laborious. These symptoms constitute the key-note of the malady. I might, if I felt disposed, entertain the reader with an elaborate article on the regular veterinary craftsman's theory of the progressive symptoms; but the intelligent reader will infer that as the disease progresses, the symptoms multiply and vary, therefore it is not good policy for me to introduce seconidury symptoms, for they only tend to obscure the real nature of the disease.

Trenturest.-I rubbed the neck and back with a portion of the following:

Cod Liver Oil.................... pint.

Oil of Cedar...................... ounces.

Sulphuric Ether................. "

The parts were rubbed once daily for a perior of ten days. During this time the animal got four drachms, night and morning, of the Fluid Extract of Indian IIemp (Cunnabis Incticus.). The horse? was located on the Bellefontain road, ten miles firm the city, consequently I did not see him as often as I wished; but a faithful servant lial charge of the horse, and I think he paid proper attention to my directions.

At the end of three weeks all symptoms of Tetanus had entirely disappeared. The disease was occasioned by a punctured wound in the near fore foot.

June 6, 1862. Capt. S: this day brought my patient to the city for treatment for atrophing of the muscles of the shoulder (commonly knewn as seceney.) The muscles of the shoulder-blade, known as 
the Antea and Postec Spinatus, are completely wasted away, so that the spine of the shoulder-blade and the head of the humerus are unnaturally prominent, on the near side. The animal is still under treatment, and appears to be doing well.

CASE 2. Mr. Wells, residing on Madison strect, in this city, requested me, May 25 , to visit a horse, the subject of Tetanus. I was informed that the animal had accidentally "picked up a nail ;" the nail had been withdrawn, and the part was dressed by a blacksmith. On making an examiliation of the case, the symptoms were about the same as those observed in case No. 1. I treated the patient on the same general principles,-administered Indian Hemp, and lubricated the surface of the body with the same kind of liniment. In the course of fourteen days the aninfal had so far recovered that I left him to the care of the proprietor.

\section{TYPHOID PNEUMONIA.}

The following will illustrate the nature of the disease and mode of treatment:

Recorded Symptoms of the Disease. - On the 4th of March my attention was called to three horses brought here by Mr. C., of and from Indiana. As their symptoms were precisely similar, I shall only describe those of one-a fine stallion aged eight years: he stood with his head pendulous, his fore limbs wide apart, and from the period of his arrival, three days, had not made any attempt to lie down. His respirations were much quickened; expiration, accompanied by a sort of subdued grunt, indicative of pain, and showing that the lining membrane of the cavity of the chest was involved in the disease. The pulse was quick, yet feeble, showing that the animal was somewhat prostrated, and had actually been sick for many days, although the owner thought differently. The visible surfaces of the mouth presented a very peculiar appearance, although not unusual in a disease of this character. They were of a light mahogany color, and the lining membrane of the nostrils was of a light leaden hue. Auscultation and percussion practiced over the thoracic region, revealed tubular respiration; also, that the chest was occupied by a considerable quantity of water; the breath had a bad odor, and the patient had no relish for food, and most of the time he was in a state of stupor. These were the most noticeable symptoms at the period of my first visit. On questioning the owner, he admitted that all three of the horses appeared a little dull, were weak-easily fatigued-and through very little exertion would sweat, and their appetite was not good.

This is the ease with most typhoid affections: they begin without any warning other than slight dullness, weakness, and some disturbance of the digestive organs, and it is only when typhoid pneumonia becomes seated on the lungs, as shown by difficult respiration and other physical signs, that the owner is aware of the horse being really sick.

The stud alluded to, was treated on the stimulating, antiseptic, and alterative plan, during a period of sixteen days, and was rapidly 
convalescing, but the owner grew impatient, and put him on board the boat, when in the course of twenty-four hours he died.

The other two animals did not survive their arrival in this city over twenty-four hours; notwithstanding the most rational treatment they died of a complication of thoracic and abdominal disease. During the progress of the malady, they had a discharge of viscous matter, which adhered in thick incrustations around the margins of the nostrils, and they suffered excruciating torment from sharp abdominal pains, and their dung was liquid and bloody; shortly before death, their tongues acquired a brown color, and their gums and teeth were covered with a dirty slime; parts of the body were bedewed with cold, clammy sweats; the evacuations became very fetid, and all the other symptoms greatly aggravated; soon they staggered and fell, never to rise again.

It is probable that this disease assumed the enzootic type; it was for a short time very fatal, especially when treated on the anti-phlogistic plan; in fact, so far as my knowledge goes, every horse so treated, died.

The only chance of bringing this malady to a favorable termination was to commence the treatment early, and then by the use of sanitive stimulants and tonies sustain the vital powers, and thus keep the patient alive while the disease ran its course.

The agents used in the above case were, ginger, poplar bark, chlorate of potass, and iodide of potass.

\section{DROPSY OF THE BRAIN.}

Operation on a Horse for Dropsy of the Brain.-The subject of the above named disease was a bay gelding, aged seven years. The animal had been out of health for a few days. When my attention was called to him, I found him down on the right side; from appearances I should judge that he had struggled considerably, but his struggles must have been of an unconscious and involuntary character, as the pupil of the eye was amaurotic, and he was completely insensible to the prick of a pin. Occasionally the patient would go into convulsions, kick with his limbs, and dash his head about, not knowing what he did. It was noticed that he often jerked his head backwards, as horses will do when the subjects of dropsy of the brain.

Having satisfied myself that this was a case of dropsy of the brain-hydrocephalus - and there being but very little if any chance of ever saving the subject, I obtained the owner's consent to trepan or trephine my patient, and then draw off the fluid.

The operation was performed as follows: having selected a point at about the centre of the parietal bones, I made a crucial-crossshaped-incision, through the integuments, and dissected them for a small circumference from the bone; I than introduced the trephine a little on one side of the suture, or ridge, and after sawing completely through the bone, removed a piece of the circumference of half a dime. I now sent a curved trocar and canula, between the lobes of the brain, down into the lateral ventricles, and after with- 
drawing the trocar-cutting instrument-about two-thirds of a tumbler full of water-serum-ran through the canula. Shortly after this the wound in the integuments was closed; not completely, however, for small quantities of serum still escaped, and were suffered to do so.

Up to the time of performing this operation-that is, since my first visit-the patient was sightless, and insensible in every part of his body to the prick of a pin, but so soon as the fluid was removed from the interior of the brain, his sight and sensibility returned, and continued for forty-eight hours, when the horse gradually relapsed into a comatose or insensible condition; and now, at the end of five days after the operation on his brain, it was decided that he could not recover, hence the owner ordered him to be killed.

Remarks on the above CASE.-This horse was not a very good subject on which to test the merits of this formidable operation; he had been over-fed, and was rather plethoric; then again, the weather was excessively sultry, and he had very bad quarters, and very little attention. I have, however, some hopes that this operation may ultimately prove successful, when the right subject is selected, and when the patient has proper care and attention; and should it prove successful, some valuable lives might be saved.

If this operation shall prove successful on the horse, why may it not, when performed on man, for hydrocephalus?

\section{SPLENIC APOPLEXY.}

During my residence in Ohio I had occasion to visit a number of animals, the subjects of Splenic Apoplexy. I found that most of them had been over-fed, and were in a state of plethora, hence to prevent the malady, the farmer must dip a lighter hand into the meal bag.

My impression is that apoplexy, wherever it locates, in the bodies of either horses or cattle, is very apt to prove fatal; there may be occasional recoveries, but these are exceptions, and not the rule.

The authorities contend that in all cases of animals stricken with this malady, the premonitory symptoms are of short duration; they may be observed at night to appearance in the enjoyment of full health, on the morrow they may be dead.

Symptoms of Splenic Apoplexy.-When an opportunity is afforded of observing the development of the earliest symptoms, characteristic of this malady, they will be found to be somewhat of the following nature: appetite somewhat impaired; countenance of an anxious appearance; visible mucous surfaces, a mixture of dull red and yellow; pulse somewhat full, and may range as high as seventy; respirations quickened; tenderness along the course of the spine. The patient will occasionally stumble and fall; he grinds his teeth, and an augmented secretion of saliva is seen to dribble from the mouth.

The bowels are usually active, and the excrement is sufficiently soft, yet of a dark color; when too soft, the patient is afflicted with 
colicky pains, gets down in torment, and often goes intoconvulsions, and soon dies.

The urine has a very peculiar appearance: it varies from pink to a dark brown color.

The diagnostic symptom of splenic apoplexy, with enlargement of the same, is a notable enlargement on the left side of the abdomen, well up towards the ribs; on standing right behind the auimal, and casting one's cye carefully along the sides of the abdominal walls, a perceptible eminence will be seen, which cannot be mistaken. The region of the spleen is between the stomach and false ribs, on the left side.

When the spleen is not enlarged, but merely congested, then we resort to percussion in order to detect the same.

The cause of death in splenic apoplexy is an abdominal accumulation and effusion of blood, in the interior of the spleen, with rupture of its constituent texture; and it is safe to infer that the disease is primarily the result of a deranged or diseascd condition of the assimilatory system, occasioned by errors in diet. The curative treatment of splenic apoplexy is very unsatisfactory; but in ease of enlargement of the spleen, we may often succeed in aiding nature to cure the malady, by administering iodide of potass and vegetable tonics.

\section{EMBRYOTOMY.}

The operation of embryotomy, as practiced by veterinarians, signifies dismemberment-disembowelment, \&c., of the fortal coltlocated within the uterus and vagina. I presume that very few persons, unless they understand the anatomy of the parts, would like to undertake this formidable operation; yet it has often been the means of saving the lives of very many valuable breeding mares; hence I propose, in a brief manner, to give the readers of this work some idea of the modus operandi.

The instrument used in the practice of embryotomy, is a crooked beak-pointed knife, which can be so concealed in the hand as not to be capable of doing any injury.

Mode of Operation.-Having introdueed the knife within the uterine cavity, I run my hand along the fotal limb to the top of the shoulder, if possible, and there turn the knife and send its beak point through the integument, and slit the same to the region of the knee; a slip-noose is affixed to the fetlock, and while an assistant is making steady traction on the same, I loosen the integument from the limb, then by a little dexterity in the use of the knife at the top of the shoulder, and elsewhere, the whole leg is drawn away. After amputating the shoulder, I make an incision through the cartilages of the ribs, this exposes the whole of the thoracic viscera, which I remove. If the bulk of the colt appears to be sufficiently remored to insure its extraction, I affix a noose to the remaining fore leg and by traction remove the carcass; the only difficulty in the way of a prompt extraction occurs, ofttimes, in consequence of the fortal head being bent round on the opposite side of the chest; but under ordi- 
nary circumstances the colt can be extracted without proceeding to disembowel it or decapitate it. If, however, either of the latter operations will facilitate the birth, I should certainly perform one or the other, or both.

Having extracted the whole of the fotus, I next remove the placenta and membranes, and then drench the mare with fluid extract of ginger, half an ounce; tincture of matico, one ounce; warm water, one quart; this will improve the condition of the prostrate animal, and insure contraction of the uterus.

The uterine expulsive power, so favorable to the liberation of the colt, if dormant, can readily be aroused by administering a stimulating drench.

\section{VETERINARY MIDWIFERY.}

\section{BREFCH PRESENTATION.}

I was requested, some time ago, to visit a valuable mare, she having been in labor some five or six hours without effecting delivery. On arrival I was informed that every effort had been made to remove the fotus, that six men having a rope attached to the same, had been pulling: "might and main" without success; that finally a pair of mules was harnessed to the legs of the unborn!

In spite of this rough and unwarrantable treatment the mare still survived, and had strong uterine pains. On examination I found that it was a case of breech presentation-hind feet presenting; the long diameter of the fœetal pelvis opposed to the short diameter of that of the mother. I merely pushed the fœtus backward and changed the position of the same, brought the long diameter of the pelvis of therone, in apposition with that of the other; and in the course of five minutes, with the assistance of one man, delivered the mare of a dead colt.

Remares.-Such cases, I am informed, are constantly occurring, and very often the life of a valuable mare is thus sacrificed at the shrine of ignorance; this is not a matter that would warrant any member of our profession in scolding about; it is a subject which demands our serious attention, and all our efforts as philanthropists and christian men, should be exercised for the purpose of putting a stop to she perpetration of similar barbarities. The only remedy, as I understand the subject, is the establishment of Veterinary Colleges and Schools throughout the length and breadth of these United States; and I entreat the readers of this work, to use their means and influence for the purpose of educating men for the responsible duties of veterinary surgeons.

It may be gratifying to our readers to know how the above case terminated, hence I append the following extract from my "case book."

After delivery, the mare appeared perfectly prostrated; pulse, at the angle of the jaw, almost indistinct; extremities cold; tips of the ears and lips icy cold; visible surfaces pale; respiration laborious, and the prognosis was unfarorable. 
Treaturent.-Administered diffusible stimulants, and drenched the patient with two quarts of hot gruel seasoned with stimulating condiments; in the course of two hours after delivery, the mare got up and commenced grazing apparently with good relish; she gradually improved and finally recovered.

\section{CANKER IN THE FEET OF HORSES.}

Canker is a disease of the tissues of the foot, affecting the sensitive parts of the frog and sensitive sole, and consists in a production of a morbid growth known as fungus.

In former years it was very prevalent in the large livery stables of the city of London; there it was supposed to rage as an epizootic affection, and often appeared in a very malignant form. At later periods, in consequence of an improved system of stable management, and the presence of educated veterinary surgeons, the disease is less prevalent, and is robbed of its greatest terrors.

It is probable that this disease, like many others, "lurks in breed," for it has been observed that a great proportion of the subjects afflicted with this malady are of coarse breed or organization, having much coarse hair on their limbs, and the same animals have large and flat feet. Canker usually attacks the hind fcet; these parts being most remote from the central organs of circulation, are very apt to become the seat of this affection whenever circumstances are favorable to its production. The circumstances favorable for the production of canker are predisposition.

Taking a common sense view of this affection, it appears to resemble that very formidable disease known, in human medicine, as cancer, for if allowed to progress, the disease acquires a deep seated origin, and spreads from frog to sole, and around the toe and quarters, and like cancer it often flourishes with a peculfar luxuriance; yet, after all, common canker, as it occurs in horses, is not identical with human cancer, for, on microscopical examination we fail to find the true scirrhus, or cancerous change of the morbid tissues.

The treatment of canker is as follows: Bathe the parts freely with pyroligneous acid, and then cover the cankerous surfaces with powdered blood-root. The dressing must be renewed often, and the parts should be completely covered with the blood-root as often as it is removed by abrasion or otherwise.

The constitutional treatment is as follows: Give the horse, daily, twenty grains of iodide of potass, and forty grains of powdered blood-root, either in the form of drench, or otherwise. Should the animal not recover under this form of treatment, the case may be considered as incurable.

\section{UMBILICAL HERNIA.}

Umbilical Hernia, commonly known as rupture, often occurs in colts, and in fact is often congenital-exists at birth. The sac, or pendulous bag, is located in the region known as the "navel," or 
umbilical region; the sac sometimes acquires magnitude so as to present an "eye sore," or unsightly appearance, which very frequently impairs the value and usefulness of the animal.

In furmer days a very barbarous operation was occasionally performed for the removal of the enlargement, which was performed in the following manner: the animal, after being east, was placed on his back; in this position the bowel generally receded into the abdominal cavity, then three or four skewers were inserted through the walls of the loose skin, and then ligatures were applied. This interrupted the circulation of blood through the parts, and the superfluous skin sloughed off, at the same time the internal parts of the sac united, and in this way the "eye sore" was sometimes got rid of; but unfortunately death often ensued, either as the result of peritonitis, or of locked jaw.

The safest mode of treatment now adopted, is that of continuous pressure:

"It consists of a common girth, properly shaped to the body, having a siff piece of oval-shaped leather introduced inferiorly, to come in contact with the rupture. This should be buckled on moderately tight, and retained in its situation as follows: place a common collar on the animal's neck, to which three straps are attached, one on each side and the other at the brisket. Two pieces of webbing should be attached to the main girth with buckles at the opposite end, to meet the side straps, and a piece of leather, instead of webbing, to meet the brisket one. This latter should be forked or split, part of the way, so as to admit of its being attached to the oval pice of leather covering the rupture. These are then to be buckled to the straps coming firom the collar, by which means the girth is held in its proper position. Over the whole a common surcingle may be placed, just behind the elbows, (the usual girthing place, in order to keep the whole snug and close to the body.

"The animal, thus harnessed, should be turned into a loose box and fed well, the object being to force the system as much as possible. The best time for applying the truss is when the animal is taken from the mare. In a general way, about three months' wear of the truss will be found sufficient to effect a cure. The modus operandi appears to be this: pressure keeps the bowels within the abdomen, thereby giving the aperture an opportunity of closing, which in many cases it will do most completely. But even should it not, you may depend upon its not getting larger. The bowel, from the general development going on in the system, hastened by the good keep, will soon do so, i. e., get larger, and consequently will not dip into the same opening, even should it remain. Partial or complete adhesion of the sides of the sac will take place, followed by an entire removal of the unsightly pendulous bag, with its contents, which constituted the disease."

\section{LYMPHATITIS.}

Premiminary.-Lymphatitis is a disease known to occur among horses of the lymphatic temperament, affecting the superficial lymphatics of the hind extremities; causing swelling, heat and tender- 
ness of the parts. The disease is known to occur among horses of "coarse breed," and the more advanced in age such an animal may be, the more subject is he to this affection; provided, however, he be of the lymphatic or lazy temperament.

Varions names have been applied to this affection; for example, in Scotland it is known as weed, thick-leg, water-farcy, shot-o' grease, \&e., \&c.,-names which throw not the least light on the nature of the affection.

Cause of the Malady.-The indirect cause is predisposition, which lurks in breed; the ordinary cxciting cause or causes are, errors in diet, over-work and mismanagement when at work (which signifies exposure to storms, \&c., and ill usage,) hard pulls and poor fodder.

Case of Lympintitis.-On visiting the patient, I was informed that the disease commenced with a paroxysm-or fit-of shivering, very suddenly. I found the animal standing on three legs; the near hind one-the seat of disease-was flexed and held about twelve inches from the floor. The affected limb was hot, tender and swollen, and the glands, or lymphaties of the groin, were "corded," or enlarged. On the inner surface of the thigh a number of corded lymphatics, or minute elevations, under the true skin, could be distinctly felt, and on exploring and gently squeezing the same, the patient would suddenly eatch up the limb from sheer pain. The pulse was very wiry, and so quick that it was impossible to count the beats.

This case was treated by means of diuretics and tonics, administered internally, and the swollen limb was bathed as often with an infusion of plantago major-common plantain. In the course of six days the animal had entirely recovered.

\section{RINGBONE - ITS NATURE, CAUSE AND TREATMENT.}

Nature of Ringbone.-The term ringbone, signifies a bony enlargement, in the region of the coronet. The ring is formed of osseous incrustations or deposits on the pastern, and sometimes the lateral cartilages are changed into bone; at other times the disease commenees on the articulatory surfaces; in such case the horse may commence to go lame some time before any enlargement makes its appearance; the disease is then termed inter-articular; soon, however, the disease spreads, and the usual change in the form of the parts is very perceptible, and the action of one or more joints beneath the cannon bone is forever destroyed. This condition is known to medical men as anchylisos, (loss of motion,) while that form of ringbone, occurring on the surface of the bones, is called exostosis, (extra growth.) Various osseons enlargements or deposits are found on the coronet and pastern bones, varying in shape, size, \&c., and some persons have denominated them "cling-fasts ;" and there is no doubt but they do "cling fast."

As regards the spreading of the disease and its magnitucle, that depends on the idiosyncracies of the animal; it has been noticed that 
animals of the "rickety" or "rachetic" diathesis are more prone to an aggravated form of the malady than others not so constituted; and in the former case the bones of the whole body are found to be deficient in animal matter, and rich in earthy matter, and nther bones of the body are found to be incrusted with earthy deposits, so that, in some cases, the affection may be of a constitutional character.

Cause of Ringbone.-Ringbone often owes its origin to hereditary influences, transmitted, either directly or inclirectly; it is not often, however, that the malady appears as the direct result of sexual intercourse between animals, one or both of which may be affected; yet there are cases on record going to show, that the disease has often been observed to occur in colts that have not even been trained, nor submitted to the ordinary exciting eauses which are operative in inaugurating the disease in the preciisposed subject. During my professional career, in this country, many cases of Ringbone, occurring during colthood, have attracted my attention; hence I infer that the malady can be directly transmitted.

Mir. Percival relates that his attention to the hereditary origin or ringbone was first aroused from a remark made by an extensive dealer in horses, in reply to a question put to him, how it happened that but few ringbones were met with, compared to the number that attracted notice in times past. The reply was: "Because no breeder of horses now-a-days, will send a mare to a horse having ringbone." A very good example for American breeders to follow, for the malady is very prevalent in this country.

IIorses predisposed to ringbone are bony-legged animals, with short and upright pasterns. The direct cause of ringbone in such animals is ligamentary sprains, induced by over-work, \&c.

Treatment of Rungbone. - The whole theory of the treatment may be contained in a nutshell. Keep the animal at rest and apply counter irritants of iodine or canthapides. Shonld, however, the lameness be very considerable and the animal appear to suffer much pain, then I should rub the affected parts with equal parts of spirits of camphor and sulphuric ether. After the treatment has ceased, the owner of the animal must exercise patience, for it will require some time for nature to perfect the cure.

\section{TREATMENT OF GALLED BACK.}

As soon as an abrasion is discorered on the back of a horse, the animal should be excusecl from duty for a few days; the abraded parts should be dressed twice daily with a portion of tincture of aloes and myrrh. This simple treatment will soon heal the parts.

Should there be no abrasion, but a simple swelling, attended with heat, pain and tenderness, the parts should be fiequently sponged with cold water. Occasionally the skin undergoes the process of nardening, (induration.) This is a condition of the parts known to the farricrs of old as " siffast," and the treatment is as follows: procure one ounce of iolline ointment, and smear the indurated spot with a portion of the same, twice daily. 
Some cases of galled back, and shoulders, are due to negligence and abuse, yet many animals, owing to a peculiarity of constitution,

"will "chafe," as the saying is, in those parts which come in contact with the collar and saddle, and neither human foresight nor mechanical means can prevent the same.

\section{OVER-DISTENSION OF THE STOMACH.}

Oct. 19th, 1862. This evening a bay gelding aged 7 years, the property of Mr. Burgess, of North Chicago, was brought to Mrr. Patrick's stable under the following circumstances:

I was informed by the owner that the animal had in the early part of the morning broken loose from his stall, and immediately commenced a desperate attack on a bag of oats, which happened to be within reach; the horse is known as a ravenous feeder, and the probability is, that he did not spare the oats, but took a pretty large dose, so as to over-distend his stomach. The services of the animal being required a few hours afterwards, he was hitched up; he soon, however, showed symptoms of distress, attempted to lay down, and and finally got into a profuse perspiration. Shortly after this, my attention was called to him.

I found the patient in great distress; his head pendulous; breathing much embarrassed; pulse very rapid; body bedewed with a chilly perspiration; legs and ears cold; continual eructations of gas by the mouth, from the stomach; and at the same time efforts to vomit, which brought away nothing more than salival secretion, which, however, was quite profuse; the patient rolled and tumbled about considerably, and would occasionally stand up for a few seconds at a time.

Treatment.-It appeared that the indications, in view of relief, were to arouse the action of the stomach, and at the same time arrest fermentation. I was under the impression that the contents of the gorged stomach could only be got rid of in the ordinary way, viz., by digestion. I am aware that it is often customary to give drastic cathartics in view of getting rid of the contents of the stomach, yet I would not advise the reader to do this, for the horse may die before the medicine operates.

The following drench was administered:

Fluid Extract of Ginger........... ounce.

" " "Golden Seal............ "

Carbonate of Soda............... 2 drachms.

Water...................... 4 ounces.

After the exhibition of the above, I threw into the rectum a couple of quarts of soap-suds, to which was added a handful of salt; in the course of about an hour the animal appeared somewhat relieved, and I repeated the dose, also the cnema. The patient very soon afterwards passed a large quantity of excrement, and so rapidly improved that I left him, and did not see him again until the next morning, when he appeared to bave entirely recovered. With the 
exception of a bran mash or two, the above comprises the whole of the treatment.

Remarks. - It was lucky for the horge as well as the parties concerned, that the animal did not get corn instead of oats; for the same quantity of corn would have surely caused death; from the fact that when this article of fodder is submitted, within the stomach, to the action of heat and moisture, it increases in bulk in a ratio of about five to one, and the usual result is rupture of the stomach; still should any of our readers be called upon to treat a case of the latter kind, there is no other plan of treatment, with which I am acquainted, that will be likely to succeed in saving the animal than the one above indicated.

A cow is sometimes "gorged," and her paunch is, in consequence, distended to an enormous capacity, and very frequently an operation has to be performed in order to remove the contents of the same; yet such an operation as the one usually performed, is attended with much danger, and rather than run the risk of losing the animal, I should first try to arouse the action of the stomach, as in the case of a horse.

\section{SWEENEY, OR WASTING OF MUSCLES.}

Preliminary. - This affection is one which prevails very extensively among Western horses, and indeed has occasionally been present in all parts of the United States, yet very little of a reliable character has ever been written on the subject; hence, as a professed teacher of veterinary science, and not being willing to carry my knowledge to the grave, it becomes my pleasant duty to give the readers of this work the benefit of my experience, and in so doing I shall endearor to be brief, practical, and also to deal in facts.

Sweeney is a term used by husbandmen, signifying wasting of the muscles in the region of the shoulder-blade; professional men recognize the affection as Atrophy-wasting; a gradual or sudden diminution in the size of muscles of a region, or of the whole body. When the affection is confined to the shoulder, it is called local atrophy; and when there occurs a morbid and progressive diminution in the bulk of the muscles of the whole body, the disease is known as general atrophy, or Marasmus.

Medical writers generally contend that sweeney or atrophy is occasioned by faulty or defective nutrition, and is usually sympathetic. Ancient authorities say, that in atrophy, the fat only is wasted. This is a great mistake: for a collapsion of the cellular, muscular and vascular systems, in a case of atrophy, is evidently apparent.

Pathology of Sweeney.-I now propose to discuss the theory of the pathology of Sweeney.

I have had several opportunities of examining horses that have died in consequence of disease or old age, who, during life, were the subjects of sweency, and I always found the muscles of the slioulder, or shoulders, pale looking or bloodless; almost resembling the muscles of a calf that had been bled to death: the ordinary color should be a reddish-brown tint. The collapsion was not only con- 
fined to the muscular fibres, but affected the blood-ressels, which appeared to be constricted; and the cellular membrane had almost entirely disappeared, merely by condensation and contraction of the skin over the region of the parts; which contraction usually ocours in consequence of shrinking of muscles beneath.

In conformity with the opinions of our veterinary anthorities, I have hitherto in most cases considered sweeney as a symptomatic affection, from the fact that I have had to treat a number of cases similar to the following:

A celebrated and valuable trotting horse, known as "Rocky" owned by a party in Cincinnati, became lame. The animal was treated for shrinking of the muscles of the shonlder blades, by setons, lotions, \&e., and a long run at grass. The treatment extended over one year. The animal was finally purchased by Alessrs. Mathews and McGibboney of Chicago. On arrival of the animal I examined him and found that the sweeney was occasioned by contraction of the hoofs. I recommended a different course of treatment. The feet received special attention; and now the owners inform me that they have been offerel a large sum for him.

In May, 1861, I was requested to see a gray gelding, aged eight years, which had recently been purchased as sound, \&c. Shortly after purchase it was discovered that the animal went lame. It was noticed that the muscles known as anterior and posterior spinati (in the region of the shoulder blate), were wasted, and it was evident that the animal had been treated for swoeney from the fact that the marks remained where setons had been introduced.

On making an examination of the foot, on the affecterl side, I found enlarement of the lateral cartilages of the coffin bone; the lateral cartilages had undergone transformation, and had changed into bone. In the region of the foot, then, was the srat of lameness, and the poor brute had been tortured in the usual manner about the shoulder for the expectint cure of that which only constituted a symptom of organic disease of the coffin bone.

The altered structure and enlargement in the vicinity of the foot had been entirely overlooked, and it is probable, as my employer had only heen in possession of the horse a short time, that the creatture must have been unsomul at the time of purchase.

The wasting of the muscles of the shoulders, is to be aceounted for in these two cases as follows:

It is a well known fact, that inaction of a muscle induces a decrease in its size. The muscles of laboring men decrease in size whenever, from choice or necessity, tho individual leads a sedentary life. A limb kept at rest for any great length of time, always undergoes more or less atroply (wasting.) In these cases the foot discases were of such a charareter as to camse the suljects much pain in progression; in noler to reliere the fect they spared their muscles, which want of fiee and full action led to diminished nutrition and wasting-atroplyy. Some of our realers must have noticel the fact of the shrinkage of the muckes of the hamnch in case of disease or severe lameness of one of the hind fect. 'This shrinkage often oceurs, as in the ease of the shoulder, fiom want of natural action and full play of the muscles concerned. We have ample proof that the wasting is the result of want of artion, in the fact, that 
when the horse becomes the subjoct of a painful disease in the hind foot, he neither advances nor rotates the limb any more than he can possibly help - but holds the foot up. On examination, the atrophy or wasting is confined to the muscles which perform these two actions; and in case of lameness or pain in one of the fore-feet, the same faulty action is observable, and the same class of muscles (whose action is almost identical with that of the hind parts) are the ones affected.

I deem it of great importance that husbandmen should fully understand this subject, for it will enable them to perceive that-while inflating horses' shoulders with a quill, or practicing any other absurd treatment in the vicinity of the wasted or sweenied shoulderthey are overlooking the real malady (in the foot), and at best are only treating symptoms. On careful examination, however, should it appear that the patient is free from any disorder of the foot or feet, and on the other hand it is clearly evident that myositis, or myalgia, of the muscles exist, then the treatment must be directed to the affected parts-the facts in either case can only be determined by a competent practitioner.

In view of sustaining the proposition that Sroceney is a symptomatic affection, I might introduce a great number of cases that have come under my own observation; but I do not wish to bore the reader, nor inflict a long article on him; therefore I submit the preceding cases as a sample of all the rest which I might offer. The malady may be of a different grade or character, but the primary disease, of which sweeney is the result, originates often in foot lameness.

I now propose to show that sweeney is not always a symptomatic affection.

I have often noticed that when horses have been over-driven, or over-worked, they become stiff and lame in those parts of the body most susceptible to the ordinary influences; for example, one horse may perform a long journey with a weighty man on his back, and the next day the animal shows symptoms of lameness in the lumbar region; his back is arched; the limbs are brought under the centre of the body, and every movement indicates that the animal suffers tormenting pains which are located in the muscles of the back; this is myositis, or inflammation of muscular fibre; sometimes, however, the malady constitutes myalgia-muscular pain and spasm unaccompanied by inflammatory action.

Another horse may be put to a similar kind of work, and in a few hours afterwards he is found very stiff and lame; but the symptoms are not the same as those just recorded; the pathology is probably identical; it is the same disease, only it has a different locality-it is myositis of the pectoral muscles, involving also the muscles of the shoulder blades. And the intelligent owner of the afflicted animal will notice that his fore extremities are unnaturally advanced; the foreparts of the body are unnaturally hot and tender; the fore-feet are feverish, and the hoofs are hotter than usual; the advanced position of the fore extremities and shoulders, gives a very marked hollowness to the forepart of the chest, and many men, on seeing such a case, would declare that the animal was chest foundered, this being the name which is sometimes given to such a condition; butreally it is owing to myalgia-muscular pain and stiffness. 
It is well known that all muscles are subject to inflammatory action and muscular pain from work disproportionate to their strength; for example, let any man undertake to saw wood, practice with heavy dumb-bells, or ride on a horse-feats that he has never been accustomed to-and whether the labor be excessive or not, the individual will shortly complain of more or less muscular pain, and if he be a weak man, the more excessive will be that pain. Now the muscles of the horse being just as susceptible to pain as those of the man, are just as easily operated on through the well known exciting causes.

In the case of a horse, when the work has been very excessive and of a character to bring the muscles of the shoulders, their tendons and coverings, into a state of over-exertion, it will often be found that some of the muscular fibres in the region of the shoulder, are fractured, small blood-vessels are ruptured, and other pathological changes take place; this is followed by inflammation-myositis. Suppose, therefore, a horse shows symptoms of myositis after excessive work, and in the course of a few days it is noticed that the muscles of his shoulders are wasting away, and they continue to waste, so that all persons who examine the animal pronounce him sweeniedwe may then infer that the wasting (sweeney) is not symptomatic, but is the result of myositis, the principal treatment for which is, rest; afterwards diminish the work, and by proper diet and tonics, increase the power to do it.

\section{LARYNGITIS.}

Laryngitis signifies inflammation of the lining membrane of the larynx; it is sometimes known as sore throat. Like other inflainmatory affections of the respiratory apparatus, it is accompanied by feverish symptoms-heat, pain, and difficult respiration.

The inflammatory condition exists during a limited period, varying from two to five days; then, generally, commenees the suppurativo stage, which is characterized by a discharge from both nostrils.

CaUse of Laryngitis.-As regards the special cause of this affection very little is known; it is supposed, however, to originate in a common cold, \&c., yet I have known horses to become the subjects of it that have not been exposed to the ordinary influences which are said to produce the symptoms of cold; hence we may infer that bad management, and the evils of domestication have something to do with it.

The fact is, disease neither respects man nor horse; each must once in a while suffer and groan, swallow drugs, get well, or else "kick the bucket ;" and as regards the horse, the greater his value, the more likely is he to get siek, from the fact that he is sure to be petted, over-fed, and generally he is too well cared for.

Srmptons. - The most observable symptoms are, protrusion of the head; a sort of half suppressed cough; slight swelling in the region of the throat; difficulty in swallowing; and if the ear be applied to this region, a grating sound is heard. 
Treatment.-The animal should be fed on sloppy bran mashes three times daily, to which add one drachm of powdered nitre, and twice daily lubricate the region of the throat with some stimulating liniment. Let the patient breathe a pure atmosphere, and he will soon get well.

\section{PLEURISY.}

This is one of the most painful among equine affections.

Persons who have suffered the pains attending acute pleurisy, describe them as lancinating; this accounts for the deplorable condition of a horse when suddenly attacked with this terrible aftliction.

Sxмrpoms.-The excruciating torment attending the early developments of the malady, causes the animal to get down and tumble about, as if he were the subject of colic; but soon it will be observed that the case is not one of colic, for as soon as the most painful features of the malady have subsided, the animal does not recline on the floor, but stands, with his fore legs wide apart, in view of preventing friction between the lungs and the interior lining membrane of the cavity of the chest; the pain is continuous, which is proof positive that the animal is not the subject of colic.

If pressure be made with the finger on the spaces between the ribs and the chest, it elicits symptoms of great pain; and should the ear be placed against the walls of the chest, a grating sound will be heard, and the respiratory murmur is not natural. This malady is apt to terminate in dropsy of the chest. In all cases of acute pleurisy the pulse is strong and wiry.

Treatment.-Supposing the disease to be in its early stage, as shown by such symptoms as above, give the patient twenty-five drops of tincture of aconite, mixed in about two ounces of water, and ten drops more every hour, until the pulse becomes softer; then omit the aconite, and give one drachm of powdered nitre, twenty-five drops of powdered blood-root, in four ounces of water; drench the animal very carefully, so as not to put him to unnecessary pain. It is possible that the animal may take this medicine if placed in a bucket containing a few quarts of water. This latter medicine may be repeated every four hours, until four doses have been taken; in the meantime, a thin paste of mustard and vinegar should be carefully rubbed on the sides of the chest and under the breast; the paste must be quite thin, or it cannot be absorbed, hence will be useless. Should the weather be chilly, clothe the lower part of the limbs with flannel.

The intelligent owner will attend to the wants of the animal, and see that he is located in a part of the stable where he will be free from annoyance.

It will be easy to ascertain whether or no the case is curable; for if, during the treatment, the patient continues to grow worse, hydrothorax, or dropsy of the chest, is sure to set in; this latter disease requires the services of a veterinary surgeon. 


\section{DISEASE OF THE SKIN - MANGE - LOUSINESS - REMEDY FOR THE SAME.}

A great many of the horses lately disposed of by the Government, as "condemned," "contraband," \&c., were, and still are, subjects of various forms of skin disease-mange, lousiness, \&c., and it is probable that when such animals are introduced into decent "horse society," they will be the means of spreading the itch, mange, lousiness, $\mathbb{E}$. ; hence, I propose to give the readers of this work some advice on the subject.

In the first place, almost all the skin diseases prevalent among army horses owe their origin to neglect and filth. Hence cleanliness -brush and curry-comb-are the best means of prevention, and are also valuable as curative agents.

The best local application for diseases of the above character, is as follows:

Mix.*

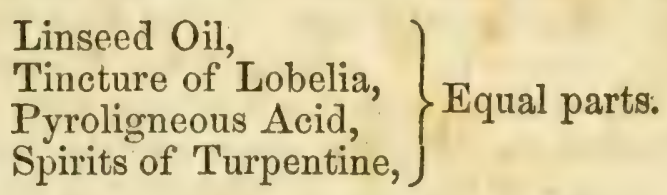

Apply, by means of a sponge, a portion of the above mixture to all parts of the body; and the patient should have an occasional dose of sulphur in a "bran mash :" four drachms of sulphur constitute a dose.

The next best advice I have to offer is, Government horses laboring under any of the notorious prevalent affections, are very dear at any price; hence, touch not, purchase not; for good money and bad horses soon part company; and as the old saying is, "that is the way the money goes."

A great many of the horses lately disposed of by the Government are the subjects of a skin disease known to medical men as mange; it makes its appearance as a pustular eruption, commencing about the regions of the roots of the hair of the mane and tail; where, soon, a scurfy state of the skin appears. The disease soon extends; and makes itself visible by spots denuded of hair; these spots are the seat of a coating of mealy powder, which can be rubbed off. Throughout the whole course of the disease the animal is tormented with an incessant itching sensation, and is continually rubbing and biting himself. It should be generally understood that this malady is highly contagious, and, therefore, can readily be communicated from one horse to another; hence, the affected animal should not be allowed to come in contact with others not so affected.

Mange, or itch, sometimes assumes a highly inflammatory type; this depends somewhat on the vascularity of the surface of the body, and the specific irritability of the skin which is peculiar to some animals of the sanguine and nervous temperaments.

In some stages of this skin affertion, a close examination will detect, under the scarf-skin, little watery eminences, known as vesicles; and at the base of the same can be seen little red patches; this 
is the seat of the parasite, and his burrowing course can be distinctly traced from one vesicle to another.

The parasites, which are said to be the sum and substance of the disease, are termed "Acari," and their " manibles,"-or mouth-are a sort of pincers, pointed and sharp, which enables them to puncture the common integument, or skin of animals, and at the same time to imbibe the animal juices, on which they thrive and propagate.

The remedy, or local application, previously recommended, often fails in curing "Itch, or Mange," simply because it is not rubbed on the surface with sufficient force to penetrate the scarf-skin; hence, it has but little, if any, effect on the concealed parasite. In order to obviate this dificulty, all excrementitious matter must be removed from the skin by means of a good stiff brush, which brush must never be used on any other animal.

The modern method of applying the local application is to rub it into the skin by means of a thick pair of leather gloves, and some "elbow grease." The rubbing should be repeated daily until the disease is conquered. Supposing the disease to be "stubborn" and protracted, the external application must be rubbed into the skin by means of a stiff brush, and the animal should be daily dosed with the following:

Sublimated Sulphur............ 1 drachm.

Iodide of Potass .............20 grains.

Powdered Poplar Bark.......... 1 drachm.

To be incorporated with the food.

\section{PITYRIASIS IN ARMY HORSES.}

I was present at a sale of army and contraband horses lately held in St. Louis, and I noticed that many of them were the subjects of a skin disease known to the members of our profession as "Pityriasis," which disease chiefly affected the face, neck, sides of the chest, and flank.

The disease presented circumscribed patches, more or less denuded of hair; the epidermis, or external covering of the skin, detached itself from the sub-tissue in white flakes, yet there appeared to be no itching sensation nor impairment of the general health, consequently I am led to infer that the disease is not contagious. By friction with linseed oil and lime water, equal parts, a cure is easily effected.

\section{BOTS IN HORSES.}

Bots occur chiefly among horses that have been recently at grass. They are generated from the larva of the oestrus equi; the larvæ are deposited on the legs and shoulders, or parts that the horse is apt to lick with his tongue; they then pass into the stomach and become attached to the cuticular portion of the same. In the succeeding summer they are discharged from the anus, and passing through the 
chrysalis stage, they appear as a gad-fly, and are then again ready to propagate their species.

1 must confess that in former years I advocated the theory, as taught at the schools and through the panges of our text books, that bots were innoxious, and seldom, if ever, did any harm to horses. In fact one of our most distinguished writers on veterinary science, (the late Mr. Pereival), suggested that "bots might serve some useful purpose by exciting the function of the stomach, they then arouse the sluggishness of this organ, by which means digestion is promoted."

Mr. Percival also promulgated the following theory: "You may boldly assert that bots are in nowise injurious; still you cannot persuade the world so, and, therefore, you must be prepared to meet the complaints of those unbelievers, who will now and then declare that their horses have bots-which must be got rid of. But I know of no medicine that has the power of destroying them; and even if we possessed such, I am not sure that we could, even when dead, detach them from the cuticular coat of the stomach to which they are attached with small horns."

Hence, in accordance with the dictum of the schools, and popular medical teachings, I formerly was a medical convert to their false theories, and dare not use my own experience and intelligence against that of the recognized authorities. But "facts are stubborn things." At the present period, having emancipated myself from the theory of the schools on the subject under consideration, I em. phatically declare that the presence of bots in a horse's stomach is conclusive evidence of an exciting cause of disease, peculiar to the digestive organs; they (the bots) are, in fact, a foreign body located in the interior of the stomach, one of the most sensitive organs of the animal economy; they must necessarily pervert the function of that organ.

There is no doubt that a large number of bots congregated within the stomach near the termination of the esophagns must interfere with the passage of food into that organ, as the following case will illustrate: I was requested sometime ago to see a horse, the subject of a climatic affection, which manifested itself in a discharge fiom both nostrils, accompanicd by some soreness of throat. The animal had been treated by its owne: and appeared to be doing well, up to the time when my services were songht. I found the patient bedewed with a cold, clammy sweat, small, thread-like pulse, and hurried respirations; his head was extended and the mouth open; he appeared to be choking, and made efforts to vomit. I explored the esophagus, and found at the lower part a very perceptible tumefaction, as if it were impacted with food. I had about determined to cut down upon the esophagus and make an attempt to remove whatever might be the canse of the obstruction, but suddenly the animal fell down, went into convulsions, and in the course of a few minutes died.

The antopsy revealed the presence of a large cluster of bots, numbering two hundred and seventy-five, located within and around the lower part of the gullet, and just within the entrance of the stomach; and so completely had they obstructed the passage, that it was impossible for the food to pass. I found the gullet completely packed 
with masticated hay, and about three inches above the stomach was a rent in the gullet of about three inches in length; this accounted for the sudden death of the horse. There were no signs of any disease about the animal except the catarrhal affection; hence, the bots may be considered as the exciting cause of the death of this animal.

In the face of evidence of this character, and on the strength of past experience, together with what Mr. Gamgee has written on the subject, I do belicve that bots are often injurious to horses, and I feel it a duty $I$ owe to those who bave perused my former writings on the subject, to own up and acknowledge my error. In the case alluded to $I$ found a very large number of perforations on the cuticular coat of the stomach, which the bots had previously made and occupied; so it would appear that these creatures had suldenly left their camping ground, and congregated together like a swarm of bees to cause the death of the horse.

I am not acquainted with any remedy that would be likely to expel the bots from the stomach; a run at grass will probably have the desired effect; yet if the reader wishes to try the effect of medicine, I should recommend the use of the following:

\section{Powdered Poplar Bark, ) \\ $\left.\begin{array}{l}\text { Sublimated Sulphur, } \\ \text { Powdered Rock Salt, }\end{array}\right\}$ Equal parts.}

Mix a tablespoonful in the food twice or thrice weekly, and feed a few carrots occasionally.

\section{DERANGEMENT OF THE STOMACH, OR INDIGESTION.}

Horses the subjects of indigestion, usually have a capricious appetite; they will often devour their bedding rather than partake of the food which is placed before them; they occasionally eructate gas both from the mouth and anus, are usually afflicted with worms, have a foetid breath, are subject to colic, and are very apt to become crib-biters.

Treatment.-Give the animal a few doses of the following:

Powdered Gentian...............2 ounces. " Poplar Bark..............4 "

Carbonate of Soda................. "

Chlorate of Potass.................. "6

Linseed Meal....................

Mix; divide into nine parts; administer one as a ärench, or mix it with the food.

The American Magnetic Powders can be used in lieu of the above, and are equally well adapted for cattle and sheep.

\section{ACU'TE RHEUMATISM.}

The faithful servant of man-the horse-does not enjoy immunity from the above distressing disease. The same causes which operate 
on the system of man to develop an inflammatory disease of this character, are, with unerring certainty, operative on the inferior animal.

In plain language, rheumatism is rhermatism, in whatever system you find it; it is always characterized by pain in "joints" and muscles; action of the same generally augments pain, although our patient, the horse, cannot always succeed in convineing his owner of the fact. It occurs among men and horses at all seasons of the year; yet, at the period of sudden transitions from heat to cold, it is most prevalent. Animals that are heated by exercise and then suffered to "cool off" without ordinary care, are very apt to become the subjects of this malady; so that prevention, to a certain extent, is within the province of all rational beings, and in the exercise of preventive measures, we may, in common parlance, "stave off," for a time, an acute disease, although it be hereditary. Rheunatism, like gout, is hereditary; no educated physician ever opposes this proposition; it develops itself in the predisposed. The indirect causes are, obstructed perspiration. Keep the animal comfortably warm and avoid undue exposure, and then we have a remedy against the development of hereditary rheumatism.

Mr. Finlay Dun thus discourses on rheumatism : "Pheumatism is neither so common, nor are its symptoms so well marked in horses, as in cattle. When, however, it does occur in the horse, it man1fests the same well-known appearances which characterize it in a!! animals. It affects the fibrous tissues of joints, the coverings of muscles, tendons, valves about the heart, and larger vessels, and manifests a peculiar tendency to shift from one part of the body to another, often affecting, in succession, all the larger joints; at one time, chiefly in the neck, at another, in the back and loins, while in many of its more acute attacks, it appears to involve almost every portion of fibrous and fibro-serous tissues throughout the body. In all its various types it exhibits a full, strong, hard, and unyielding pulse, caused by the inflammation involving the serous and fibroserous tissues of the heart and circulating vessels. During its existence various excrementitious matters accumulate in the blood, and the fibrinous constituents of the same exceed their normal proportions, as indicated by the production of the bufiy coat on the blood. In severe or badly treated eases, the inflammation is very apt to be transformed from the joints and muscles, to the heart and its investing membranes, and it is the danger of this change in the seat of the disease that renders rheumatism so formidable, and often so fatal. It always leaves the parts affected so altereal as to be extremely predisposed to subsequent attacks, and it is more than probable that this altered condition is reproduced in the progeny of rheumatic subjects, and constitutes in them the inherent tendency to the disease.

"Horses sometimes suffer from rheumutic inflammation in the fibrous sheathing envelops of the muscles of the neck, constituting what is popularly known as the chords. When thus affected, the animal is rery stiff, remains as much as possible in one position, and is unwilling to bend his neck either one way or the other, or to elevate or depress his lead. There is always more or less ferer, with a strong, full pulse. Sometimes, as in lumbago, in the human sub- 
ject, it affects the mascles of the back and loins, causing stiffress, tenderness, and pain, which are especially evinced on moving or turning the animal. These rheumatic affections are very readily produced in predisposed subjects by exposure to rain and cold, especially when accompanied by overheating or exhaustion.

"Rheumatism sometimes occurs in horses as a prominent symptom of that epizootic affection which usually receives the much-abused. title of influenza. In such cases the rheumatism is of a somewhat more sub-acute or chronic character than common, and is accompanied by that low, debilitating fever so often the concomitant of epizootic maladies. It usually affects all parts of the body susceptible of the rheumatic inflammation, is attended particularly by those symptoms which indicate disease of the heart and pericardium, as an intermittent pulse, \&c., and often terminates fatally by effusions into the pleura or pericardium, thus causing death by arresting the motions of the heart."

The reader has now before him some of the most important features of acute rheumatism, and I shall now allude to the treatment.

The remedies used by different practitioners are: Colchicnm, calomel, opium, Dovers powder, tartar emetic, cimicfuga racemosa, hellebore, aconite, iodine, nitrate of potassa, acetate of ammonia; each article has its advocate, and at certain stages is indicated. I have great faith in colchicum, yet have often succeeded in producing a favorable termination in the use of guiacum, nitrate of potassa, and liquor acetate of ammonia.

The theory of the treatment of acute rheumatism, contemplates antiphlogistics, to be continued so long as inflammatory symptoms shall be severe; yet we must exercise ordinary discretion in the use of antiphlogistic remedies, for should we continue them until all inflammatory symptoms have subsided, we may purge, nauseate, and bleed our patients into the vicinity of death's door, without accomplishing our object.

The old-fashioned method of combating an inflammatory diathesis, in the use of lancet and drastic cathartics, is fast dying out, at least a very marked change for the better is observed, and practitioners, now, depend more on sedatives, diuretics, febrifuges, and nauseants, than on the above. One of the principal objects in the treatment of acute rheumatism is, to excite diaphoresis; and in this view we recommend a solution of acetate of ammonia, known as Liquor Ammonice Acetatis; this is an excellent febrifuge, and diaphoretic, and may be given in broken doses to the amount of eight ounces per day. One or two drachms of nitrate of potassa (common salt petre), may also be given in the form of bolus, yet in order to insure diaphoresis, and prevent these agents from passing off by the kidneys, the heat of the body must be augmented by clothing.

Practitioners of human surgery are often in the habit of using nitre, in much larger doses than we have dared to administer, yet, in some cases, with marked benefit to the patient.*

* Nitrate or Potassa.-In a case of synovial rheumatism this remedy was given by a Boston physician, in a single dose of one ounce, dissolved in a pint and a half of barley water. This was followed by one grain of opium. In fifteen hours the pulse was found reduced, and the pain absolutely gone; and in a fer days the tongue was clean, and the swelling entirely abated. The remedy 
These agents will probably moderate the heart's action and relieve the pain; should they fail to do so, we must resort to nauseants and sedatives. The most popular nauseant for horses, is white hellebore, yet it is an agent that can only with safety be used under the direction of a qualified practitioner. Mr. Morton recommends it to be given in "doses of from twenty to thirty grains, every four or six hours, until its action becomes manifest. As soon as this takes place, the repetition of the dose must be carefully avoided, lest efforts to vomit are produced."

Should we fail in the use of one or more of the above remedies, to lessen the heart's action, and the pulse be fifty or more per minute, the breathing somewhat hurried, and the pain excruciating, then a full dose of medicine must be given (about seven drachms of aloes). It may be proper to administer a physic ball in the early stage of the disease, and perhaps employ the lancet; these are matters which may be left discretionary with the medical attendant. If a mild diaphoresis can be brought about, it will do more good than we can expect from the use of either lancet or cathartic. A constipated state of the bowels, however, must be overcome either by physic, mashes, clysters, or saline aperients. The bicarbonate of soda is a very valuable adjunct in the treatment of acute rheumatism, because, in seven cases out of ten, the whole system is in $\varepsilon \mathrm{n}$ acid condition, and if we can (in the language of the chemist) saturate it with alkali, or in other words, establish an alkaline condition, our patient is on the high road to health.

Now, in case a cathartic be indicated, we must consider the condition of the patient; he may be suffering excruciating torment, firom inflammation of the pleura, pericardium, or synovial membranes, and if so, our object must be to mitigate pain in the use of opium or some other narcotic; should the patient, therefore, exhibit lameness in one or more of the extremities, and the joints of the hind or fore limbs become swollen and painful, a local application may be of some service, and in this view we recommend the following:

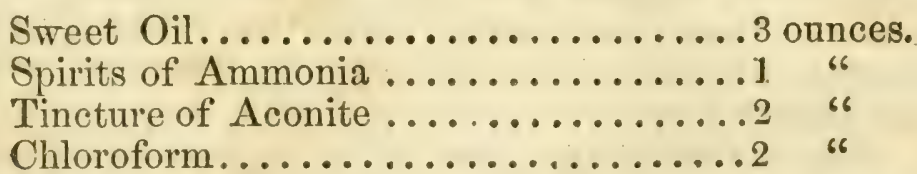

Mix. Apply a portion to the affected limb or joint, twice, daily. In an inflammatory state of the joints it is customary to apply

caused neither emesis nor catharsis, but passed off by the kidneys. In another case of acute synovial attack, following chronic rhcumatism, the same dose was prescribed without any good effect, causing active catharsis. Again, half an ounce of nitrate of potassa, largely diluted, was given every two to four hours, until the patient took three ounces in eighteen hours, with two doses of opium of one grain each, with entire relief to the pain and fever. When tho potash was reduced to drachm. doses, nausea and vomiting followed, which were relieved by vesication with aqua-ammonia, the blister being sprinkled with half a grain of morphine. The patient recovered. Another physician had used the remedy to the extent of half an ounce in twenty-four hours, for three successive days. He found that if the salt be given well diluted, it will purge, and vice versa. The physicians of the Massachusetts General Uospital had used the remedy, one ounce in twcnty-four hours, without good effects, and its use was abandoned. It appears to be conceded, that it is safe to give the remedy in this quantity, although symptoms of gastritis sometimes followed its use; but it was ahays largely diluted, and generally in demulcent liquids. We are in the habit of giving it in rheumatism and other inflammatory affections, in doses of twenty or thirty grains, every two or three bours during the perind of excitement or exacerbation, combined with tartar emetic; but have been deterred from the exhibrion of the larger doses above mentioned, from fear of its toxical effect. We have found this combination particularly useful in pneumonia.-Iremphis Mfedical Recorder. 
cooling applications, yet the practice is open to the following objection, viz., it may augment the acute symptoms in and around the joints, while it lessens them on the surface; nevertheless, if action of the cutaneous vessels can be maintained, refrigerating lotions cannot do harm.

As soon as the inflammatory. symptoms have subsided, and all danger of internal disease seems to have disappeared, we must commence a different plan of treatment; we must give tonics, not only to promote the convalesence of the patient, but also in order to prevent the disease assuming a chronic type, which is very apt to be the case when the prostrating plan of treatment has been too long continued, or practiced with undue severity. From among the following agents the practitioner can select a suitable tonic: Sulphate of iron, cascarilla bark, gentian, quill bark, quinine, golden seal, chamomile flowers, to either of which a small portion of ginger may be added, provided a stimulant be indicated.

\section{CHRONIC RHEUMATISM.}

Chronic Rheumatism is generally a sequel to the acute, yet if the subject be closely watched, a train of phenomena may be observed, very similar to those attending the acute stage, yet differing in its gradual accession, obscure state of the phenomena, and less functional and structural changes.

At times, chronic rheumatism is nothing more than a modified and protracted state of the acute stage; it is migratory like the former, attacking this, that, or other tissues, without reference to its original locality. For example, a horse may, after a brisk driving and subsequent exposure, become lame in the region of the fore extremities. This lameness may, perhaps, be defined as sub-acute, or chronic rheumatism, from the fact that there is no increase in arterial, or respiratory actions; but the first thing we observe is, that the subject is laboring under hypertrophy of the heart, perhaps carditis, or endo-carditis, and this is proof positive of the migratory character of rheumatism.

But why should rheumatism attack the heart? This is quite an interesting question, and thus we answer it. The physiology of the heart instructs us that its motions are governed by the impression made upon the susceptible nervous tissues. Its responses are physiological when the whole system is unembarrassed. It is the centre not only of circulation, but of sympathy, and responds to the inpressions made upon the general system; so that if any disturbance shall occur in the animal economy, in the form of fever, spasm, \&c., or the horse be affrighted, punished, or exposed to sudden variations in temperature, the heart is one of the organs first deranged. Rheumatism, therefore, being migratory, is apt, in traveling from tissue to tissue, to locate on a deranged organ, especially when that organ is one so easily excited as the heart.

Causes of Rheumatism.-The especial cause of rheumatism is, hereditary :predisposition. In certain families, morbid tendencies 
are transmitted from parent to offspri $\mathrm{g}$, and display themselves in the development of parental defect and deformity. There are, also, general exciting causes, such as exposure after perspiring freely, damp and cold stables, errors in diet, or stable management, over-work, \&c.

Principal symptoms of chronic rheumatism. - The subject is generally observed to travel a limited, or stiffened gait at first, when taken out of the stable. He appears "stiffened up," as the saying is, yet "limbers up" as he proceeds. This depends, however, somewhat on the temperature of the atmosphere, for the animal is nothing less than a walking barometer, and the slightest alteration in the weather affects him very sensibly.

The disease may manifest itself in the diffuse form, affecting the body as well as the limbs and feet, which gives to the animal a sort of wiry, spare appearance; yet otherwise, he appears well, and can play his part at the game of food as well as any horse. In the absence of all inflammatory symptoms, this peculiar and almost ruined condition is designated by some as general founder; and as no one has ever drawn a line of demarcation between what is known to medical men as chronic rheumatism, and what the rest of the world denominate chronic founder, we shall consider that chronic rheumatism is founder, and vice versa.

Passing from the diffuse form, this chronic affection may locate in the muscles of the trunk; then it gets the name of "body founder." The animal is then unable to move the body in lateral directions, without showing an awkward stiffness; and on being made to turn a corner, when going at a smart gait, a stiflness, apparently in the spinal regions, is generally perceived.

At times it locates in the pectoral region, and in consequence of either long continued pain (which is known to exhaust muscular rotundity), or innutrition, the parts present a shrunken or hollow aspect. In the absence of acute symptoms, this is the veritable " chest founder."

A disease of this character long confined to one or both shoulders is often followed by a similar wasting of the spinatus muscles, and is often termed "sweeney." The same condition of parts, however, may be the consequence of diseased feet, for we often observe an atrophy, or wasting of the above muscles in animals that have long been the subjects of chronic laminitis, and altered structures about the feet. The term founder is often applied to a ruined state of these parts. Chronic rheumatism is more apt to localize itself than the acute kind, and once located, it is not so easily removed, although the animal may receive benefit from the ordinary means, such as warm clothing, and stimulating embrocations; yet, when exposed to wet or cold, he again relapes into his former condition, traveling stiff and lame as ever. The stiffness and lameness, if there be any, attending chronic rheumatism, disappears to a certain extent after a brisk trot, whereas acute rheumatism is generally aggravated by exercise.

Chronic rheumatism may, however, appear in one spot to-day, and to-morrow manifest itself in another, yet the affected parts exhibit none of the heat or tenderness, difficult respiration, wiry pulse, or functional disturbance which attend the acute stage, s? 
that the difference between the acute and chronic conditions of this affection is very marked.

Treatument of Chronic Rheumatism.-Local treatment consists in the application of vapor, warm blankets and leggings, and stimulating liniments, the patient to be located in a warm, yet ventilated stable.

The following is probably one of the best local applications:

Sulphuric Ether................. ounces.

Oil of Cedar.................... 6

Camphor.......................

Proof Spirit...................

Soft Soap....................

Dissolve the oil of cedar in the sulphuric ether; then dissolve the camphor first, and soap afterwards, in the proof spirit, and mix.

Apply a portion of the above to the affected parts, night and morning, so long as the case may seem to require it.

Constimutional Treatment. - The constitutional remedies are various. Those entitled to our greatest confidence are:

First-Medicines which act upon the cutaneous vessels.

Secondly-Medicines recognized as pure tonies, which impart tone and activity to organs, without inducing subsequent prostration.

Thirclly-Medicines known as general stimulants, that excite without depression.

As an example of the above, we give the following formula: Thayer's Fluid Extract of Black Cohosh, diaphoretic.....2 ounces.

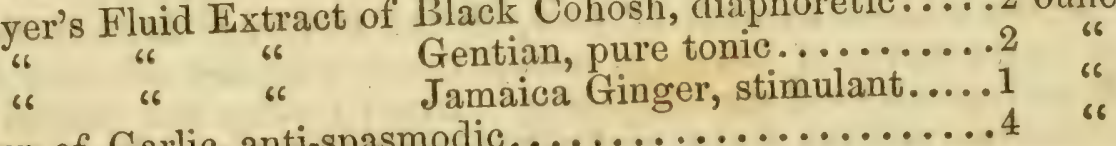

Syrup of Garlic, anti-spasmodic.................

Mix.

One-fourth of this mixture may be given night and morning, in the form of drench.

Other medicines are in high repute, such, for example, as hydriodate of potassa, nitrate of potassa, phosphate of ammonia, camphor, aconite, capsicum, \&c., \&c.

\section{HERPES IN HORSES.}

The term " Herpes," is derived from the Greek, which signifies "I creep," because the disease creeps and spreads about the skin.

In the United States, I believe, this cutaneous affection has never raged in an epizootic form. I have seen and treated a few isolated cases, and the subjects of the same were of a lymphatic and scrofulous temperament. In these cases, it appeared as an eruption in the form of vesicles, and scurvy roughness of the skin; the vesicles or eruptions, at first, were in irregular elusters, but in the eourse of a few days they became confluent, or ran tugether. There existed some heat and tenderness in the vioinity of the diseased localitieshead, neck, shoulders and limbs-and the general health of the ani- 
mals was more or less impaired. After a period of from ten to twenty days, some of the clusters of vesicles were ruptured, leaving a rough furfuraceous scale.

Treatment of Non-cutanenus Herpes. - The surface of the body is to be thoroughly sponged with a tepid alkaline wash, which isists of-

Warm Water................... gallon.

Carbonate of Soda.............. ounces.

This will remove all extraneous and morbid matter from the sur ace. The animal must be rubbed perfectly dry before the "herpes lotion" is applied.

Herpes Lotion. Glycerine, two ounces; Oil of Turpentine, four ounces; Cod Liver Oil, one pint. Mix.

Sponge the affected parts every night, prior to the reapplication of the lotion. The parts to which it has been applied, are to be rubbed dry by means of a piece of coarse crash. During the period of the local treatment, the patient should get a few doses of altera. tive medicine. The following is a good example:

Fluid Extract of Sassafias.........7 ounces.

Hydriodate of Potass .............. drachm.

Dose : one ounce daily.

The most alarming form of Herpes is the epizootic, and as the husbandmen of this country have great interests at stake, yet know very little about its nature and symptoms, I here introduce some remarks fiom the pen of Prof. Papa:

"At the commencement of 1849, Count Faverage invited Prof. Papa to the valley of Borne, in Savoy, to see a disease affecting animals, and which even spread to men. Every facility was offered by Government to Prof. Papa, and many persons having affected animals were requested to perrnit their inspection, and indeed, threatened with a fine if they did not. Papa saw about three hundred horses and mules affected. The disease appeared in circular patches of furfuraceous scales, with greyish-white scabs. These patches had usually well-defined margins, about the size of a dollar, or fiveshilling piece. Usually they were isolated, but at other times they were confluent or running together in groups. The head, neck, withers, shoulders and loins were the parts chiefly affected; more rarely the upper portion of the extremities, and never on the lower part of the limbs, chest, or belly. The malady commences with a violent itching, and an eruption in small circumscribed points, about the size of a lentil, is witnessed. The scabs form, with the exudation drying and entangling cuticle and hairs. In the vicinity of the first, other eruptive spots appeared, which widening, bccame confluent, and ran into one another, especially where the skin is folded, and animals have a chance of rubbing themselves. A scab forms on the sore surface, and the surface beneath is red and tumefied, but in a little while desquamation occurs. A very careful microscopical examination failed to indicate the existence of any acari."

The disease is contagious, and Papa says, all those who come more or less in contact with herpetic horses and mules, and especially the conductors of the same, were covered on the arms, legs, chest and 
face with pruriginous eruptions, limited and circumscribed, sometimes isolated, occasionally confluent, in the form of red patches covered with papulæ and vesicles, which become encrusted with brownish-yellow scabs, beneath which purulent deposits formed. In consequence of the violent pruritis attending this disease, it was believed to be scabies or itch by the people, and though in many houses individuals were affected, they were ashamed to confess it, and it was with great difficulty that Papa collected information on the subject; but having gained the confidence of the latter, the people more freely related their cases to him. The first to be affected, were those entrusted with dressing the diseased animals. The parts first attacked were the articular regions, about the forearm, arm, face, and rarely the lower limbs.

Papa describes one of many cases of direct contagion. It occurred in a lad of sixteen, who had jumped on the bare back of an affected horse to take it to a watering place. Two days afterwards, on the inside of the thighs and legs, from the pubis to the calf of the leg, there was extreme pruritis. The skin became of reddish-brown color, and vesicles full of a yellowish lymph formed, which gave way to vesicular patches or scabs, rough to the touch, first isolated, and afterwards confluent.

The transmission occurred from horse to horse, horse to man, and from man to man; in fact, persons who never touched an affected horse, were infected from individuals they came in contact with. A soldier having arrived in perfect health from his regiment, slept with his brother who suffered from the disease, and became affected. The wives of carters not only took the disease, but communicated it to their sucking infants.

\section{WATERING HORSES.}

Although few persons pay proper attention to this department of stable management, yet a little reflection will prove of how much importance it is, that the horse should be supplied with such water as is most palatable to him. Horses have a great aversion to what is termed hard water, and have been known to turn aw ay from the filthy stuff found in the troughs of some of our stables: the water of wells and pumps in our seaport towns is usually hard, and possesses a degree of coldness not at all congenial with the palate of the animal. The intense coldness of well water, in the summer months, has been known to gripe, and produce spasmodic colic, injuring the animal in other ways.

Pure water will never hurt a horse, if given to him at proper times and in small quantities; the English grooms generally water from a bucket three times, daily; water given in this manner scarcely, if ever, does harm; but let a horse be driven hard, and then allow him to go to the trough and imbibe water, ad libitum, more than he actually needs, the same may prove injurious, and result in some disease known as "founder." The latter clause is in accordance with the popular theories of the day, which are always open to argument. Hence, we shall now examine into the merits or the case. 
I don't believe one-half the multitude of stories that are told about water "foundering horses," in a great majority of cases the blame rests with Mr. Fastman, who has either over-driven or overworked the poor brute, or else has suffered him, when heated, to cool off without the necessary care and attention which should always be observed when animals are fatigued or perspiring freely.

Hard usage, willful neglect, and wanton cruelty, are more likely to produce disease than the "universal beverage" so acceptable to the palate of a weary or thirsty horse. How often do we see a "let" horse come into the stable all exhausted and used-up, scarcely able to advance one limb before another! Examine into the facts, and we shall find that the powers of the subject have perhaps been overtaxed. He has been driven too far, or at too rapid a rate for the present state of his constitution to endure; and perhaps he has not had sufficient nourishment to repair the waste incidental to the living mechanism, under the states of rapid and protracted labor. Is not this enough to account for the used-up condition? Is it not more rational to suppose that abuse of the respiratory organs, and those of locomotion, operates far more unfavorably on the horse than water? It is. But Mr. Fastman must, if there be any blame rightly belonging to him, try to shift the same from his shoulders, and therefore he avails himself of a popular error, "He drank too much vater." Yet the individual has no means of ascertaining the precise quantity needed. We might say the same as regärds our dray horses, whose labors are very fatiguing. They come from their work, and as soon as unharnessed, go to the trough and imbibe from one to three buckets without any bad effect. Some horses need more water than others; the kind of work, the temperature of the atmosphere, and the nature of the food, whether it be wet or dry, all tend to diversify an animal's want. The dornesticated horse requires a bountiful supply of good water; his body is composed of seventy-five per cent. of the same, and he can no more exist without it than he can without food.

Consider for a moment the condition of the people of this city during the sultry season. Thirst almost amounts to a disease; to allay the same, they are continually imbibing water, rendered cold, hot, sour, sweet or alkaline, just as fancy dictates, or as fashion prevails; cold ices and other fixings are called into requisition to smother the fire of thirst that races within; everybody partakes freely, the young and the aged, the exhausted and vigorous; the laborer, exhausted by a hard day's work, and the rich man, of no work-each and all are doing their best to see the bottom of the pitcher, and to pitch their bodies into the watery element; yet, after all, how few persons complain of any bad effects from the same.

Inquire into the bistory of some of the acute maladies that are supposed to arise from water-drinking, and it will be found that many of the sufferers have a peculiarity of constitution, which renders them amenable to the laws of primogenial disease, which, although latent, under ordinary circumstances, can, by disturbing the life forces, through neglect, eruelty and over-work, be developed at almost any time of life.

At this stage, my argument as regards what water "will not do" ends. I have at the commencement admitted that, under certain circumstances, if a horse be permitted to imbilue too much, it may 
izjure him; but this is rather a faulty assumption, because no one can ever determine the precise quantity suitable to meet the wants of all animals, and therefore the assumption falls to the ground.

Horses should, in warm weather, be watered often, say two to three quarts erery three or four hours, provided the horse be at work; should he be in a cool stable enjoying a sort of lazy life, he will require less, and three times a day will be often enough to supply his wants.

"Strange water," as it is termed, is not good for borses, yet when given in sinall quantities at a time, seldom, if ever, does harm.

Stagnant and filthy water is always more or less injurious, and should never be offered to so noble an animal as a horse.

On the road a horse may be watered often, provided he have but a small quantity at a time; if he obtain more, it occupies space in the abdominal cavity, and in rapid motion interferes with the physiological action of important viscera.

Watering immediately after a full meal is a practice highly censurable; for at such times water retards digestion, and the food, instead of being digested, is apt to undergo a process of fermentation.

\section{TEETHING IN HORSES.}

There is no doubt that many young colts suffer as much pain in cutting their teeth as is the case with children; and the pain does not always arise, as some persons suppose, from irritation of the mucous membrane of the mouth, occasioned by the point of the tooth, but frequently from pressure on, and irritation of, the dental nerve. The remedy (instead of tormenting the suffering creature with a rect hot iron for the purpose of "burning out the lampas," as some persons profess to do) is a common thumb lancet. Make an incision through the gum, or mucous membrane of the mouth, in the region of the tusks or incisors, wherever the difficulty may be, and relief is almost immediate. This is a sure remedy to relieve local distension of the mucous membrane of the mouth, if it exist, and at the same time prevents the fang of the tooth from irritating the dental nerve.

Sharp and Projecting Teeth.-Owing to the unequal wear of some horses' teeth, they become sharp on the outside margins, and are then apt to irritate and perhaps lacerate the buccal membrane of the cheeks. Should this be the case, we generally find that the salivary secretion is augmented, mastication is imperfect, and the subject generally looses flesh, and appears unthrifty. The remedy is a mouth rasp. By means of this instrument, the sharp or projecting edges may be smoothed.

Inflamed and Tender Mouth.-Inflammation, tenderness, and tumefaction of the horse's mouth, arising from whatever cause it may, generally indicates the application of cooling and astringent lotions; and light diet of bran mashes, cooling lotion, composed of solution of hydrochlorate of ammonia, or chlorate of potassa, are indicated when the mouth is hot or inflamed. A tender mouth, accompanied by corrugations and ${ }_{6}$ relaxation of the soft palate, known as "lam- 
pas," requires a few applications of some astringent lotion, made of alum, gum catechu, raspberry leaves, white oak bark, or diluted tincture of muriate of iron.

\section{LIGHT IN STABLES.}

Stables should be so constructed, by the insertion of windows in various parts of the building, that they should be "light as day." A "dark" stable is only a suitable black hole-prison house for such a vicious specimen of the equine race as the notorious "Cruiser." It is also the very worst location for any kind of animal. Sir A. Nylie (who was long at the head of the medical staff in the Russian army) states that the cases of disease on the dark sicle of an extensive barrack, at St. Petersburg, have been uniformly, for many years, in the proportion of three to one to those on the side exposed to a strong and uniform light. Humboldt has also remarked that, among bipeds, the residents of South America, who wear very little clothing (thus allowing the cutaneous, as well as the orbital surfaces, to receive a free ray of light), enjoyed immunity from various diseases which prevailed extensively among the inhabitants of the dark rooms and underground locations; and so exeellent an authority as Linnæus contends that the constant exposure to solar light is one of the causes which render a summer journey through high northern latitudes so peculiarly healthful and invigorating. Dr. Edwards has also remarked that persons who live in caves or cellars, or in very dark or narrow streets, are apt to produce deformed children; and that men who work in mines are liable to disease and deformity.

Light, therefore, is a condition of vital activity; and in view only of preserving the sight of a horse, it is absolutely necessary that while he be the habitant of the stable, his optics shall have free access to the sun's rays.

If a horse was in the same condition as a polype, with no organ of vision, which shuns light, a dark stable might prore to be his earthly paradise; but as the horse has special organs of vision, evidently susceptible to the influence of light, and the integrity of his organism, or part of the same, depending entirely on the admission of light, it is absolutely necessary that stables should be constructed accordingly.

\section{GLANDERS.}

This is one of the most terrible diseases to which the horse is subject. In fact, it is also terrible to man, for it is communicable from horse to man, and many cases are on record going to show that whole families have been destroyed by absorbing the glandered virus. The discase has been styled "the phthisis, or consumption of the equine race," from the fact that the lungs of the glandered subject are the seat of tubercles, and many other features of the disease resemble those attending human consumption. Glanders is, however, unlike consumption. 
Catese of Glanders.-In former years, glanders was very prevalent among horses in the city of London. At that time very little attention was paid either to ventilation or cleanliness. At the present time, however, the disease is rare, from the fact that horses are now better treated and cared for than then.

The predisposing causes of glanders probably lurk in breed, and when such animals become the subjects of neglected or protracted nasal discharges and nasal gleet, glanders is very apt to supervene.

The direct cause of glanders is innoculation. Animals become innoculated, in consequence of the virus, or discharge from the nose, coming in contact with an absorbing or highly vascular surface; by infection, also, the malady is propagated; for example, should a glandered horse be placed in a filthy, unventilated stable, beside an unaffected animal, the latter will soon become a victim to the disease.

The indirect causes of glanders are impure air, exposure, harrassing marches, overwork, and food of bad quality. It must be remembered, also, that the disease may have a spontaneous origin.

Whenever a large number of horses are congregated together in a very limited space, glanders is apt to occur. Mr. Percival contends-

1. That farcy and glanders, which constitute the same disease, are propagated through the medium of stabling, and this we believe to be the more usual way in which the disease is communicated from horse to horse.

2. That infected stabling may harbor and retain the infection for months, or even years; and although by thoroughly cleansing, and making use of disinfecting means, the contagion might be destroyed, yet it would not be wise to occupy such stables immediately after such supposed or alleged disinfection.

3. The virus or poison of glanders may lie for months in a state of incubation in the horse's constitution, before the discase breaks out. Of this we have had the most positive evidence.

4. That when a stable of horses becomes contaminated, the disease often makes fearful ravagres among them before it quits; and it is only after a period of several months' exemption from all disease of the kind, that a clean bill of health can be renclered.

Nature of Glanders.-It consists of a discharge from the left nostril, of matter, which, by transfer or innoculation, will produce the disease in another animal (of the equine or human specics), and which discharge is, sooner or later, accompanied by chancrous ulcerations on the lung membranes of the nose, and by an enlargement of the lymphatus glands within the angles of the lower jaw. In the latter stages of the disease, a discharge takes place from both nostrils.

The deep seated lymphatus are also affected, and finally tubercular deposits take place in the lungs.

The subject of glanders usually bas an unhealthy appearance, loses flesh, and finally becomes a "dog horse."

The disease sometimes assumes the acute form, and runs through its course with fearful rapidity. The chronic glanders is more insidious in its character, and the affected animal may live a long time. 
Trentment of Glanders. - I am satisfied that there is no spe cific remedy for a pure ease of glanders. Experiments on a very extensive scale have been made in England and France, by some of the most experienced veterinary surgeons, and they do not offer very much encouragement for us to attempt the cure of glanders. The fact is, there are very few cases of cure on record, and the same remarks apply to the cure of confirmed phthisis, or consumption.

Whoever undertakes to attempt the cure of this awful malady must remember that he is running a great risk of losing his own life, for the absorption of the least particle of the virus will cause death in one of the most horrible of all forms.

My advice is, that when a horse shows unmistakable symptoms of pure glanders, that he be destroyed.

In cases of suspected glanders, when the diagnostic symptoms cannot be detected, it may be proper to place the animal under medical treatment; for, in the absence of such symptoms, the case may happen to be one of nasal gleet, for which I recommend the following:

Phosphate of Lime.............6 ounces.

Powdered Poplar Bark........... "

Mix. Dose, one onnce daily.

In allusion to the curability of pure glanders, it may be proper for me to remark that many men contend that they have cured glanders. This arises from the fact that they made a mistake, and confounded glanders with another disease.

In view of furnishing the reader with collateral evidence as regards the causes of glanders, I introduce the following quotations:

"The causes of glanders may be considered under the general heads of predisposing and exciting.

"Predisposition may lurk in breed, in constitution, in age; or it may be generated through the influence of soil, climate, aliment, \&e.

"Breed, we have, I think, pretty satisfactory evidence, carries with it predisposition to certain diseases. To use a vulgar, but expressive phraseology, "they run the blood." Periodic ophthalmia is, perhaps the most striking instance of this.* Roaring, according to many authorities, is another.f Whether glanders or farcy can be ranked in the class of hereditary maladies, I am not prepared to say. Leblanc hesitates not to assert that it can. I should certainly give it as my opinion that inasmuch as tender or delicate constitutions are inherited by horses, to the same extent they become predisposed to certain diseases; to those, in particular, affecting the respiratory organs, and with these, to glanders; and the same appears to be the notion of Dupuy, when he informs us that the 'lank, ill-conditioned horse, the one that is soft in constitution, and soon knocked up at his work,' is the subject the most likely to breed or contract 'the tuberculous affection,' as he calls glanders and farcy. Furthermore, a constitution originally strong and resistant, may be reduced to a weak or 'ill-conditioned' sus-

* See Part 1, Vol. III, of the Hypopathology, page 90, et sequent.

+ See Vol. II of the Hypopathology, page 29. 
ceptible state, by bad keep, over-work, exposure to cold and wet, \&c., or through the failure of any of its principal organs, especially of the lungs. Constitutional predisposition may, therefore, prove to be either natural or acquired.

"Age, we well know, has considerable influence in predisposing horses to take diseases of the air passages-to take catarrh, bronchitis, strangles, glanders. We have no reason, however, to suppose that this influence is operative in the case of glanders in particular, for the same reason that a young horse is more likely to catch a cold than an old. For the same reason, should he go within the reach of the exciting causes of glanders, he may be considered as especially predisposed to that disease. Out of forty cases of farcy and glanders occurring in the Ordnance, under the superintendence of my father, and, latterly, of myself, the ages of which happen to be registered, one was three years old, one four years old, six in the sixth year, six in their seventh year, six in eighth, five in their ninth, eleven ten years old and upwards. Consequently, so far as this brief account goes, the adult and middle ages appear to suffer most from the disease.

"In respect to climate and soil, it would appear that glanders is a rare disease in cold, and absolutely unknown in hot climates, in Arabia and Africa, to which, I believe, we may add India; my cousin, Mr. Charles Percival, having informed me that, during his eight years' residence in. Bengal, while serving in the eleventh light dragoons, quartered at Meerut and Cawnpoore, he had not a single case either of farey or glanders. M. Saunier, veterinary surgeon to the king of Portugal, assured Dupuy that no case of glanders had occurred, to his knowledge, during the thirty years he had been living at Lisbon. This was prior to the occupation of that country by British troops. At the time of the Peninsular campaign, every body in our army knew that both farcy and glanders prevailed to a great extent, particularly among the mules that were in our employ as bat animals. To what such dread changes were owing-why a country, at one time said to be free from any such disease, should, some years after, become, as it were, the very focus of contamination-is a fact which, if I mistake not, may prove of some importance to us in the investigation we are about to make in the exciting causes of glanders.

"Wet and cold are at all times prejudicial to horses' constitutions, and especially to those either very young or very old; and though the better their feed the less they are likely to suffer under such exposure, yet will these agents predispose and be very apt to lay the foundation for pulmonary, mesenterie, and glandular disease, which, in the end, will produce farcy and glanders.

"Before we proceed to the consideration of the second class of canses, viz., the exciting causes, it will be well for us to inform ourselves of the opinion of such veterinary writers, foreign as well as British, as appear to have paid much attention to the subject, and particularly to that all-important branch of it, contagion; a branch which, at one period of time, has had supporters on all sides, while at another it has been left almost without any. These I shall arrange in the order of the date of the respective works.

"Solleysell, 1669, pronounced glanders to be "the most contagious 
distemper to which horses are obnoxious; for not only, says he, 'does it communicate its venom at a small distance, but it infects the very air, and seizes on all horses that are under the same roof with him that languishes from it.' 'There are, (however) several kinds of glanders, some of which are not so extremely infectious as others, though there are none that ought not to be suspected.'

"The 'causes of glanders' Mr. Smith enumerates to be: 1, General debility; 2, A previous disease ; 3, Breathing an impure air ; 4, Exposure to a current of cold air, or being permitted to drink cold water when hot; 5 , A sudden transition from cold to heat, and vice versa; 6 , Infection. The first three of these Mr. Smith regards as preclisposing causes; the latter three being exciting causes. 'General debility may be considered the forerunner of every disease, the system being thereby rendered more susceptible to morbid impressions.' 'Glanders is frequently produced by a variety of other diseases.' 'I have seen the mucous membrane ulcerated, the bone carious, and all the characteristic symptoms of glanders produced by a cut of a sabre. I have also seen one case in which glanders was produced from the effects of a severe fall, by which the frontal sinuses were perforated ; in another, the os frontis laid entirely bare, and the concussion so violent as to excite a copious discharge of mucus and pus from the nostrils; and in another, the same symptoms produced by a blow on the superior part of the nasal bones.'

"To conclude with my own opinions on the subject of contagion, they are, shortly, these: I have no more doubt of glanders being a contagious disease, than I have of syphilis, or small-pox, or itch being contagious. At the same time, from the known fastidiousness of contagion in regard to its operation, and firom the several collateral circumstances required to insure its effect in the case of glanders in the horse, in the generality of instances the chances of escaping under its influence, greatly, I believe, exceed those of contamination. The comparatively few examples that any of us can adduce of contagion, even after an experience of many years, in my mind seems to warrant this inference; at the same time, these examples are fully sufficient, both to establish the fact and warn us against running any risk of propagating the disease. The lamentable, as well as discreditable difference of opinion that has hitherto existed on the contagiousness of glanders, seems to have arisen out of the narrowness of the circuit of observation whence the deductions have been made. One man's practice may not have furnished him with any well-marked examples of contagion, another's may have shown him several; the former infers that glanders is a disease of self-origin, the latter that contagion is its source; both too precipitately and confidently running to their opposite conclusions. Let us hope, however, now that our sphere of observation and experience is becoming so much enlarged by the contributions of fellow-laborers, both in our own and in foreign countries, that we shall approximate in our opinions on this vita!ly important question; and, as a humble step toward such desirable agreement, I believe the conclusions I have, after a good deal of deliberation and some experience, come to here, will not be found widely diverse from the opinions entertained by the majority of veterinarians whose works or words are, at the time I am writing, known to us." 


\section{FARCY.}

Authorities define Farcy to be a disease of the lymphatic vessels, making its appearance in the form of circular swellings, termed farcy buds, which terminate in a discharge and ulceration.

Symptons. - The horse usually exlibits some symptoms of a deranged condition; sometimes, howe"er, scarcely noticeable, at others very apparent. The horse is not in his usual spirits, appears dull, and does not partake of food with his accustomed relish. Some horses will have febrile symptoms, pulse quicker than natural, mouth hot, urine high-colored, \&c.; others are suddenly attacked with a swollen leg. Horses often become suddenly lame in one of the hind extremities. Mr. Percival remarks : "I have known horses so lame from farcy, before the disease had in any local or characteristic form declared itself, that shoes have been removed, and feet searched, \&ce, to discover the cause and seat of lameness, no suspicion having existed, at the time, that farcy was present in the animal's system. It may so happen, how ever, that none of these preliminary symptoms are observed or observable; that, on the contrary, farcy at once develops in an attack on some locality-most probably one hind limb. Indeed, so sudden, sharp, and severe are attacks of farcy in some instances, that in the course of one night the horse's limb will be swollen to a frightful size, so as to incapacitate him almost from turning in his stall and walking out of the stable.

"Ordinarily the development of farcy plainly accounts for the halting or lameness; now and then, however, the lameness appears without any ostensible cause.

"Viewing the affected limb from behind, we perceive a fulness on the inside of the thigh, along the course of the femoral vein ; and the apphication of our finger to this will immediately detect a corded, nodous swelling, which has been happily enough, in the sensation it conveys to our feel, compared to a 'cord with so many linots tied in it.' 'This is at once declarative of a disease in the lymphatic vessels of the presence of farcy.

"Tracing the cord upward from its place of origin, which com. monly is above the hock, the hand is carried into the groin, and there discovers a lobulated tumor, a swelling of the inguinal glands, which may, without impropriety, be called a bubo; sometimes, however, the bubo does not make its appearance until after the full development of the cord.

"Farcy does not at all times make its attack in this open and unambiguous form; on occasions it presents itself in a shape so insidious, that at first we hardly suspect it to be farcy, unless there happen to be present cireumstances to indruce suspicion of its existence. Sometimes one of the limbs, most likely the hind, will swell below instead of abore the hock, and the swelling will increase around the fetlock, and an abscess will fur'm there. In other cases, blotches or isolated pustules will break out upon the limbs, more likely upon the inner than the outer side of them, or upon the body, or upon the shoulders, neck, breast, or quarters; and these will break and discharge among the hair, clothing those parts with an ichorous or dirty-looking, thin puriform matter." 
These are the general symptoms of farcy; if any doubt, however, exists as to the nature of the disease, it will in a few days, sometimes in a few hours, be dispelled by observing corded lymphatics issuing from these patches, which soon become running sores.

A case of farcy came under my observation a short time ago. The subject had for some time been suffering under constitutional derangement, gradually losing his appetite and flesh. An influenza was now prevailing in the stable, which attacked all the inmates. The one alluded to had a fetid discharge from the nose, differing from that of the other horses; and soon farcy buds made their appearance, accompanied by swelling of the legs. The fetid breath, together with the constitutional symptoms, would seem to favor the hypothesis that the patient was a subject of decp-seated farcy, and, probably, had been such for a length of time. It was thought advisable to destroy this animal. The others all recovered; four of the number, however, having swollen legs, were permitted to run a few days at grass before they could be put to work. Veterinary writers speak of several forms of farcy; but these are only varieties of the same disease, differing only in their symptoms and duration, assuming a mild or malignant form, as the case may be, in exact ratio to the general health of the subject.

The first stage of farey is tumefaction of the lymphatics- "development of the farcy bud."

The second stage is commonly a suppurative one, terminating in a farcy ulcer. After passing through these two stages, the disease may, and frequently does, terminate in glanders. Hence the prognosis of farcy, in most cases, is considered unfavorable. Yet, when it attacks horses in good condition, some hopes may be entertained of a cure. In the diagnosis of farcy, we are not apt to be mistaken, provided we keep in mind the language of a distinguished veterinary writer, who says, "No swelling of a hind limb (or any other part) constitutes a case of farcy, apart from the unequivocal signs of lymphatic disease. There must be present corded, nodulated swellings-buds in some form or other-together with actual or approaching tumefaction of the lymphatic glands, or the case is not farcy."

"I cannot help thinking," says the same author, "from accounts I have perused in some veterinary works, that both glanders and farcy have been mistaken; or, rather, that diseases of another kind have been mistaken for them, and for farcy oftener than for glanders. One disease in particular, and one that is by no means so very rare in its occurrence, I feel quite certain has been called by the name of farcy, and under this appellation appears to have been 'cured,' and to have been recorded as such. 'The disease I allude to is that which is now known by the name of diffuse inflammation - of the cellular membrane-a disease consisting in the generally sudden appearance of lumps or patches of sub-cutancous effusion, of a solid and even firm description, attended by œdematous, swollen states of the limbs, belly, sheath, \&c., and thus having, so far, the character of water farcy.* But in these cases, let it be well ob-

* What mas in former times known as water farcy, is now understood as superficial dropsy-an effusion into the cellular tissue. 
served that there is no lymphatic disease, nothing like farcy buds and cords; in which circumstance it is (connected with the course and termination these respective diseases are seen to have) that we are to seek a correct diagnosis.

"But how are we to distinguish farcy buds from some cutaneous eruptions-from surfeits, ${ }^{*}$ which appear so much like them? There is but one species of farcy for which these eruptions ean be mistaken, and that is the aiffuse, or broadcast variety - the button farey. Now, should the attack be farcy, the probability is, from its being a general one, that the animal will show signs of ill health at the time, whereas a horse that has 'broken out in a surfeit all over his body,' is commonly in unusually good, what is termed fine condition. Then, again, surfeit lumps are often large and irregular in form, and frequently appear in patches; whereas the buds of button farcy are small, and regularly spheroid in shape, and spread pretty uniformly over the body. Again, surfeit eruptions are often but of an hour or two continuance. Rarely are they visible on the following day. Any donbt, therefore, that may impend over the case, is not likely to be of lengthened duration."

The causes of farcy exist in any thing that deranges the lymphatic system; and probably the same causes that operate, cither by contagion, or otherwise, to produce glanders, will produce farcy. "By innoculation, farcy has been produced by the matter of glanders, and glanders by the matter of farcy: and, consequently, there is every reason to infer a similarity, or rather an identity in the viruses of the two diseases; and in further proof of this, as we said before, one diseașe, or form of disease, almost invariably terminates in the other prior to dissolution. There can be no question but that the same contaminated or miasmatic atmosphere of the stable, or elsewhere, which produces glanders, may occasion farcy, and vice versa."

Treatarent of Farcr.-The patient should be placed in a well ventilated stable. If, however, the season permits, a run at grass, in the day-time, will be preferable. Pure air, and green food combined, are almost certain to produce a favorable effect; for pure air decarbonizes the blood, deprives it of those impurities which abound in farcy subjects, and at the same time distends the lungs to their normal capacity; by which means the blood is circulated with more force to the extreme vessels. The green food, while its action is alterative, provides for the laxity of the bowels, keeps them free and unobstructed, and entirely dispenses with cathartic medicine; the latter being generaliy considered necessary to clear out the bowels; hut in my opinion, the "brisk dose of cathartic medicine," so highly extolled by some, is calculated to produce unfavorable results, especially if the patient shall be in a state of debility. Any man who has ever been foolish enough to practice the common error of periodical dosing with salts and senna, castor nil, \&c., can testify as to their prostrating effects; but this is only an item in the catalogue of evils ; great pain, griping, loss of appetite, subsequent constipation and dyspepsia, are the consequences of cathartics and purga-

* Surfeit. A disease of the skin, consisting in an eruption of small pustules. It appears to arise from a diseased state of the stomach and bowels. - White. 
tion. Therefore, if the fecal accumulations can be got rid of under the exhibition of so safe and desirable an agent as grass, it is certainly to be preferred to the tripe-scouring compounds of the day.

The grass may perhaps act as a cathartic, especially if the subject has been accustomed to corn and oats. If this should be the case, a sufficient quantity of dry food should be allowed to supply the waste of the body, and promote the living integrity; for without oil the light will go out, and food is to the system what oil is to the light. Therefore, in such case, a liberal allowance of nutritious food will be indicated.

When green food cannot be obtained, a sort of substitute can be compounded, consisting of boiled carrots, beets and turnips, thickened with shorts, or fine feed, and the whole pounded up together, to which a tablespoonful of salt may be added.

As regards the drink, we need only observe that pure water, in small quantities, is perhaps the best; yet if the patient be in exceedingly poor condition, he may then be allowed two quarts of hay tea, and a pint of fresh cow's milk twice a day.

Animals suffering firom either glanders or farcy, should have a liberal supply of common salt.* A quantity should be placed in a situation where the animal can belp himself; in addition to which the food should be salted.

\section{Mecticines.-These must possess the following properties :}

1. Antiseptic. To preserve the system from putrescence. The principal one is pyroligneous acid; dose, one ounce twice a day, in a pint of sage tea.

2. Alterative. To change morbid action; the following is an example:

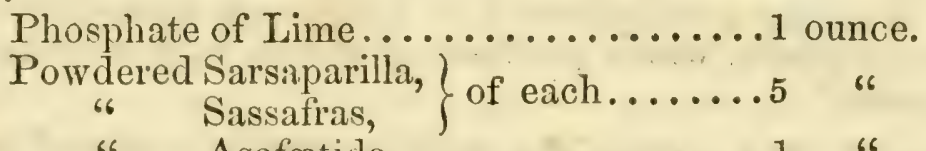

" Asafœtida................

Mix, and divide into twenty-four powders; one to be given, night and morning, in thin gruel.

3. Stimulant. To arouse vital action; the chief are capsicum

\footnotetext{
* Saline matters are essential constituents of the blood, of the organized tissues, and of the secre. tions. They are, therefore, necessary components of our food, for without them, health and vitality cannot be maintained.

The alimentary salts, which, on account of their occurring more frequently and largely in the sys. tem, may be regarded of the most importance, in a dietetical point of view, are common salt, and the earthy phosphates. Ferruginous compounds (salts?) and probably salts of potash, are also indispensable ingredients of our food.

1. Common Salt (Chloride of Sodium). Though salt is a constituent of most of our foods and drinks, we do not, in this way, obtain a sufficient supply of it to satisfy the wants of the system; and nature has accordingly furnished us with an appetite for it. The salt, therefore, which we consume at our table as a condiment, in reality serves other and far more important purposes in the animal economy than that of merely gratifying the palate. It is a necessary article of food, being essential for the preservation of health, and the maintenance of life.

It forms an essential constituent of blood, which fluid doubtless owes many of its important quali. ties to it. 'I'hus it probably contributes to keep the blood corpuscles unchanged; for when these are put into water, a powerful and rapid endosmose takes place, in consequence of which they swell up and assume a globular form; whereas in a weak solution of salt they remain unchanged. In maliznant cholera, and some other diseases in which there is a deficiency in the saline ingredients of the blood, this fluid has a very dark, or even black appearance; whence it has been assumed by some writers that the red color of the blood is dependent on the presence of its saline ingredients. From the salt of the blood, aided by water, the gastric juice derives its hydrochloric acid, and the blood and the bile their soda. The soda which exists in the blood, in combination with albumen, passes out of the system in union with organic matter, represented hy chloric acid. In other words, bile contains the elements of chlorate of soda, though not necessarily arranged as such. Lastly "the soda" which has been used in the vital processes, and any excess of soda, must be expelled in the form of salt, after being separated from the blood by the kidney.-Liebig.
} 
and ginger. The author has used the following preparation with considerable success :

Iodine (reduced to powder).........4 scruples.

Proof Spirit. ................... 4 ounces.

Tincture of Capsicum, or Ginger.....6 66

Dose, one ounce, twice a day, in thin gruel.

Another:

Hydriodate of Potass............20 grains.

Dissolve in a pint of water; then add one ounce of tincture of ginger. To be repeated daily.

Such are the remedies on which our hopes of cure are to be founded. They are not to be given conjointly, but separately, as the various stages of the disease indicate.

Should the horse's hind limbs be enormously swollen, so that he cannot move about without inconvenience and pain, then the following drench must be administered:

Powdered Socotrine Aloes..........4 drachms.

Tincture of Gentian.............4 6

Sweet Spirits of Nitre............ " "

Syrup of Garlic....................... ounce.

Mix.

Flour Gruel.................. 1 pint.

It will probably not be necessary to repeat this dose. In fact, we should not recommend the aloes, were it not that the horse is now unable to seek an equivalent in the pasture, and the grave nature of the case calls for some agent capable of producing a change in the system, diverting the fluid (which is now accumulating in the cellular tissues of the limbs) from the parts to the central membranes. Lest we may not be understood by the reader (non-professional), we remark, that aloes act as a mechanical irritant on the alimentary surfaces, and a copious secretion of fluid from those surfaces always follows the exhibition of drastic medicine.

The swollen, hot, and tense state of the limb calls for some local application. We therefore first wash the parts with a weak ley of saleratus, and afterwards apply astringents, composed of a strong infusion of one of the following articles: Bayberry, white oak, nutgalls, gum catechu. Bandages moistened with equal parts of vinegar and water, form a good evaporating, cooling lotion, when pain and inflammation are evident. Yet, after all, voluntary exercise, such as the animal will take while procuring food in the pasture, will generally have a better effect on a tumefied limb than all the local applications we can make.

The local treatment of farcy buds is a matter of importance; for the discharge from them is sometimes so corrosive, irritating, that it destroys the surrounding skin and sub-cellular parts. White, and some other writers, recommend the most destructive poisons as topical applications, such as corrosive sublimate, muriatic acid, lunar caustic, red precipitate-in effect, no doubt, setting up a worse disease than the one already present. In such articles we have no faith. On the contrary, we consider them first-rate poisons, capable of altering, and, in a great majority of cases, destroying one or 
more of the functions necessary to the support of life. The following will form the best local application we know of:

Pyroligneous Acid................ pint.

Tincture of Blood-root.............. gill.

Linseed Oil........................ "6

Mix, and wet the farcy buds with it morning and evening.

\section{SPLENT-ITS NATURE, CAUSE AND TREATMENT.}

The term Splent, or splint, as it is sometimes called, is derived from the Italian word spinella, a splint-a name properly belonging to those small bones, at the posterior parts of the cannons, known, in the fore, as small meiacarpal, and on the hind extremities as metatarsal; they being considered by some persons, as splinters of the main or cannon bones. The name of the bone is, therefore, erroneously transferred to the disease, the proper name of which should be exostosis, (a morbid enlargement or tumor of bone.) The splent bones answer a useful purpose in the animal economy; - they are designed to receive a portion of the weight of the body, and aid the cartilages of the knee in guarding against concussion. They are united to the cannon by a fibrous cartilage, which admits of slight motion, upwards and downwards; in the disease called splent, the articulating cartilages become ossified, (changed into bone,) the function of the part is destroyed, and all motion, or elasticity, ceases. As no hopes can ever be entertained of changing bone into soft tissue, we may, without fear of contradiction, assert that Splent is incurable.

CAUSe of Splent.-Overworking a horse, or hard galloping, by which any undue or sudden pressure is brought to bear on the splent bones, whereby the fibrous cartilage is stretched, strained, or lacerated, so as to produce inflammatory action, and subsequent osseous effusion, may be regarded as exciting causes. Trotting young colts by the side of their mothers, and imposing on them heavy burthens at too tender an age, are practices, considered operative in producing this mischief. Mr. Percival, the best authority on this subject, writes: "Over-work, over-action, at a tender age, is the ordinary cause of Splent. In the anxiety there is to bring young horses into use, in the precocious practice of breaking, \&c., we cannot feel surprised at unperfected parts giving way, or being reconstructed in a different manner from the original design. Nature is forced beyond her powers, and finding that the soft and elastic material, placed for a certain wise purpose between the splent and cannon bones, insufficient against weight and force, osseous material is substituted for it. Even before breaking or using the colt commences, the mischief may be perpetrated. A gallop, jump, or gambol, in the field, or yard, may occasion a Splent. Again, a blow, or other external injury, may produce a Splent, though this is comparatively a rare case. To whatever cause, however, it be referable, the fact is notorious enough, that hardly any horse completes his fifth year witbout Splent, latent or demonstrable."

So far as regards American horses, the disease is far from being uni- 
versal, and this may be owing to the difference in our roads, which, contemplated as a whole, are more easy for travel, than those of England. Still we have enough cases of this disease among American horses, to excite our attention.

Does Splent constitute unsoundness? I think not; because it is seldom associated with perceptible lameness, and so long as the horse can perform the duties of an ordinary horse, he is sound to all intents and purposes. I never knew lameness to arise from this disease. Should Splent, however, extend in an upward direction, and involve the knee bones, it must then occasion lameness.

The author just quoted sustains this opinion. He remarks: "There is an old notion very prevalent among unprofessional people, that splent often lames horses; and to the groom who thinks so, or to the veterinary surgeon, who prev ails upon himself to believe so, such a doctrine is often very acceptable and opportune, inasmuch as it serves to help him out of any embarrassment he may feel, to say for certain, where the horses' lameness is located. Young practitioners ought to be extremely wary how they pronounce a horse lame from Splent. They must never venture to do so, without unquestionable evidence that such is really the case.

Treatment of Splent.-When the Splent first makes its appearance, our object should be to lessen inflammatory action, and thus limit its development. Supposing it to arise from strain or overwork, rest, cold water, refrigerating lotions, and bandage, are the most rational means. Should it really occasion lameness, no better course can be pursued; therefore, we are justified in resorting to it.

If the tumor becomes very large, so as to be, not only an eye-sore, but also interfere with the action of the limb, an operation must be resorted to, which can only be performed by a medical man. But the reader must bear in mind that Splent cannot be cured; yet the horse may be relieved of the lameness.

\section{SPAVIN - ITS NATURE, CAUSE, SYMPTOMS AND TREATMENT.}

There is a sort of irregular, or incomplete spavin, which may exist without accompanying lameness. It is found just beneath the bones composing the hock, in the form of a knotty tumor, technically called exostosis; in common language, a "jack." In such case the mechanism of the joint is not involved, hence, absence of lameness. But the animal may from overwork, or sprain, become lame in a joint remote from this; the owner or attendant not possessing the requisite skill to discover the precise seat, finds a tumor at the point indicated, and immediately pronounces the horse spavined, and this serves as an excuse for adding to the poor brate's sufferings the torture of fire; during the rest which necessarily follows the application of the same, the original lameness disappears, and this furnishes an illustration of one of the boasted cures of spavin, which disease in reality never existed.

Natuiz or SpatrN.-In order to comprehend this, the reader 
should know, that the joints of the hock are composed of several bones, two of which form the joint proper, the remainder, eight in number, are concerned in the articulation and composition of the same. Between each bone is inserted a cartilaginous cushion for the purpose of warding off concussion, and thus preventing injury to the bones, which would otherwise occur. These bones have all their proper capsular membranes, which separate one from the other, making them distinctive points. A synovial membrane pervading the whole, furnishes synovia, ("joint oil") which successfully guards against friction.

Spavin generally originates in inflammation of the periosteal tissues, (membranes proper to all bones-their external covering, or else, in the ligamentary, or cartilaginous structures, contiguous, or within the joints. A high grade of inflammatory action, pervading for some time, causes absorption of the cartilages between the small bones, they become consolidated and immovable. This cartilage being changed into bone, cannot possibly be restored, and is therefore incurable.

Spavin having, in this manner, an internal origin, is not perceptible; consequently, some persons are unwilling to admit its existence until they can both see and feel it. If it shall commence externally, (on the inside of the hock) in the form of encrustation, termed exos. tosis, which is very often the case, all doubt is at an end. In plain language, spavin consists in a loss of motion, between parts that were once movable, and may exist with or without bony tumor.

If a student were asked the question, What constitutes a spavin? he would answer, "Anchylosis and exostosis of the tarsal (hock) bones." Ask him if it can be cured, and he utters a decided "No." He only mitigates the lameness.

The malady is similar to that occurring among children, known as hip disease, when the head of the thigh bone unites to the pelvis; and $\mathrm{n}$ ( one pretends, at least never succeeds, in effecting a radical cure. But, as regards the horse, the disease is more complicated, because a greater number of bones are involved; yet in effect, the disease is less serious, because it does not prevent flexion and extension of the joint proper.

In a very brief manner I have now considered the pathology or ncture of spavin, much interesting matter (and really valuable to students) is necessarily omitted, in order to render the article brief as possible.

Cause of Spavin.-Its pathology demonstrates inflammation of one or more tissues proper to the point, which is produced by overwork, sprain or concussion; the tumor and transformation of the cartilages into bony substances, always being preceded by lameness, indicates injuries of this character, yet they are not in all cases operative ; for some of our truck horses, especially those used in shafts, are often compelled to perform extraordinary feats of strength, that would in ordinary horses induce ligamentary lameness, ultimately resulting in spavin, yet they are remarkably free from it; the reason is, they are free from predisposition.

It is a fact, well known to the profession, that many spavined horses labor under either local or constitutional predisposition. 
Local predisposition is determined by a short-pointed hock, lengthy cannon, and upright pasterns. This is the kind of hock that is most subject to strain, in backing heavy loads, and concussion, while galloping, or trotting fast on hard pavements.

Constitutional preclisposition exists in breed, and is inherited from sire or dam. A spavined mare transmits the disease, of which we have evidence in colts that have never been brole. But in the majority of cases, spavins are indirectly transmitted in the form of a weak, fragile, bony structure, which is prone to throw out osscous (bony) effusion. Such animals are often termed overgrown, from the fact that their frames have outgrown their strength ; consequently, they are unable to bear heavy burthens, without strain or injury to the joints. The bones of horses predisposed to ossific effusion, in the form of spavin, splint and ringbone, are remarkably light, porous and brittle; and on inspecting the same, we wonder how they have supported even the carcass of the animal.

The reader has probably noticed in cattle large bony tumors under the jaw, called osteosarcoma, which finally end in caries, (death of the bone, and others, located on the hock and on various parts of the shaft bones; these appearing without any apparent cause, illustrate what I mean by ossific diathesis, or constitutional predisposition.

We may safely conclude, therefore, that spavin originates from predisposing and exciting causes, acting conjointly, or otherwise.

Symptoms of Spavin.-These vary according to the nature and intensity of the attack; yet there are some, always present, so that a man of ordinary observation can readily discover the seat of the lameness.

The First is, heat and tenderness on the inside of the hock.

Secondly. Inability to flex the hock with perfect freedom, the act being accompanied with a sort of "catching up," or spring-halt motion. Spring-halt is a remarkable feature of spavin, and it has been noticed by several writers, Simaspeare, for example, thus refers to it:

"One would take it,

That never saw them pace before, the spavin

And spring-halt reigned among 'em."

Thirdly. The animal starts stiff and lame, "planting" his toe on the ground, rather than the heels; he improves, however, after a short drive.

Fourthly. The above symptoms connected with a tumor on the inside of a hock, in the region of the small tarsal bones, exclude all doubt. Yet the tumor, as I have just observer, is not necessary to make out a case of what is technically called inter-articulcir spavin.

Treatment of Spavin.-No man can possibly succeed in curing spavin. We may palliate-relieve lameness-and hasten anchylnsis, (stiff joint,) and render the subject useful for certain purposes, but there will always exist a certain amount of stiffness about the joint, which is considered unsoundness, and a hard trot will often induce temporary lameness.

In the treatment of sparin, we borrow an illustration from Naturc - the best and wisest of doctors-she strengthens a weak joint, by 
making it solid and unyielding, and this must be our object in its treatment.

Medical men always have this object in view, viz., to produce anckylosis, to hasten ossific effusion, and render the sensitive tissues insensible.

In the early or inflammatory stage, rest, and cooling lotions are indicated. In the latter stage, counter irritants, such as preparations of cantharides, \&c., are generally resorted to.

The reader, if he be in any way interested in the welfare of "live stock," will probably appreciate the value of correct information regarding the nature and cause of the discase. For in the first place, it aims a death blow at ignorance, quaclsery, and cruelty, practiced very frequently under the guise of science; between which, however, there exists less affinity than between oil and water.

In the next place, it enables him to adopt preventives, by which the chances of disease are lessened.

It teaches him that physical defects are as certainly transmitted as good points, and although bad qualities are not always directly transmitted, yet the day of reckoning appears in a future generation, just as surely as like begets like.

The most popular remedy, now in use, for the treatment of Sparin, is the acetate of cantharides. The American Magnetic Liniment, manufactured by Messrs. Lord \& Smith, of this city, is also a very excellent remedy for the treatment of both Splent and Spavin.

\section{INFI,AMMATION OF THE KIDNEYS.}

Symptoms.-The animal is feverish, his pulse is quick; he strains when urinating, has a straddling gait, and the urine is high colored, sometimes tinged with blood; when slight pressure is made over the region of the kidneys, the animal manifests symptoms of pain.

Treatment.-Feed the patient lightly, and give him one wineglass full of fluid extract of buchu, night and morning.

\section{HAMATURIA, OR BLOODY URINE.}

This discase preceeds fiom a disease located in the mucous membrane of the kidneys and urinary passage. Oceasionally the disease results from plethora, but is often brought on by the action of diuretics.

Treatment.-Give the patient twice, daily, a wine-glass of fluid extract of buchu, in a pint of infusion of slippery elm. 


\section{SUPPRESSION OF URINE.}

Suppression of the urine is often the result of spasn of the urethra, and usually disappears soon after the exhibition of the following:

Sweet Spirits of Nitre ........... $1 \frac{1}{2}$ ounces.

Powdered Gum Asafœetida .........2 drachms.

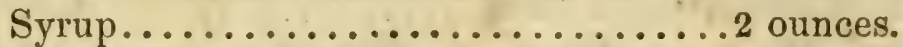

Mix; and drench the patient with the same. The dose may be repeated at the expiration of one hour, if necessary.

In cases of flatulent and spasmodic colic, the animal is often unable to urinate. In this event, the catheter should be introduced, and the urine drawn off.

Enemas of warm water thrown into the rectum, often tend to relax spasm, and favor the evacuation of the accumulated urine.

\section{DIABETES, OR PROFUSE DISCHARGE OF URINE.}

In this affection it will be noticed that the horse passes a va $\mathrm{s}$ quantity of urine, out of all proportion to the quantity of water drank; the stall floor is continually wet, and the animal is usually very thirsty. The cause of this disease, in the horse, is rather obscure.

Treatment.-Give the patient one wine-glassfull of fluid extract of buchu, and to each dose add ten grains of iodide of potass. Some change in diet will be necessary, and it should be of the very best quality. I sometimes use fluid extract of styllingia instead of buchu.

I find that carrots have a very good effect on animals suffering from diabetes.

\section{ALBUMINOUS URINE.}

In a disease of this character the urine is loaded with albumen, is thick and clear, and if a portion of it be submitted to the action of heat, it coagulates like the white of an egg.

Treatment.-Prepare the following:

Fluid Extract of Buchu............8 ounces.

Chlorate of Potass ................ "6

Tincture of Sassafras Bark..........4 "6

Mix. Dose: one ounce night and morning.

\section{THICK AND TURBID URINE.}

It is often noticed that horses pass urine of a thick and turbid character. This is occasioned by a morbid condition of the body, and is sometimes an effort on the part of nature to rid the system of morbiâc material. 
The discharge of morbid urine generally tends to the restoration of health, and the treatment necessary is, to give the patient some medicme of an alterative and tonic character. The following is an example:

Powdered Golden Seal............4 ounces.

Todide of Potass ............... "6

Powdered Poplar Bark............6 "

Mix. Divide into twelve parts, and give one every night in the food, or in a bran mash.

If the above medicine cannot be obtained, the American Magnetic Horse Powders may be substituted. (See last page).

\section{NAVICULAR DISEASE.}

Navicular disease consists of deep-seated injury within the hoof, often involving the navicular or shuttle bone. The injury may arise from sprain, contraction of posterior walls of the hoof, from puncture of the sole, from an ulcerated state of the bone, and may be the sequel of laminitis.

The principal symptoms of navicular disease are, acute lameness; the foot is pointed forward when the animal is at rest; and when traveling he takes short steps, and is unsteady in his gait.

Treatment.-Should the hoof be contracted, the quarters are to be rasped quite thin, so as to remove the pressure from the sensitive parts. The following preparation is then to be applied to the hecls until they are well blistered:

Powdered Spanish Flies..........4 drachms.

Raw Linseed Oil ...............6 ounces.

Mix. Apply by means of a sponge, and keep the hoof lubricated with neatsfoot oil.

It must be remembered, however, that the blister is not to be applied to the heel until the inflammatory process has subsided; while there is perceptible heat and fever in the foot it must be bathed often with cold water.

A horse lame from navicular disease must be excused from duty, and it may take many months to restore the animal to usefulness.

\section{TO PROTECT-ANTMALS AGAINST THE TORTURE OF FLIES AND INSECTS.}

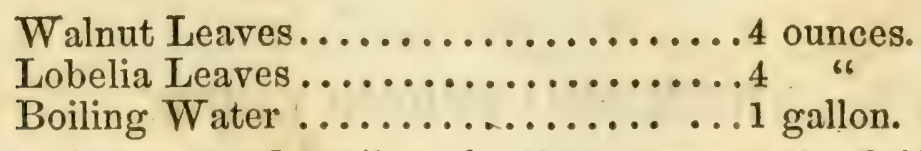

Let the mixture stand until cool; then express the fluid through cotton cloth, and add four ounces of the tincture of aloes.

Drrections. Apply a small quantity of this compound, daily, to the surface of the body, by means of a sponge. 


\title{
ANTIDOTE FOR THE BITE OR STING OF VENOMOUS REPTILES.
}

\author{
Plantain Leaves (plantago major) .....4 ounces. \\ Lobelia Leaves .................2 "6 \\ Boiling Water ................. quart.
}

Direcrions. When the mixture becomes cool, bind a quantity of the herb on the affected part, and give the animal, as a drench, four or five ounces of the remaining fluid, every four hours.

\section{THE ENDURANCE OF HORSES.}

Some curious experiments have been made at the Veterinary School at Alfort, by order of the Minister of War, to ascertain the endurance of horses-as in a beseiged town, for example. It appears that a horse will live on water alone twenty-five days; seventeen days without eating or drinking; only five days, if fed but unwatered; ten days if fed but insufficiently watered. A horse kept withont water for three days, drank 104 pounds of water in three minutes. It was found, too, that a horse taken after being fed and kept in the active exercise of the "squadron school," completely digested its "feed" in three hours; in the same time at the "conscript's school," its food was two-thirds digested; and if kept perfectly quiet in a stable, digestion was scarcely commenced in three hours.

\section{SPRAIN OF THE FETLOCK.}

This is a very formidable lameness, and also a very painful one, and when a horse becomes the subject of it he should be immediately excused from duty, for every movement of the parts only aggravates the difficulty. I have found the following liniment to be of great value in the treatment of all recent sprains:

Olive Oil..................... pint.

Gum Camphor ..................2 ounces.

Laudanum..................... "6

Sulphuric Ather ................. "6

Dissolve the camphor in the rther, then add the oil, and lastly the laudanum.

In some cases of severe sprain of the pastern, or fetlock, I have known cold water bandages to have a very marked effect in moderating the pain and inflammation of the parts.

\section{TO RELIEVE MUSCULAR PAIN IN HORSES.}

The datura stramonium, or thorn apple plant, is a very excellent remedy, as an external application, for the treatment of muscular 
pain, ligamentary lameness, sprain of the fetlock, \&c. It is a remedy of great efficacy in chronic pains and inflammatory tumors. Four ounces of the plant to one pint of boiling water, are the proportions. When cool, the parts are to be bathed often; when practicable, a flannel is to be saturated with the fluid and bound on the affected parts; the whole to be covered with oiled silk.

\section{HORSES SHOULD BE EXERCISED DAILY.}

Horses require daily exercise in the open air, and can no more be expected to exist without it than their owners. Exercise is an essential feature in stable management, and, like well-opportuned food, tends alike to preserve the health of horses.

Daily exercise is necessary for all horses, unless they are sick; it assists and promotes a free circulation of the blood, determines morbific matter to the surface, develops the muscular structure, creates an appetite, improves the wind, and finally invigorates the whole system. We cannot expect much of a horse that has not been habitrated to sufficient daily exercise; while such as have been daily exercised, and well managed, are capable not only of great exertion and fatigue, but are ready and willing to do our bidding at any season. When an animal is over-worked, it renders the system very susceptible to whatever morbid influences may be present, and imparts to the disease they may labor under, an unusual degree of severity. The exhaustion produced by want of rest is equally dangerous; such horses are always among the first victims of disease, and when attacked their treatment is embarrassing and unsatisfactory.

\section{VALUE OF CARROTS.}

Carrots are very excellent "fodder" for horses that have been long kept on highly carbonaceous food, and whose digestive organs may be out of order in consequence of their constant activity in reducing meal and oats into the elements of animal nutrition. With a fair allowance of carrots, ground oats, and sweet hay, a horse will enjoy good health and spirits, have a loose hide, shining coat, and healthy lungs. A daily allowance of carrots should always be furnished to horses, the subjects of indigestion; whose food often runs into fermentation, inducing diarrhoa, or a lax, washy state of the bowels. Carrots furnish an acid called pectic, which possesses the curious property of gelatinizing the watery contents of the digestive cavities. A few drops of this pectic acid will gelatinize both, and when mixed with the juice of an orange, changes the same into jelly. So that if the alvine discharges of a horse are watery, carrots can be used as a valuable therapeutic agent, both in view of arresting the same and restoring the tone of the stomach and bowels. By examining the excrement of a horse, fed in part on carrots, it will be found to contain no undigested hay nor oats, and therefore we may safely infer that they promote digestion, so that by the constant use of carrots, less quantities of hay and oats will suffice than when a 
larger amount is consumed, and parted with, in an undigested state. For fattening animals, carrots are exceedingly valuable. It will be urged that carrots are not very nutritious - that may be; still, if they possess the property of gelatinizing the contents of the stomach and bowels, they aid in the manufacture of fat out of other food, which might, otherwise pass out of the system.

It is said that the milk of a cow in mid-winter, fed on carrots, is equal in flavor to that supplied from clover in summer, while the butter made from such milk presents a rich orange color, and does not taste, as some persons suppose, of the peculiar flavor of this vegetable. Two buslicls of oats and one of carrots is better food for a horse than three bushels of oats without carrots, and when the animal is used for light work only, the quantity of carrots may be increased.

The reader must bear in mind, however, that animals, like ourselves, have their peculiar idiosyncracies or susceptibilities-_" what is one man's food is another's poison" - and some might digest, and thrive amazingly, on a given article of food, while an equal number shall lose both flesh and spirits. There appear's, however, to be less objection to the juclicious use of carrots than many other vegetables, both as regards horses and cattle.

If the reader happen to have what is termed a "siall-fed horse, and the same shall be the subject of heaves," (sometimes a symptom of indigestion, only), let them take away the fine meal and substitute carrots, and, my word for it, the horse will improve.

\section{ON THE STRUCTURE AND FUNCTION OF THE LIVER OF THE HORSE - ITS DISEASES, \&C.}

The liver of the horse is situated between the stomach and diaphragm, in what is known to anatomists as the epigastric and hypochondriac regions; it is confined in this situation by means of what are termed its ligaments, which are chronicled as five in number. Anatomically divided, the liver is convex on its front or anterior surface, concave on its back, or posterior, and has clefts which divide it into three lobes of unequal size.

The chicf mass of the liver is made up of colls, like many other parts of the body; and these cells are placed in the vicinity of the terminations of the portal veins, from whence the former derive their blood.

The liver has a covering, common to all the organs contained in the cavity of the abdomen, known as the peritoneum, a beautifully transparent membrane; it plays an important function in the animal economy, inasmuch as it furnishes the means necessary to guard against friction, which would otherwise occur, to the utter ruin of the contiguous parts.

It was formerly supposed that the function of the liver was merely to eliminate bile from the renous blood, and thus it reccived the appellation purifier-a purifying organ-but modern physiologists have discovered that the blood itself is materially changed during its cinculation through the vessels of the liver; for example, the liver 
claborates febrine from albumen, and fat from sugar, and sugar from fat. The fact in relation to these agents, sugar and fat, is, they do not materially differ in their chemical composition, only that one contains a little more oxygen than the other; and, from satisfactory data, we are led to infer that the liver occasionally stores up fatty matter, or sugar, for the day of adversity, or starvation day, so that when the system has no other means of obtaining it the liver must supply it, or yield up what it contains of fatty matter.

The circulation of the liver is a very interesting matter for the investigation of amateurs and inquirers. The liver, like other organs of the body, is supplied with arterial blood, from the great aorta, for its own support and nourishment, and it also receives an immense amount of venous blood from veins commeneing in the gastro-intestinal cavities, terminating in a vessel known as the vena portce, or "gate vein." Portce is dcrived from the Latin, which signifies "gate," or " entrance." The vena portce, on entering the liver, ramifies in various directions like the common arteries of the body, and ultimately terminates in veins peculiar to the liver. Hence, it will be perceived that the venous blood, instead of being permitted to return directly from the stomach and intestines to the heart, is compelled to complete the cireuit of circulation through the liver, and by this peculiar arrangement the transformations alluded to are effected. The lirer, therefore, performs the double function of excretion and secretion; secretes gall or "bile," and excretes carbon and hydrogen from the system.

As regarde the Diseases of the Liver. It is probable that the liver often becomes diseased in consequence of overfeeding; it is well known that the livers of men and animals can be artificially enlarged, by cramming either with an unnecessary amount of food; favorite dishes are often prepared from the livers of geese artificially enlarged, by stuffing the animal with food, and at the same time confining it in a dark room without exercise. We learn that under such barbarous management there is a disproportion between the oxygen respired in the lungs, and the carbon introduced into the system in the form of food. An excess of carbonaceous material in the system of man or horse, is apt to affect the integrity of the liver and develop the condition known as jaundiee, and this cause is more certainly operative in the systems of animals of the bilious temperament.

Jaundice, as it occurs among horses, is usually a functional disorder, yet should it remain unrelieved for some lapse of time, and the same errors of diet and management be continued, the chances are in favor of its ending in structural disease. Occasionally the bile thickens and accumulates in its ducts, and leads to the formation of gall stones, which finally occasion the death of the subject.

The principal symptoms of liver disease are a yellow tinge of the visible surfaces ; languid pulse ; dull, sleepy appearance ; urine highcolored; excrement dark-colored; bowels constipated, \&c. \&c.

Common salt is a valuable agent in preventing bilious diseases, for salt undergoes oxydation in the system and forms soda, and this soda is employed in the formation of bile. Bile consists of carbon, hydrogen and soda; its carbou and hydrogen are the carbon and 
hydrogen that are thrown, as waste material, into the blood by the destruction or decomposition of textures containing these elements. The waste carbon, and a considerable portion of the waste hydrogen of the body, are separated by the liver from the returning venous blood, and are then thrown out into the boweis in the form of bile.

Bile can be converted into a sort of soap by the addition of soda, which fact indicates that we should use soda, or salt, in the treatment of liver diseases. The reader is probably aware that common salt is nothing more than soda combined with chlorine, and that soap is merely oil mingled with potass or soda.

Salt is considered as a specific for " rot" in sheep. The disease known as rot, originates in a diseased condition of the liver, which gives origin to parasites known as flukes (distoma hepaticum), hence it is good policy for sheep raisers to see that their flocks have free access to salt.

Very many unnecessary cases of liver disease, and premature deaths, in consequence, are constantly occurring, which may often bo traced to errors in diet, therefore I advise all persons having charge of domestic animals, not to over-feed. This part of the United States in which I am now located is the great corn-bin of the country, and there is great danger of men (who love to see their animals in good condition), dipping their hands too deep into the pile of corn, to the sure and certain ruin of many fine specimens of the horse kind.

Gall Bladder. I presume that most of my readers are acquainted with the fact that the liver of the horse is destitute of a gall bladder; yet on the upper and inner edge of the right lobe is a small duct, just large enough to admit of the introduction of a common sized pencil; this duct receives many small ducts from tubes from the interior of the liver, and through them the bile finds its way into the main duct, and from thence into the duodenum.

Treatment of Functional Disease of the Liver.-The indications to be fulfilled, in the treatment of this affection, are to administer agents which are likely to have a tonic and alterative effect, and in this view I recommend the following:

Podophyllum Peltatum............. ounce.

Carbonate of Soda ................

Chloride of Sodium.............. "6

Golden Seal...................... "6

Mix. Divide into 8 parts, and give one night and morning.

\section{ON THE MODES OF PERFORMING OPERATIONS.}

Securivg the Horse.-In performing most of the minor operavions on horses, the Rarey strap on one fore leg, and a twitch on the nose, are the means needed to insure submission. Sometimes, however, when performing operations about the region of the throat, and the patient being unruly, it will be necessary to blindfold him, so that if he should strike with the fore feet he cannot take aim; in this way the operator may escape a very severe blow. 
In some more important operations the side line is resortod to; it is applicable when nicking or docking a horse, that is disposed to strike behind. The side line consists in passing a hobble around the pastern of one hind leg, and then carrying from a loop around the neck the end of a rope, which is passed through the iron ring of the hobble, and then back to the loop where it is secured; this, when properly secured, prevents the horse from kicking; sometimes both hind legs are secured in this way. When eastrating, or performing any very important operation, the horse should be cast; some persons prefer to cast after the fashion of Rarey, and then secure the animal's legs when down. My plan is, to cast by means of plain and simple hobbles, one of which is buckled to each leg, below the fetlock; the rope is then rove through all the rings, and the ring through which the end of the rope comes last, is called the main hobble, and into it, the clasp end of the rope is to be inserted; a couple of persons pull on the rope which approximates the limbs, bring them under the centre of gravity, when a slight push will throw the horse on his side.

The surgeon is assisted much, when performing any important operation, by xtherizing the animal; this renders him insensible to pain, and he lies on the floor as tranquil as if he were asleep.

\section{OPERATIONS.}

Castration.-In the United States are a great number of persons who, from long practice, have made themselves quite competent in the performance of this operation, and, consequently, where the services of such persons are to be obtained, the veterinary surgeon is not often called upon. The most safe and successful method ever practiced in this country, is by means of the caustic clams or clamps, which are applied to the spermatic cord. The caustic lodges in a groove cut in the centre of the internal surface of the clams. The clams may be made of different kinds of wood, but it is said the "elder" wood is most preferable, as it already contains a groove, and is quite light when compared with harder wood. The canstic used in my practice, of late, is composed of one drachm of red precipitate, half a drachm of corrosive sublimate, and one ounce of simple ointment; these are to be well mixed; then fill up the groove in the wood with the same, and it is fitfor use.

When the clams are applied to the spermatic cord, they should be brought together by means of pincers or screw forceps, so as to secure complete pressure on the arteries and thus prevent after bleeding. The clams may be removed about sixteen or twenty hours after the operation.

When it is suspected that the animal has, or may, become the subject of scrotal hernia, the covered operation is to be performed, then the clam is placed outside the external peritoneal covering of the cord.

Mr. Goodin, a celebrated castrator, always performed the covered operation.

I have often performed the operation by placing a ligature around the cord, but I think that it is rather more painful than to apply the clams. 
Operation for Stone in the Bladder.-This operation, known as lithotomy, is usually performed on the male by making an incision into the urethra. We first introduce a whalebone staff or urethral catheter in the ordinary way by the penis; when the point of it can be felt, just beneath the lower margin of the anus, an incision is made right into the urethra; this opening must be enlarged so as to admit the lithotomy forceps, and allow the stone to be extracted; the operator now introduces the forceps into the bladder, seizes the stone and extracts it; the incision is then brought together by a few stitches.

Tracheotonr.-Tracheotomy consists in making an incision into the windpipe; the place selected for the operation is from seven to ten inches beneath the throat. In performing the operation an incision is to be made through the skin right down upon the windpipe. then slit open the windpipe to the extent of two inches, and insert the tracheotomy tube; should the instrument not be at hand, insert a piece of India rubber tubing until a bent tube can be obtained. Some surgeons prefer to dissect a circular piece of cartilage, which must correspond to the calibre of the tube. I have performed in both ways and have no preference.

It is necessary to perform the operation when the danger of suffocation becomes imminent, either from the presence of tumors in strangles, obstructions within the larynx, spasm of the larynx, and sometimes when an unswallowed substance remains in the œsophagus and threatens to choke the animal; although in the latter case it may be more prudent to open the œsophagus, or gullet.

CEsophagotomy.-This operation consists of an incision throngh the skin and gullet, on the left side of the neck. It is usually performed when a large quantity of food obtains a lodgment in the œsophagus. The mode is to operate, or cut down, upon the centre of the impacted food and remove it; after sponging the parts with warm water, bring the edges together by means of sutures, then wipe the parts dry, sprinkle with flour, and dress with collodion.

After an operation of this kind, the patient should be sparingly fed on sloppy food.

Neurotomy.-This operation consists in a division of the sentient nerves of the foot; there are two modes practiced in performing it. In one case the metacarpal nerves above the fetlock are dividedthis is called the high operation; in the other, the nerves beneath the fetlock are the seat of the incision and division, and this is called the low operation, which latter I believe is the most rational one.

In performing this operation, we cast the horse and secure him; one fore leg at a time is then released from the hobble, a welling or small rope is then placed around the hoof, and firmly held by an assistant. The nerve lies in close proximity with the perforatus tendon, which is a sure guide to its locality. The hair being shaved off at the precise spot, an incision through the skin and cellular tissue exposes the blood vessels and nerve; the latter may be known by its whiteness. A needle or bistoury is then passed under the nerve, 
and the nerve is divided. It is customary to amputate a small piece from that part of the nerve next the foot, so as to prevent immediate reunion. If both feet are to be operated on, the nerve on the same side of the other foot may be divided; then roll the horse over and operate on the other sides of the feet.

Drvision of the Flexor Tendons.-Division of the flexor tendons of the fore limbs is usually performed in view of curing "sprung knees;" which are often the result of contraction of the annular ligament, which ties down the flexor tendons just below the knees, or it may be occasioned by contraction of the tendons themselves.

The tendon, or tendons, once divided, and their surfaces kept apart, by a mechanical contrivance appended to the toe of the shoe, interstitial deposits are thrown out, and when the parts are again united, length has been acquired, and in some cases the animal is much benefited and his usefulness increased; it would not be good policy, however, to operate on an aged horse; it is only when the operation is performed on young animals that it is likely to be of any benefit. One or both tendons may be divided without the least danger; the strong suspensory ligament inserted at the upper part the cannon passes down at the back part of the same, and is so disposed of at the fetlock that it is impossible for the parts to give way, notwithstanding the temporary loss of function of the flexors.

When about to perform this operation, the horse should be cast, and secured; then make a small incision along the inner edge of the flexors, about midway between the knee and fetlock, introduce a probe-pointed bistourie with convex edge, and by a sort of sawing motion, sever one or both tendons; an assistant, however, will be required to keep the limb rigid while the tendons are being severed, or they cannot be cut without doing some injury to other parts.

The operation finished, a cold water bandage is to be applied, and the horse should then be allowed to rise.

The heels should now be pared very thin, and a toe piece tacked on, having a projection in front, which will keep the divided edges of the tendons apart.

Operation for ANERUISM.-Aneurism is a pulsating tumor filled with the arterial blood; it usually arises from the rupture of the muscular coat of an artery and dilatation of its cellular covering. The only plan of curing is to cut down upon the artery and place a ligature around it.

Operation for Fistula of the Parotid Doct. - A fistulons parotid duct signifies an unnatural outlet for the saliva secreted by the parotid gland; instead of the fluid passing into the mouth, it now, in consequence of a wound just below the ear, runs outwardly down the neck and face. The old method of treatment was very barbarous, the budding iron was the instrument with which the unfortunate creature was tortured, and it very seldom did much good.

The modern treatment is more rational; it contemplates a closure of the fistulous opening without doing injury to the surrounding 
parts. The method is as follows: Send a steel pin throngh the edçes of the orifice, and wind horse hair around it after the fashion of closing an orifice in the jugular vein; having done so, keep the parts coatcd with collodion.

\section{DESCIRTTION OF THE HEART OF THE HORSE.}

The heart of a horse is a powerful and wonderful piece of mechanism; its function is of the involuntary order, so that regular contractions and expansions, or beatings occur in the normal state, without the animal being conscious of the same; these contractions and expansions, however, can be modified, by means of various medicinal agents which act upon the nervous system, thus producing a sort of mixed action-voluntary and involuntary-all medicines known as sedatives, operate to depress the action of the heart, and lessen for a certain time the number of its pulsations; while on the other hand, stimulants augment action, and increase the number of beats.

The weight of the heart is about seven pounds, yet considerable variations in this weight will oceur among the varions breeds of horses, even at an adult age. For example: A horse having a coarse and gigantic, bony, and muscular organization, will be likely to bo in possession of a much larger heart than a compact horse of the nervous temperament, even although both shall be of the same age.

The interior of the heart is divided into four eavities, two of which being in the superior and anterior direction, and in consequence of bearing some resemblance to the external conformation of the ears of a dog, are termed auricles ; the auricles, therefore, should be known as the superior cavities of the heart. These cavities are known as right and left, or rather anterior and posterior; their division occurs through the intervention of their septum, or wall of muscle, known as the septum auriculorim.

The right auricle is the receptacle for venous blood, and three venous trunks terminate in it, viz., the anterior vena cava, which returns the venous blood from the anterior extremities, head and neck-next, the vena cava posterior, which returns the venous blood from the posterior parts, and lastly, the coronary vein; the latter returns blood which has circulated through the heart itself for its own nourishment. A considerable quantity of dark venous blood is generally found in this auricle after death, and it opens into the right or anterior ventricle, by an aperture denominated the auriculo-ventricular opening, yet in consequence of a valvular contrivance within the ventricle, the blood cannot recede into the auricle.

Internally, the right auricle is lined by a glistening vascular membrane, having on various parts of its surface, small muscular eminences, termed musculi pecunati, the small cavities which occur, in consequence of this arrangement, are termed cul-cle-sacs. The right, or venons ventricle, is also lined by a nicely organized membrane, and has beneath it several muscular prominences named carnce columnce which give origin to as many tendinous slips, which are known. as chordce tenclino, they are inserted into a fibrous membrane in the region of the articulo-ventricular opening, and then get the name 
(membrane included) valvuli tricuspis. The lateral contractions of this ventricle are aided by small tendinous cords having muscular origins from the wall and septum. The venous blood passes from this cavity into the pulmonary tissues for oxygenation, through the pulmonary artery, which emerges from the superior part of the ven-e tricle. At the commencement of the pulmonary artery are found three yalves termed semi-lunar; their function is to guard against a retrograde movement of the blood, so that it has no other channel than this which leads to the lungs.

The left auricle has scarcely any anatomical or structural differences from those observed in the right, although its cavity is smaller, and its walls are somewhat thicker than those found on the right. It receives the blood from the lungs, after purification, by means of the pulmonary veins, which have four openings into this cavity, tiwo proceeding from the right, and two from the left lobes. The left, or arterial ventricle, is the reservoir for arterial blood, which is destined to reanimate, replenish, and perpetuate the vital economy; having a vastly more important function to perform (which requires augmented muscular mechanism, than its duplicate found on the right side, the thickness of its walls must, therefore, necessarily exceed those of the right; this is found to be the case, so that the outer wall of this cavity is about three times as thick as that found on the other side, and this guide is useful to us in determining, at sight, after the heart is detached from the body, which is the left ventricle and vice versa.

The channel of communication between the left auricle and ventricle is named, as is the case on the opposite side, auriculo-ventricular opening; it is furnisbed however with only two, instead of three, valvular openings, termed valvula bicuspis or mitralis.

This ventricle is one of importance for our consideration, from the fact that the great aorta - the plastic hose, which seldom, if ever, requires cobbling or repair, here originates. Its margin or outlet is guarded by a complete set of valves, three in number, termed semi-lunar, similar to those found at the origin of the pulmonary artery. This ventricle is divided from the one on the opposite side by a muscular and tendinous partition, termed septum ventriculorum.

Form, situation, and attachment of the heart.-Its form describes that simulating a cone, having a body, base and apex; its base being in a superior direction, it follows, as a matter of course, that its apex has an inferior insertion downwards and backwards.

Situation.-The heart lies in the region occupied by the fourth, fifth and sixth dorsal vertebræ, right in the central region known as the cavity of the chest; its apex is inclined to the left side.

Attachment. - The base of the heart is attached to the anterior and superior portion of the cavity of the chest, by the venous and arterial trunks running to and from it, and these in turn have their immediate and intermediate unions with various tissues in the vicinity, which tend to keep the heart in its proper position and allow of some degree of motion. Above the roots of the large blood-vessels, and adhering to the pleura, commences the pericardium, a strong membranous sac, which contains the heart; this sac is attached to the sternum, and to a part of the tendinous portion of the diaphragm. Pericardium.-This tunic, ealled by butchers the heart-bag, is 
composed of two membranes, united together by cellular tissue; the external one is of a fibrous character, dense and strong; the internal is smooth and glistening, and very much resembles that found within the cavity of the chest, known as the pleura; its function is to secrete a fluid called the liquor pericardii ; this fluid being interposed between the internal surface of the pericardium and the membrane proper of the heart, guards against friction. It is within the pericardium that we occasionally meet with a disease known as hydrops pericardii.

\section{REASONS WHY HORSES DO NOT BREATHE THROUGH THEIR MOUTHS !}

The soft palate, as it is technically called, velum palati, is a sort of curtain affixed to the roof of the mouth, in the region of the palatine arch; it has a free edge which rests upon the epiglottis.* It slants in a posterior direction, so that anything in the shape of food coming from the mouth, raises and pushes it backward; but anything coming from the œsopbagus or trachea, pushes it forward and downward, closes it, and thus prevents all egress. So that air is expired and respired through the nasal outlet, and all matter vomited from the stomach must also be ejected through the nostrils. In the act of coughing, however, which is a spasmodic astion, the air returns in body and with force sufficient to raise the velum palati, so that a passage through the mouth is, at the moment, secured.

The mechanism of the soft palate is as follows: Its composition is nearly the same as that of the hard palate, yet it abounds more in glandular substance and muscular fibre; by means of the levator palati, its substance is raised. On the lateral and internal portion of the membrane we find bundles of muscular fibres, constituting a pair of muscles known as depressors, which aid in retaining the palate in its place, viz., on the epiglottis. From the above brief remarks the reader will perceive that it is not natural for a horse to breathe through his mouth.

\section{USE OF THE HARD PALATE, OR "BARS" OF A HORSE'S MOUTH.}

The palate of the horse's mouth is divided, according to custom, into two parts, denominated soft and hard. The soft portion runs in a superior and posterior direction, to the region of the base of the tongue, and serves to separate the mouth from the fauces.t The hard palate is marked crosswise by prominent ridges and furrows from side to side, which are called the "bars." They serve to aid in keeping the food within the mouth during mastication. Were it not for this contrivance (the horse's head being pendulous), it would

\footnotetext{
* Cartilage at the root of the tongue.
}

+ Fauces. The back part of the mouth. The soft palute is a mere expanded urula. It originates at the arch of the palate bone, where the hard palate terminates. 
be very difficult for the animal to retain food within the mouth during mastication. The hard palate is not very highly organized, nor so sensitive as some persons seem to suppose. It is said to be the seat of lampas, which is a mere state of relaxation, causing the folds or bars to appear tumefied, so as to be almost on a level with the upper incisors. For the removal of this painless tumefaction, a barbarous remedy is resorted to, viz., the actual cautery, ${ }^{*}$ an operation never necessary nor safe ; and, knowing these facts, no gentleman, I think, will ever allow so noble and useful an animal as a horse to be thus painfully used. Knowing as we do the function of the bars, and setting aside the barbarity of the actual cautery, such an operation must be injudicious, because it involves a loss of structure, and the bars are never so prominent as before. Aside from this, we are doing our very worst to create a sore mouth.

Structure of the Palate.-It is composed of epithelium (scarf skin), condensed basement membrane, mucous and areolar, or cellular tissue.

The mucous membrane makes up the greatest part of the thickness of the palate. Its sensibility, when compared with that of the skin, is very inferior. It seems to be better adapted for absorption and secretion than for the function of sensation.

While discussing this matter, we may as well inform the reader what is the best plan of treatment for tumefaction or relaxation of the palate, known as "lampas." The remedy is astringent lotions, and proper attention to stable management. A little powdered alum rubbed on the palate once daily, for a short time, will frequently effect a cure.

\section{CHOLERA IN ANIMALS.}

It is said that during the prevalence of cholera in Bromberg, horses were unusually subject to cholic and other intestinal affections, and sometimes passed blood with their evacuations.

\section{ROT.}

According to the best authorities, rot may be considered a parasitic disease. It is actually a state of systemic debility, the parasites abounding simply because the system is in a condition favorable for their development. The remedy is, equal parts of salt, sulphur, charcoal and ginger; the dose varying from a tea spoonful to five or six drachms occasionally.

\section{PLETHORA.}

Mr. Gamgee says, "The subject of plethora, especially with regard to the changes suddenly occurring in the blood from a variety 
of causes, calls for the most serious attention of reterinarians; and we may, in the course of time, unravel some of the mystery attending that very numerous class of diseases described by continental authors under the head "Carbuncular Affections," or different forms of anthrax. From the Latin carbo, the term carbuncular has been derived; and all the diseases thus designated have the peculiarity of inducing, or being attended by, a black or a very dark color of the blood. But this character is too vague to warrant the grouping together of many maladies distinguished from each other by very important signs and results."

\section{POISONING BY ARSENIC.}

The following case from my note book may furnish the reader some valuable information in view of saving the life of a horse when accidentally or maliciously poisoned by the destructive agent known as arsenic, or rats-bane.

Hrstory of the CASE.-The subject, a roan gelding, aged eight years, the property of Messrs. Flanders \& Eastman, of Boston, was employed in the capacity of a truck-horse, and used as a leader. On the 10th of August, 1861, a quantity of arsenic, packed in kegs not properly coopered, was landed on one of the wharves, and the above firm were engaged to truck it to the store of the consignees. While rolling the keg 3 on the truck, a quantity of the arsenic was distributed over the shafts, and before the driver was aware of it, the horse had gathered and swallowed a quantity of the poison. Immediately on discovering what the animal was about, the driver, with a gloved hand, removed from the tongue and lips as much as possible of the poison. The horse was shortly afterwards taken to the stable of its owner, when I was called to attend him.

Appearance of the Patient at the Stable. - The pulse, at the angle of the jaw, was quickened, yet scarcely perceptible; showing that the poison had acted as a sedative or depressor of the heart's function; respiratory action rather laborious; surface of the body rather chilly; lower parts of the limbs quite cold: visible surfices, viz., those of the mouth, nose and eyes, considerably injected or reddened; mouth hot, and the breath had a very bad odor. On applying my ear to the walls of the abdomen, I detected an actire rumbling noise.

Trentment.-Administered one pint of lime water, and the white or albumen of two eggs; the surface of the body was then faithfully rubbed with straw, and willing arms; and finally, a pint of lime water to half a bucket of pure water was placed before the patient, so that in case he should be thirsty he might satisfy that thirst, and at the same time introduce a portion of lime water within the stomach. It now being near midnight, I gave one ounce and a half of pure glycerine, and left the animal in charge of his owners.

Early on the following morning I found active purgation had commenced; this I considered a favorable omen-an effort of nature to 
rid the system of poisonous and morbid material-and I felt that no immediate danger was to be apprehended. I however attempted to drench the animal with a small quantity of lime water and powdered charcoal, merely to alkalize and deodorize the contents of the intestinal canal, but $\mathbf{I}$ found it impossible to get a drop of it down the œsophagus, in consequence of constriction at the upper portion of the same, a condition of the parts that usually follows the administration of an overdose of arsenic.

The symptoms, as observed on my previous visit, had undergone but slight change, yet the surface of the body was warmer, and the animal appeared to suffer slightly from intestinal pain. In view of producing counter irritation, I applied mustard, liquified, to the throat and abdomen.

During the day the excremental discharges were very profuse, and emitted an intolerable stench; towards night an attempt was made to drench the animal with a pint of port wine, which was at. tended with success, the constriction at the upper part of the œsophagus being somewhat relaxed.

On the following day the discharges were less frequent, and the patient appeared much better; he managed to swallow some flour gruel, and was again drenched with a pint of port wine.

The above cornprises the whole of the medical treatment. By means of good nursing, \&c., the animal so far recovered as to be able to resume work atter a period of twelve days from the time of the accident.

For the benefit of the reader I would say that, "nature, who is ever busy by the silent operation of her own forces," did more for the restoration of this animal from the effects of a well known poison, than the medicinal agents which were used; and I take this opportunity to enter my protest against the orthodox method of treating cases of this kind, which contemplates the use of large doses of the hydrated peroxide of iron, which, unless it be expelled from the sys. tem by the administration of active purgatives, is as destructive as arsenic-the original poison.

\section{FUNGUS HAMATODES OF THE PENIS.}

Prelininary.-Fungus is a term used in morbid anatomy, to express any luxuriant formation of flesh in the shape of a soft excrescence. Homatodes is derived from the Greek language, and signifies bloody appearcioce. In plain English, Fungus Hæmatodes is a luxuriant formation in, or on, the soft parts of the body, presenting a bloody appearance-the bleeding fungus.

The ancient writers describe this disease as a species of soft cancer or medullary - soft-sarcoma (a fleshy excrescence), and the probability is, that it is a cancerous affection, for I have several times removed excrescences of this character, and they invariably re-formed and acquired considerable magnitude, even although the most scientific remedies were daily used for the prevention of their after-development.

The modus operandi of the development of these kind of tumors is as follows: They commence with a soft enlargement, or tumor, on 
the various tissues of the body; for example, in the region of the eyes, testicles, penis, extremities, and breast; the tumor becomes elastic and painful; in form it is irregular, having innumerable convexities and concavitics, bulging out in various directions into an irregular mass of morbid production, and from the surface of which blood often exudes.

The above brief description of the nature and pathology of the disease, is offered as merely explanatory, for the benefit of a large proportion of readers who are not supposed to be versed in the technicalities of the schools of medicine.

The following case will show the mode of operation:

History of tue CAse.-The subject, a bay gelding, aged twelve years, of the sanguine temperament. For six months it was noticed that he did not urinate freely (a mechanical difficulty), and in view of treating a supposecl disease of the kidneys, some person prescribed the usual diuretics, nitre and rosin, which did the patient more harm than good, for he soon passed bloody urine; the owner then sought the advice of another person, expected to know something about the diseases of horses, who blect, to the amount of a large bucket full, and gave daily doses of medicine, all to no purpose; for the horse daily grew worse, urinated with much difficulty, and instead of the urine being voided in the usual continuous, single stream, it described a backward current (wetting the hind legs), of various streams, as if coming from the perforated muzzle of a watering pot.

This was the condition of the horse at the time of my first visit. I found a pin in his neck, where "old Lancet" had bled him, and a bottle of "cure all" at his side. An examination of the penis revealed the presence of a fungus tumor on the glans-penis; this I proposed to remove, and the owner of the animal consented.

Operation for the Removal of the Tumor.-The horse was cast by means of the hobbles, and when fully under the influence of chloroform, the penis was drawn from its sheath, exposing a tumor of about half the bulk of a man's fist; it was attached to the head of the penis, and to the surface of the urethral ontlet. By careful dissection, the whole of the morbid production was removed without much loss of blood. Thus ended the difficulty.

\section{WORMS.}

Worms are usually the result of a deranged condition of the digestive organs; the usual symptoms are, a voracious appetite; loss of flesh, and a general unthrifty condition, accompanied often by a dry, irritable cough ; the excrement is usually slimy, and the anus is often the seat of a morbid secretion.

Treatment.-It was customary in former times to give powerful vermifuges for the expulsion of the parasites; but the most rational method is to impart tone to the digestive function and organs, in the use of tonics, stimulants, and alteratives. See article on Bots; or use the American Magnetic Horse Powders. 


\section{DIPTHERIA.}

Diptheria among horses is not a very common malady, yet it does sometimes occur, as the sequel of suppurative laryngitis. It is a very dangerous affection, from the fact that the exudation and morbid material generates within the respiratory passages.

In view of furnishing the reader some reliable information on this subject, I here introduce a case, as recorded in my note book.

The subject is an entire colt, aged four years, son of the celcbrated Patchen, now owned by J. McPherson, of Chicago, and valued at twenty-five hundred dollars.

On the 25th of September, 1862, I was requested to proceed to the "Cattle Pens" and examine the above named horse, the messenger informing me that the animal was "choking to death." On arrival I found the animal in a dangerous condition; he appeared to be gasping for breath ; a loud stertorous noise, which could be heard at some distance, indicated the nature of the difficulty as depending on obstruction within the larynx; the pulse at the angle of the jaw was very indistinct; both pupils were dilated or amaurotic; the extremities and external surface of the body were deathly cold; the tongue and visible mucous surfaces were livid, indicating speedy death. Once in a while the animal would be seized with a convulsive or spasmodic fit of coughing, which every time seemed to threaten his existence ; in these fits of coughing, he passed from his nostrils a sort of cheesy matter, which seemed to be mixed up with a diptherial exudation and yellow matter, and from the mouth constantly streamed a frothy and glairy discharge.

Under the above circumstances, I considered that the attempt to administer medicine would only be trifling with the life of the patient; hence, I decided to perform the operation of tracheotomy, which was done in the following manner:

Having secured the survices of a couple of assistants, the horse was led to a convenient spot in the centre of the stable. I then commenced an incision over the central part of the trachea or windpipe, about eight inches below the angle of the jaw. The animal did not appear to like this sort of treatment, and seemed disposed to resist and give battle, so that I was obliged to put a twitch on the point of his nose. Having laid bare the trachea, I punctured it, and by means of a probe-pointed bistoury dissected out a circular piece, corresponding to the calibre of the tracheotomy tube. At this moment the horse experienced immediate relief and offered no further resistance. The tube was then inserted and secured to the neck by means of elastic tape, and in the course of a few minutes the alarming symptoms had entirely subsided.

I then applied a counter-irritant to the region of the throat, (larynx), composed of cod-liver oil, spirits of ammonia and camphor, ordered a "bran-mash," and secured the services of a faithful watchman. The operation was performed at night, guided by the uncertain rays of a couple of dilapidated stable lanterns, yet luckily "all is well that ends well ;" my patient came out all right.

For several days he had a very copious discharge from both nostrils, and also from the tracheal orifice, so that the tracheotomy tube 
had to be removed and cleansed several times during the day and night. Four days after the operation, the tube accidentally slipped out of the trachea, and on my arrival in the morning $I$ found that air from the lungs had inflated the whole cellular tissue of the neck, from head to breast, so that about these parts he appeared like a juvenile elephant.

I reinserted the tube, and rubbed the neck with the liniment already in use, and gave a dose of ammonia in water, with some fluid extract of prickly ash bark.

On the fifth day after the operation, I removed the tracheotomy tube and dispensed with it, leaving the animal to breathe through the orifice, he still being unable to breathe through the nostrils.

During this day and the sixth, a very copious discharge from the nostrils, as well as the tracheal artificial orifice, occurred, much of the same resembling that attending diptheria. The animal now began to show symptoms of dropsy, in the region of the breast, belly, sheath and legs, for which I prescribed sweet spirits of nitre, combined with my favorite tonic (golden seal.) The dropsical swelling at the point of the sternum being very large, I there introduced a seton smeared with olive oil and spirits of hartshorn, which finally had a very good effect; and in the course of a few days, by means of this and slight scarifications, the swelling had entirely sulsided, together with the other dropsical symptoms.

From day to day the patient gradually improved. I sutured the wound made in opening the trachea, on the tenth day after the operation, and now, at the time of writing this article, (fifteen days from the time of my first visit) there is a slight discharge from the nostrils, also from between the stitches taken to close the wound in the aeck, neither of which am I in a hurry to arrest, as I consider them favorable symptoms.

The horse has now a good appetite, is in fine spirits, lays down at night, and is out of all danger; and what is most remarkable, does not appear to have lost much flesh. This is probably owing to the fact, that the horse had a fine vital temperament, which sustained him through the trial of his malady, and during the same he got no medicine of a prostrating character, my aim being to keep the horse alive while the disease run its course.

Remaris on the CASE.-I hope the reader will not infer that every case of diptheria requires the above treatment; this, like every other discase, must be treated according to its indications, and it is very rare that the disease assumes the complex form which characterized this inusual affection.

\section{VETERINARY SCIENCE-HOW TO INAUGURATE IT IN THE U. S. ARMY.}

The necesssity which now exists for the services of veterinary surgeons in the U. S. army, needs no argument on the part of the author of this work. Eivery man possessing the least particle of humanity for that much-abused class of animals known as "army 
horses," and being conversant with the facts in relation to the outrageous treatment they receive, must feel that a reform is most sadly needed.

A short time ago I was requested by a government officer to present a feasible plan for making the knowledge I possess available. The following was my answer:

I am sorry to have to inform you that up to the present period there exists no law authorizing the employment of competent veterinary surgeons; therefore, any rational plan calculated to ameliorate the condition of army horses, or to prevent the many unnecessary cases of disease and premature death which are now constantly occurring, or to guard against the great pecuniary losses which the Government and people of this country are now compelled to submit to in the condemnation and forced sales of deteriorated horses, cannot, as I understand the subject, be considered by the "powers that be" until Congress shall legislate upon the subject. I now propose to inform you how I shall render the knowledge I possess availabie.

In the first place, I should follow the systems of instruction and the organizations of the veterinary schools of London, Edinburg, Alfort and Saumeer, and prepare suitable text-books, adapted to the wants of a nation, of a people, who have never given the subject that attention which its importance demands.

In the selection of pupils I should favor the excellent plan proposed by Gen. McClellan, which is as follows: "The pupils for the veterinary school might be selected from among the best recruits; indeed, it is not improbable that the advantages of such an institution would induce excellent men to enlist for the purpose of availing themselves of its benefits. Should such be found to be the results, it would be well to require them to enlist for longer than the usual time, as a compensation for the time spent at the school." Cavalry offeers, farriers, or blacksmiths, should be permitted to attend lectures on anatomy, physiology, and the obvious diseases and lamenesses of horses.

In cases of emergency, a competent veterinarian should be $\mathrm{em}-$ ployed in each cavalry regiment, whose duty it should be to select an intelligent farrier from each company, and instruct such person, in a brief and practical manner, on the management of cavalry horses in camps, the prevention of diseases, and the most rational method of treating diseases incident to camp life.

Should it be found impossible to secure the services of a sufficient number of competent veterinarians for the above purpose, let those who have shown themselves qualified, by an examination before a medical board, march from camp to camp, give instructions, see that the sick and disabled are separated from healthy animals, and that the former be placed in a covered hospital, and then issue special regulations for the use of mounted troops in garrison and the field, for the purpose of guarding against the consequences of ignorance and abuse of the animal machine.

It would be advisable to establish a veterinary professorship at West Point, and there locate the National School. The Government has there a very fine French model of the horse, a skeleton, and 
various preparations of morbid anatomy, \&c., \&c., which, together with other material available, will furnish all that is necessary for the purposes of veterinary tuition. It would also be advisable for the Chief Veterinary Surgeon to issue to his subordinates such orders as shall secure proper sanitary regulations in camp. The horses should be as well cared for as the troops, for in cavalry and artilery service, the success of a campaign, for attack and defense, depends much on the health and efficiency of the horses. It should be the business of some members of the veterinary corps to station themselves at accessible points, and there erect temporary hospitals for the reception of sick and lame horses, where the latter shall receive the benefits of a rational system of medication and nursing, whereby, in their restoration to usefulness, many millions of dollars might be saved to the Government in a short time. I contend that the condemnation and ruinous sale of sick and lame horses is a wanton waste of property; and it would be just as rational, if rational at all, to sacrifice, neglect or abandon sick or disabled soldiers, simply because they are not in fit condition for present duty.

It has been suggested that "the erection of hospitals for sick horses will cost too much." This is a miserable subterfuge, and bears comparison with the insane policy of Farmer Neverthink, who contended that when corn was sold at a high price and cost considerable money to plant it, it voas much cheaper to starve to death.

Th following paragraph will serve to illustrate the necessity which now exists for the services of veterinary surgeons:

"A short time ago, 1,185 condemned horses were sold under the hammer, by the Quartermaster at Washington. They brought prices ranging from $\$ 20$ to $\$ 45$. These animals had been in service only about six or eight weeks, and cost the Government, originally, from $\$ 115$ to $\$ 128$, and it is asserted that another sacrifice, in the sam way, was to be made in the course of a few days! In a transaction of this kind the Gorermment loses, in the short space of a few weeks, over two hundred thousand dollars, which sum would secure the services of a most efficient veterinary corps, like that now attached to the British or French armies, for a period of a year or more; and by such an arrangement over seventy per cent. of the sick and disabled animals might in a short time be rendered fit for the service."

\section{THE BITE OR STING OF VENOMOUS FLIES AND REPTILES.}

In Texas, and in some of the warmer regions of this country, horses suffer intensely from the sting or bite of winged insects and venomous reptiles. The best remedy, in view of counteracting the effects of the same, is, plantain (plitmbago major.) A small quantity of the fluid extract of plantain should be applied to the affected part, and the afficted animal should be drenched daily with two ounces of the same.

The American Magnetic Lotion is an excellent remedy as a local application. 


\section{THUMPS.}

This is a term applied by some persons to a disease known to the members of our profession as Palpitation of the Heart. It is not always an organic affection of the beart, but is often symptomatic, or sympathetic.

Thumps, or Palpitation of the Heart, is easily discoverea by placing the hand on the region of the chest, just beneath the shoulder; the thrmps or palpitations are then distinctly felt.

Should the animal be the subject of any well-marked disease, and palpitation accompany it, I should not feel alarmed about the palp1tation, but proceed to treat the disease. In the restoration of the animal to health the palpitation would cease.

Thumps, or palpitation, often occurs in consequence of spasm of the diaphragm, or midriff; when confined to this muscle, the palpitation is noticed to occur at the flanks instead of in the region of the chest, and the inference is that the disease is not organic, but is of nervous origin; hence, in such cases I recommend the use of anti-spasmodics. The best anti-spasmodic drench that I know of, is composed as follows:

Fluid Extract of Indian Hemp .......2 ounces.

Powdered Asafœida ............. scruple.

Syrup of Garlic................. ounces.

Mix. Dose : one ounce night and morning.

The whole region of the spme should be anointed once daily, with some stimnlating liniment. The American Magnetic Liniment is the best preparation I know of for the purpose.

Occasionally, thumps or palpitation, is the result of dropsy of the brain. When this happens to be the fact, a cure is almost impossible; yet if the animal be a valuable one, I should try my best to save his life. The only reliable agent in a case of this character, is iodide of potass, twenty grains of which should bo administered, twice daily, in the form of a drench.

\section{WARBLES.}

WARBLES are a kind of local abscess occurring in the region of the back, induced by undue or unequal pressure from the saddle. When matter can be detected in them, they should be opened and dressed with compound tincture of aloes and myrrh. If this cannot be obtained, apply the American Magnetic Lotion.

\section{ROARING IN HORSES.}

Roaring is usually the result of structural alterations within the larynx or upper part of the windpipe bordering on the trachea. In mild cases of roaring, we usually find a thickened state of the mem- 
brane lining the upper portion of the respiratory passage; and when roaring is occasioned by thickening of this membrane, its degree depends on the ratio of decrease in the calibre of the tube breathed through.

Roaring is a very aristocratic disease. Many of the rery best and fastest horses in England were, and now are, notorious roarers. Flying Childers, as fast a horse as erer wore horse shoes, was one of the worst roarers ever knnwn. The story runs, that when Childers was at full speed, his roaring resembled juvenile thunder!-he could be heard when distant half a mile!

The worst form of roaring (as paddy says) is mhistling. This is the sharp, shrill note, not only sceasioned by the thickening of the lining membrane of the primary passages of respiration, but by alterations in the form and structure of the larynx-the larynx being, in popular language, known as the "voice box."

Roaring is more prevalent among stallions than mares and geldings; and the kind of horse most subject to it is the one having a thick, chunky neck, and having the angles of the jaws in very close proximity with the neck.

Roaring, snarcely, if ever, admits of a radical cure, and when of hereditary or congenital origin, a cure is impossible. A roarer should never be encumbered with a check-rein, for it has the effect of causing undue pressure on the larynx, and thus augments the difficulty.

Roaring can, however, be relieved by an operation known as tracheotomy, which is performed at a point a few inches below the larynx.

At a late meeting of the Imperial and Central Socicty of Veterinary Medicine, M. Leblane read a communication on tracheotomy which was performed on a carriage horse. "The operation had been performed because the horse was a severe roarer, and he wore the tube eighteen years and a half, doing fast work all the time. The animal was destroyed at twenty-three years of age, the owner not desiring to make further use of him, nor to sell him. Since the operation, Leblanc had not observed any change in the horse, except a depression of the bones of the face. After death, the larynx was found very narrow, the mucous membrane and sub-mucous cellular tissues were thickened, the epiglottis deformed, very obtuse, and averted at its free margin. 'The change in the larynx was the original cause of roaring. The depression of the bones of the face was connected with constriction of the nasal chambers, and was evidently secondary to the change in the course of the air in the process of respiration. The parts of the trachea in contact with the tube had undergone a transformation into very hard tissue, which replaced both mucous membrane and cartilaginous tissue. Jt filled the trachea above the point where the tube had been introduced, and, intermixed with this firm, fibrous deposit, was cartilaginous and osseous tissue, which offered great resistance to the scalpel."

Roaring, thick wind, whistling, \&c., are often the sequel of strangled influenza, laryngitis, and other affections of the respiratory passages, and hence may have an accidental origin; in such cases we may entertain a hope of doing some good by means of medicinal agents and counter-irritants. 
The medicines which have proved most successful in my practice are as follows:

Iodide of Potass............... ounces.

Fluid Extract of Stillingia...........

Dose: two ounces daily, in the form of a drench.

The region of the throat should be rubbed daily with a portion of the following:

Spirits of Camphor............6 ounces.

Mix.

Diluted Acet. Acid..............12 "6

\section{SURFEIT.}

Surfeit somewhat resembles the nettle-rash of children. Tumors, varying in size, suddenly appear in various parts of the body and limbs; they create an intolerable itching sensation, and when punctured, a watcry fluid escapes.

Surfeit is usually the result of derangement of the digestive organs.

Treatment.-Make a sloppy bran-mash and add to it one ounce of powdered podophyllum, and four drachms of powdered nitre; in short, any medicine of an alterative character is indicated, and I know of no better alterative than that manufactured by Lord \& Smith, of Chicago, known as the American Magnetic IIorse Powders. Their Magnetic Lotion is also a suitable external application, for this disease. A small portion of it should be applied twice daily, by means of a sponge.

\section{ERYSIPELAS.}

Erysipelas is known by the eruption of inflammatory, nodulous swellings, usually appearing about the head and limbs. The swellings are generally hard, hot, and painful; sometimes they become. purple and spotted, and sloughings supervene. The disease often occurs in consequence of an impoverished state of the blood.

Trentment.-Pure air and nutritive food are indicated, and the medicinal treatment is the same as for surfeit.

\section{ON THE NERVOUS SYSTEM OF THE HORSE.}

Winat provores Muscular Action. The influence which provokes muscular action is brought to them by the nervous threads or filaments-termed nerve threads. These are distributed amongst the muscular fibres in all parts of the body; and on the external surface of the body and extremities they are very minute and delicate, which accounts for the sensitive condition of the skin, nose, feet and ears of the horse. A knowledge of these facts should operate to 
prevent much barbarity which is even now unknowingly applied. For example, a horse lame is brought to a blacksmith, in view of discovering the seat of lameness. The blacksmith, acting on the aphorism of "every man to his trade," sees nothing inside or outside of the foot-which happen to be the geographical boundaries of his craftsman knowledge of equine diseases; he applies a pair of pincers, wielded by strong, muscular arms, perhaps supposing that the whole foot is as insensible as the generous slices which he has been accustomed to remove from the crust and sole. The effect of the mechanical force employed is often to create lameness in a region, perhaps, where it never existed; and the same is true as regards many other supposed innocent barbarities which the horse is compelled to submit to.

Nerve Threans. Nerve threads are minute tubes consisting of very delicate firms capable of transmitting from the great galvanic battery - the brain-its mandates of intelligence. Somia of these threads, or tubes, enter the muscles as large branches, and then ramify and are distribued in all directions through the muscular substance.

Nerve Brancmes. The nerve branches are bundles of distinct tubules, bound together in a common sheath, yet to the naked eye they appear as a common thread.

Nerve Tubules. The nerve tubules are kept distinct from each other, or isolated, from the fact that their function is the conveyance of distinct impressions to particular parts of the animal economy.

The Spinal Cord. The spinal cord is carefully invested in its bony canal by membranes similar to those which enclose the brain. The spinal cord, like the brain, is composed of two apparently different substances, one being white, which is termed medullary; the other of a gray color, termed cineritious.

The white substance of the brain contained in the nerve cells, is a combination of fat, phosphorus and water.

Two ounces of every pound of nerve substance is albumen. Albumen is a substance similar to the white of an egg.

Every pound of nerve substance contains eleven ounces of water, one-third of an ounce of phosphorus and one ounce of fat.

The gray color of the brain is due to the presence of a vast number of minute blood vessels.

Each nerve which is sent out from the spinal cord, or marrow, has a double root or origin; the outer one distributes itself to the superficial or external parts of the body; the inner branch furnishes nerves to the deeper seated tissues of the body.

Sentient and Motor Nerves. The skin, or external surface of the body, is abundantly supplied with what are known as the extremitics or terminations of the sentient nerves; and most of the nerves of the body consist of an admixture of two different kinds of nerves; hence, we have motor as well as sensitive.

The sentient nerves enable the animal to acquire information of the external world, as to the temperature of the atmosphere, \&c.

All the outer extremities of the sentient nerves are associated with nerve cells and capillary blood vessels.

Sentient impressions are vital changes connected with the destruction of nerve substance which has to be replaced through the ordin- 
ary course of nutrition; hence, all the organs of scnsation must be abundantly supplied with blood. The blood furnished to the nerve substance carries to it oxygen, and this oxygen effects the decomposition on which the nerve force depends for its integrity. Every thought, muscular action, pulsation, and act of respiration occasions nerve waste or decomposition. Respiration rather augments oxygen than diminishes, yet a certain amount of nerve waste occurs even in the physiofngical function of the lungs.

Nerve waste is peculiarly rapid during the employment of nerve force, so that a horse of the nervous temperament-when performing feats of speed-will become sooner exhausted than another of the lymphatic temperament, whose nervous system is not so delicately organized. The sum and substance of the matter is, that men and horses of the nervous temperament wear out, as the saying is, very fast.

The spinal cord receives impressions from the external regions of the body, and emits motor force. For example, if we rudely handle an animal, the act occasions combative muscular movements.

Some of the movements or evolutions carried on by the spinal cord are involuntary, and therefore may be considered as unconscious, simply because they occur when will and sensation are suspended, during the time when sleep prevails; therefore it may be inferred that the spinal cord takes charge of various operations of the body, which would be less perfectly performed if left to the ordinary action of voluntary muscular and nervous actions.

Many of the movements effected under the influence of the brain and spinal marrow, are instinctive, and in no way connected with the will. For example, a floating foreign body in the air approaches the eye of a man or horse, and ere either one knows anytling about it, the eyelids are instantaneously closed (involuntarily, of course); hence, such muscular movements are in no way connected with the will.

All animals that possess any trace of a cerebrum, or brain proper, are capable of performing some kind of intellectual operation.

MrvD. The results that are worked out through the activity of the brain are termed the "mind." Horses have a brain, hence must think and reason; their manifestations of mind not differing from that of man, only in degree.

\section{ON THE TREATMENT OF DISEASE.}

During the past fifty years much of the live stock of this country has been most outrageously over-doctored and over-dosed, many people supposing that, by converting a sick horse's stomach into a sort of apothecary's shop and grocery store, the sooner would he get well, when the very reverse is the case; for I am satisficd from long experience, and having been a careful observer of the effects of medicine on the animal economy, that the less drugs a sick horse gets, the more likely is he to get well.

For example, when a large quantity of medicine is administered to a horse, it very frequently so disturbs the animal economy as to 
create a medicinal disease of a very grave character; add to this the original malady, and the reader will perceive that nature-the "Good Samaritan"-does not have a fair chance. If let alone, she (nature) is equal to the task of curing any curable disease ; but when meddlesome medication assails the citadel of life, the forces of nature being overpowered, they resign the living citadel to the enemy, and death is the result.

Many medicines-so called-such as antimony, hellebore, strychnia, arsenic, \&c., \&c., when administered in repeated doses, accumulate in the system, are absorbed, act as depressors of vitality, and the animal dies, actually poisoned by the so-called medicine.

After eighteen years of actual practice, I have come to the conclusion that the business of the physician is to aid nature, and administer medicines of a sanative character, which are calculated to preserve the integrity of the vital forces while the disease runs its course. Many medicines are supposed to have a specific effect on disease. I very much doubt this proposition, and believe that most of the curable cases are self-limited, and only require the exhibition of some simple form of medicine, the action of which is alter. ative.

The effect of an alterative is to change morbid action; and it does not matter what species of animal is aftlicted, the laws of the animal economy are uniform, and whether we prescribe for a man, horse, or cow, our system of medication must, on the principles of reason and past experience, be of a sanative character, calculated to preserve the integrity of the organism; so that, if any of the readers of this work have sick animais in the barn, sheep-fold, or hog-pen, I advise them to administer medicmes of an alterative, yet sanative character. Messrs. Lord \& Smith, of the city of Chicago, have recently prepared the "best alterative" ever known to science, containing no agent that can possibly have a bad effect on the system of any living creature, yet calcukated to be potent in the cure of disease. The American Magnetic Equine Powders can be used for almost all forms of disease that do not actually need the services of a veterinary surgeon. While the late Gen. O. M. Mitchell was in command of the Department of the Ohio, and afterwards under Buell in Kentucky, he ordered his division wagon master to use these powders, in all cases of disease occurring among horses under his care, and the consequence was, that the lives of many valuable horses were saved. So in reference to the Lotion and Liniment; they had the same effect.

While in Kentucky, almost all the horses attached to General Mitchell's brigade were the subjects of grease and scratches, and other cutaneous affections. He was supplied with a quantity of the American Magnetic Equine Lotion, which soon had the effect of eradicating the disease.

See advertisement at end of this work. 


\section{AGE OF HORSES.}

The age of a horse may be known by marks in the front teeth and tusks of the under jaw, until he is about eight years old, after which period it is a matter of guess-work; yet those who are experts can tell very near the exact age. There are many circunastances which tend to show whether a horse be old or not. The number of a horse's tceth is forty - twenty-four grinders, and sixteen others-by some of which his age may be known up to a certain period. Mares have only thirty-six teeth, as in them the tushes are usually wanting. A few days after birth, the colt puts forth two small front teeth in the upper and under jaws, and soon after two more ; these are called nippers. The next four shortly afterwards make their appearance. The four corner teeth-as they are termed-come a few months after the last named. These twelve teeth, in the front of the mouth are small and white, and continue without much alteration until the colt is about two years and a half old, when he begins to shed them. The two teeth that first make their appearance are the first that are lost, and are replaced by two others, called horse's teeth, considerably stronger and larger than those that have made way for them. Between the third and fourth year, the two teeth next the first fall out, and are in like manner replaced by horse's teeth. Between the fourth and fifth year, the corner teeth are changed; the tushes make their appearance. About the fifth year, the horse is said to have a full mouth. After this period, up tor the eighth year, the age of a horse can, with some degree of certainty, be known by the cavities in the teeth, which at first are deep, but are gradually, by the process of mastication, worn down, and abuut the eighth year disappear. After the fifth year, the above criterion of age may be corroborated by the grooves in the tushes of the male, which are inside; they are two in number. At six, one of these cavities, viz., the one next the grinder, disappears; at seven, the other is considerably diminished; at eight, is almost, but not always, entirely gone. After this period, the tushes become more blunt and round. The marks in the upper teeth are by some considered indicative of the horse's age ; those in the two front teeth disappearing at eight, in the two next at ten, and in the corner teeth at twelve. The marks in the lower teeth will disappear about the eighth year.

As a horse grows old, he generally turns more or less gray; the cavities above the eyes become deeper; the under lip falls; the gums shrink away from the teeth, giving them the appearance of a greate $1^{\circ}$ length; the back becomes hollow, or curved. 


\section{AN ESSAY ON SHOEING HORSES.}

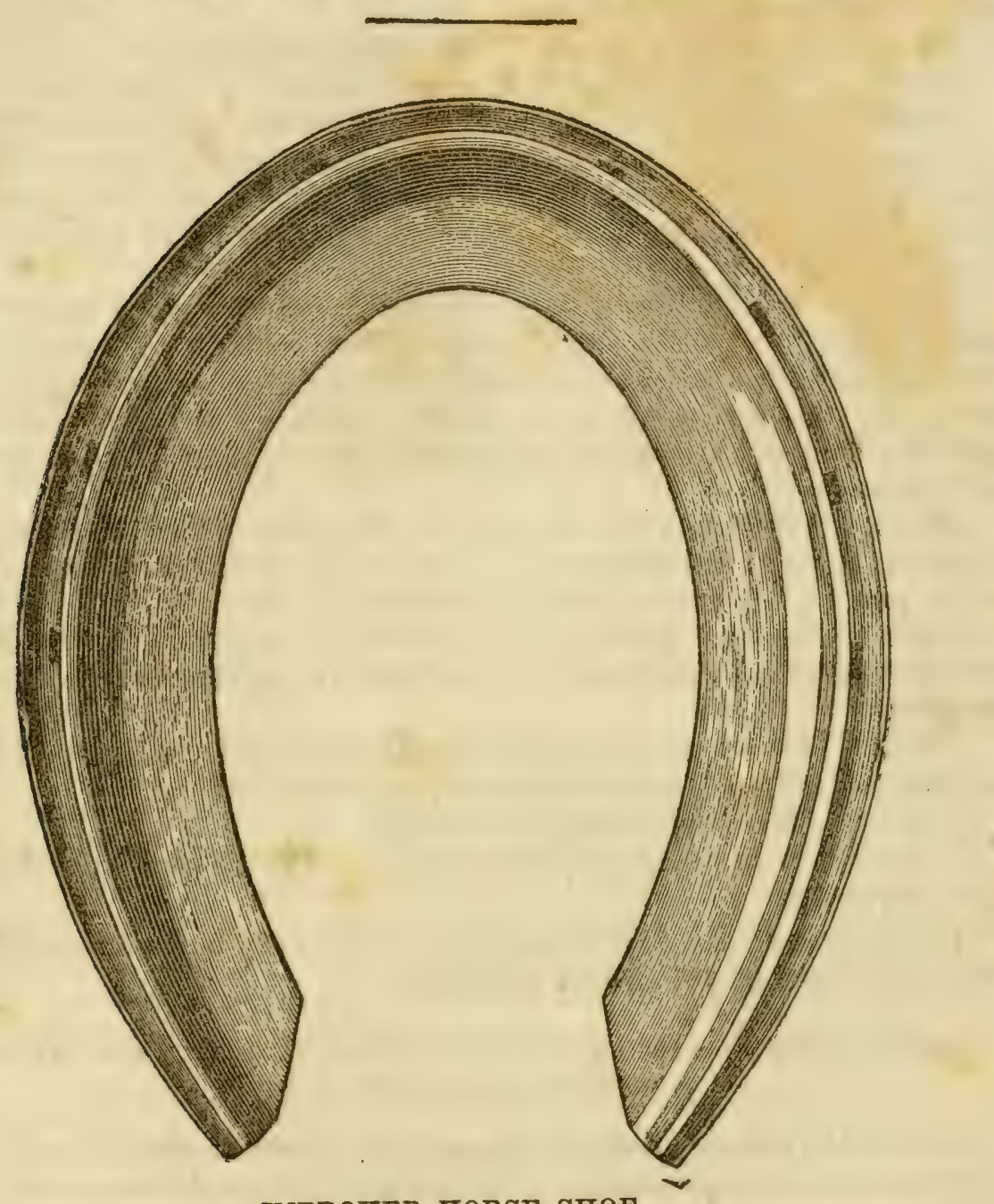

IMPROVED HORSE SHOE.

Patent owned by RoBrrt HALs, Fitchburg, Mass.

This Shoz is one of the most valuable ever invented, and those persons who are in favor of a more rational system of shoeing horses will certainly give the enterpirsing owner of this " patent shoe" their countenance and support. The shoe has a continuous calk, pointed to heel, which is something very desirable, and a very great improvement on the ordinary calks, which are on the principle of a triangle, and a rickety sort of an arrangement for any poor horse to stand on.

I think this new invented shoe is better calculated to preserve the natural tread and functions of the foot than any other now in use, and $I$ advise the readers of this work and all persons owning horses to give this shoe a fair trial, for I fully indorse all that the proprietor claims for it. The above shoe has been used in various parts of the United States, and has given universal satisfaction. 
It has upon its outer cdge a narrow projection, of even thickness, with a thin internal web-the narrow projection forming a continuous calk, in which is a groove through which the nails are driven. The web is much thinner, and the whole shoe thus formed, weighs about one-fourth less than any common shoe, and at the same time is stronger and stiffer.

This shoe possesses the following advantages, viz.:

First. Is less in weight than any other of the same size.

Second. Admits of being nailed around the toe, where the shell of the hoof is thicker than at any other part, and of course requires less nails at the heels, or quarters, leaving this part of the foot free, neither being crowded in or out by being confined to a rigid bar of iron.

Thirct. Admits of the frog coming in contact more readily with the earth, thereby absorbing the requisite moisture to keep it in a bealthy condition and soft, as nature intended, in order that it might act as an elastic cushion, to receive in part the force of the blow and prevent injury to the whole system when stepping on hard surfaces or stones.

Fourth. Prevents the slipping of the foot either back or sideways on any soil or surface when traveling-and with the same muscular power, a horse will travel more miles per day.

Fifth. Greater ease and comfort when standing, as the foot is raised alike at the heel and toe, and bears upon the shell in a natural manner.

Sixth. The internal web protects the sole from injury by contact with any hard substances-and also prevents balling.

Seventh. Great economy in shoeing.

This shoe is in every respect superior for all horses used for military purposes.

The shoe is made of puddled iron, of the very best charcoal-blown iron with steel calks, and of all steel.

\section{HORSE SIIGES SHOULD BE CONCAVE NEXT THE GROUND-EVILS OF CREATING LENGTHY TOES.}

One of the principal objects in applying shoes to the feet of horses, is to preserve the concavity of the natural foot, at its sole. A horse in his natural state, and, indeed, up to the moment of affixing the first pairs of shoes to his feet, has a noticeable concavity of sole; the hoof' somewhat projecting beneath the sole, may be compared to claws, or to the nails of man, each of which aid in securing so many points of resistance; hence, in the case of a horse, such conformation of foot aids materially to prevent slipping on smooth pavements, also secures good foothold, so that the body can be advanced with less muscular exertion than if the shoe and foot presented to the ground a convexity, in which case no hold or fulcrum could be obtained.

The evils of a convex, or even flat surface, next the ground, is best observable in the hind extremitics, the main use of which is the propulsion of the body forwards, and when hauling a loaded vehicle, also. In accomplishing the labor, the power is derived from the muscles and tendons; the bones of tho leg are the compound levers; 
the muscles and tendons being inserted into the bones, it follows that the toe and outsire border of the hoof or shoe (provided the latter is concave next the ground) become the fixed points of the leverage; any deviation from this simple mechanical contrivance operates much against the animal's powers of hauling.

Therefore I contend that the ground surface of the shoe should be concave, or sancer shape; the outer rim or edge being prominent, takes the place of the outside edge of the unshod foot, and the surface next the ground being concave, it corresponds to the natural concavity of the hoof.

Unforturately for the poor horse, very few persons who preside at the forge, take the above view of the case; hence, if we take up a horse's foot and examine the shoe, we shall often find that the shoe is wrong side up, viz., the convex surface is next the ground; and any person acquainted with the facts in the ease, and having the least sympathy for the poor horse, cannot do otherwise than deplore this very faulty method of shoeing.

When Surgeon Percival first entered the British army, the above faulty method was universally practiced; he immediately ordered the shoes to be reversed-turned upside down-and the cavalry horses were much benefited by this improvement, for it prevented an unnecessary waste of muscular power.

It therefore matters not what may be the form of the foot, whether it be high or low heeled, contracted at the heels, lengthened or shortened at the toe, or having a concave or convex sole; the shoe must, or ought to be, concave on the ground surface. In other parts of the shoe, deviations from the general rule are absolute in consequence of the ever-varying form and action of the foot under the states of health, disease, and malformation; and in concluding this part of my subject, I remark that in the concave ground surface of the feet of quadrupeds, and even bipeds, we are presented with a pattern for the ground surface of shoes, requiring no improvement, and if we were to follow this pattern more closely, there would be fewer accidents from falling, and a less number of unnecessarily lame horses.

The next evil prevalent in a faulty method of shoeing, is that of paring the foot, so as to produce unnecessary length of hoof at the toe. These long toes are a mechanical disadvantage to the horse: he cannot raise the limb and foot, evenly, upward and forward; hence, describes a sort of curve, and in so doing often strikes the opposite fetlock, and thus, as the saying is, "interferes."

Long toes also tend to produce strain, or sprain of the flexor tendons and other parts, and soon the knee bulges out in front on a line with the lengthened toe; then the flexor tendons either shorten, or the annular ligament, at the back part of the knee, contracts, and then we have a genuine case of "sprung knee," an unnecessary disease, a permanent eye-sore, and the animal is ever afterwards unsound; unless, by the operation of tendinotomy, and the fect being put into a proper shape by a sensible shoeing smith, the animal is able to perform ordinary horse labor; or, in other words, is able to perform the "ordinary duties of an ordinary horse." Dr. Cuming, a very experienced man in the art of shoeing horses, thus discourses on the evils of lengthy toes: 
"Another evil, resulting from the length at which the toes are commonly left, is interfering. The horse, finding the long projection in front of his foot as so much leverage, acting to his disadrantage, gradually gets into a habit of shifting it, by raising himself from one or the other of the quarters. This is still more the ease when, in addition to the long toe left on the hoof, a small round knob of steel is set into the point of the shoe, as if in contempt of all that nature teaches. With these absurd contrivances placed between his weight and the ground which supports it, it is next to impossible for a horse to raise himself evenly upward and forward, and hence the number that one way or another interfere. If in raising his weight from the ground, the pressure be upnn the inside quarter of the foot, then the thick part of the pastern is thrown inward, in the way of being struck by the upper edge of the hoof of the other side. If the cant be the other way, and the outside quarter raise the weight, the inside edge of the shoe is thrown round and upward, and he runs the risk of cutting with it the opposite leg. Even when the horse, from having a naturally good gait, escapes both these evils, still he is not free from trouble caused by this shape of shoe.

"The fore foot of the horse, as nature makes it, has no such projection in front and downward, as that which the smiths here give it, but rather the reverse. The sole surface at the toe is commonly broken off and notched back at the middle, so that the pressure, when the foot strikes the ground or the animal is raising his weight, is distributed over the whole front of the foot. In accordance with this, the coffin bone, which fills the internal cavity of the hoof, has the same turned-up and notched-back form. In England, France, and on the Continent of Europe generally, wherever Veterinary Schools exist, and scientific attention is given to shoeing, this natural form of the foot is more or less followed in the shape of the shoe, and the animal has preserved to him, along with the protection from wear which the shoe gives, the position of tread for which nature has constructed the other mechanical arrangements of his organs of motion. Why it is not so here is perhaps partially due to the use of butteris for cleaning out the foot when it is shod, as it is impossible with this antiquated instrument to bring the hoof to the proper shape in all its parts; but it is more due to want of study on the part of those who shoe, of the structure of the foot, its uses, and the relation existing between it and the other motive organs, the bones, tendons, and ligaments of the limbs.

\section{IN REGARD TO THE RULES OF SHOEING HORSES.}

The reader is, probably, well aware that great diversity of opinion exists among men regarding the best method of applying shoes to horses' feet, yet it is my belief that the best system is that which is calculated to preserve the natural function, position, and action of the feet, and adopts that kind of shoe which affords the most protection, yet allows the frog to come in contact with the ground on which the animal stands or travels over.

No specific rule can obtain in the general art of shoeing, for the simple reason that the feet differ very much under the conditions of health and disease; hence, a certain form of shoe well adapted to 
meet the requirements of one condition, might prove positively injurious in another, as is often the case.

It is generally understood that the hoof is sufficiently elastic to guard against the jar and concussion which occurs every time the feet are planted on the ground. This elasticity, as observed in a healthy and unfettered hoof, occurs in downward and backward directions. It is scarcely perceptible, yet wisely is it so ordained, for if there was much expansibility, or lateral motion to the hoof, it would prove ruinous to the foot, and the chances of securing a shoe to the same, without positive injury, would be very small.

It is evident that nature has provided for some slight action of this kind, for the hoof is left open at the heels, between which is interposed a soft, elastic substance, known as the frog, which allows of the motions alluded to. Had the intention been otherwise, the hoof might have presented itself in the form of a hollow cylinder.

The parts within the hoof known as the laminæ, or leaves, articnlate with each other, and the extent of their articulation is that of the joint contraction and expansion of the hoof, modified, of course, under the influence of partial or complete pressure while traveling on the road.

Now, in order to favor this physiological action of the foot, the nails must not be inserted any nearer the heels than the safety of the shoe requires; for should the shoe be nailed all around, as the saying is, the hoof, at its solar border, is fettered; hence, the action of articulation cannot occur, and the horse soon becomes lame. Three nails on the inside and five on the outside, are all that are needed to secure the shoe to the foot; provided, however, the nail heads be countersunk, and the points well clinched; if they are not, the shoe becomes loose, in consequence of the nails being driven upwards by repeated blows on their heads as the horse travels on hard roads and unyielding pavements.

If possible, the frog should be allowed to come in contact with the ground, for it acts as a pad, and very much lessens jar or concussion, which otherwise must necessarily occur; it thus becomes a wall of defense, and the nature of the ground over which the creature travels, determines the form, charncter and endurance of the frog.

'Thus, in the unshod colt we usually, in a healthy foot, find the frog well formed, prominent, and callous; this is the result of the stimulating hard knocks it receives when traveling on hard roads. On the other hand, should we examine some animals' feet after they have been long submitted to the evils of domestication, which includes faulty shocing, we shall find that the frog is often imperfect, both in function and structure.

I would not have the reader infer from these remarks that the blacksmith is always blameable for loss of frog, \&c., for in the winter season calks seem to be necessary, and, under such circumstances, it is almost impossible to bring the frog in contact with the ground; hence, it may deteriorate. Then again, there are various diseases of the foot which interfere with the integrity of the frog as well as that of other parts which enter into the composition of a horse's foot. 


\section{REMARKS ON THE FROG.}

There are several reasons why large portions of the frog should not be removed, and I will briefly allude to some of them. In the healthy frog there is a solid wedge-like portion of horn, extending from the cleft to the point of the same; it lies directiy under that small, yet very important bone, known as the "navicnlar"-which signifies boat-shape-and this bone, its region and contiguous tissues, often become the seat of a very painful disease known as navicularthritis-inflammation of the parts. This disease often arises-so say the authorities-in consequence of removing the bulbous prolongation termed the anterior point and bulb of the frog, the function of which is to protect, to a certain extent, this bone, and the sensitive parts connected with it, and to shield them from the injuries which might otherwise occur when the animal is made to travel fast over hard and uneven roads.

A very distinguished physiologist has asserted that when once this bulbous enlargement is cut off, it can never be reproduced, and thus this peculiar bulbous enlargement is seldom found in a horse's foot after he has been pared and shod. This enlargement or thickening of horny substance in the frog not only protects the navicular region, but it also shields the coffin joint, yet there is no part of the sole which receives such a thorough paring as this,

The bulb of the toe once removed, nature causes angmented secretion of horny substance to make up for the loss of this bulb; this secretion is often very abundant, but nature is no match against knife and butteris-the faster the horn grows, the better chance is there for those who feel disposed to cut and whittle it at every subsequent shoeing; then the secretory function soon becomes impaired, and we find that the part finally becomes inelastic and brittle.

'The frog, as a whole, is that cushion-like substance, which, by coming in contact with the ground prevents jar and concussion, not only to the sensitive tissues within the hoof, but to the joints above; -in fact, by the same means, some jar or concussion, which might otherwise occur to the whole body, is lessened.

'The frog is a part which is developed in the same ratio with other parts of the hoof, provided the parts are in a healthy condition, and thus the integrity of the whole is preserved; the frog, therefore, serving as a part of the basis of the animal structure, cannot be removed with impunity.

The reader is probably aware that if the frog be cut away, so that nothing but the shoe comes in contact with the earth, the body of the animal has little, if any, solar support; hence arises strain of the laminæ, and finally descent of the sole.

Strain, or sprain of the laminæ, and descent of the sole, is followed by structural alterations of tissues and parts within the hoof, and then the animal is said to be "foundered"-ruined in the feet.

When preparing the foot in view of applying the shoe, it may be proper to remove just about as much of loose and rough portions of frog as the animal might be supposed to wear off, provided he wero not shod; and yet, according to the testimony of eminent surgeons, this is not always good policy, for these ragged and uncouth looking 
parts usually serve as a protection to new formations beneath, and should not be removed until the latter are perfected.

I am aware that the frog looks better when pared, but a healthy condition of the parts does not consist altogether in good looks, and the same reasoning also applies to the body of the animal; there are many fine looking horses in this city, yet many of them, in consequence of hereditary predisposition and insidious disease, may be next to death's door. We get a very handsome looking hoof and frog, by means of knife, butteris and rasp, but I defy any man to preserve their integrity and keep them healthy by such instruments.

There was a time when the practice of cutting away the fiog was recommended by surgeons themselves, so that the smiths who now, in good faith, practice it, are not always blameable. One author, whose work I have perused, endeavors to smooth the matter over as follows: "The frog offers so little resistance to the knife, and presents such an even surface, so clean and nice, and cuts so easy, that it requires more philosophy than many smiths possess to resist the temptation to slice it away, despite a knowledge, in some instances, that it would be far wiser to let the frog alone."

One of the most distinguished cavalry surgeons to the British army says, that he never allows a knife or butteris to touch the frog, for the simple reason that a long experience has shown conclusively that the frog possesses, under certain circumstances, less reproductive powers than some other parts of the hoof, and the individual alluded to has had horses in his possession for more than five years, whose frogs never scraped acquaintance with a knife or anything of the sort.

The reader may desire to know how the frog is to disencumber itself of its ragged and apparently superfluous surfaces; if so, I answer that nature has provided a means, which is a process of casting off or sloughing, and when this does occur, a new growth is seen beneath it, a smaller frog is visible, yet it is an entire one, and soon acquires magnitude in ratio with its connections.

Among some persons an idea prevails that a hoof should be circular. This is a great mistake, for on examination of a colt's foot we find that the segment of a circle is more apparent on the outside of the hoof; on the inside, from the toe to the heel, we have less curve.

This appears to be a wise arrangement, as there is less liability to strike the inner angle of the hoof against the opposite limb; therefore I infer that any attempts by means of knife and rasp to make the inner margin of the hoof describe the segment of a circle, is contrary to the intention of nature, and injurious to the feet.

\section{REMARKS ON THE APPLICATION OF HOT SHOES.}

Hot shoes, as they are often applied, tend to carbonize the sole and crust, increase the temperature of the foot or fect, and thus, for the time being, induce functional derangement of the plantar system; and if the horse be the subject, of an inflammatory diathesis, or at all predisposed to disease of the feet, of an acute character, the hot shoe may possibly - and it often does-operate as an exciting cause to develop a latent affection.

In view of giving the non-professional reader some idea of the anatomy of the parts, that he may exercise his own judgment in the 
premises, I offer the following: By means of a microscope, we detect on the inside of the hoof-superior and inferior parts-a vast number of perforations, resembling the net-work of a seive; these are termed "plantal porosities." In contact with these parts are the sensitive tissues, composed of slender fibres or filaments, termed papillæ-nipple-highly organized structures, consisting of cellular, venous, arterial and nervous tissues. Supposing that we use a microscope which magnifies 250 times, or diameters, each papillary arrangement appears of the size of four twenty-fifths of an inch, and they are to be found throughout the entire circumference of the fleshy sole ; the papillse are in contiguity with the porosities, and their function is to secrete the equivalents of organization, and thus maintain the integrity of the feet.

The porosities alluded to are the inlets, outlets, commencements, and terminations of the agglutinated hollow tubes-numbering many thousands-which collectively compose the wall and base of the hoof. Into these hollow tubes are prolongations. The latter are heated, burnt, or altered in structure, when brought in contact with a red-hot shoe; hence, the function of the same must necessarily be impaired.

In the crust, or wall of the foot, the tubular arrangement is somewhat perpendicular. They insidiously increase in length, in a downward and forward direction, which gives length to the hoof. In the sole, the tubes are horizontal, which explains the multiplication of the same, and the modus operandi of the physiological or natural thickening of the sole.

The tubes of the crust and sole are usually considered as continuous; consequently, if we cut or pare in the region of their junction, we not only open their canals, but weaken their bond of union; and in such cases we must expect dislocation of the laminæ, which is equivalent to descent of sole, known as "flat, or convex feet."

Hence, a rect-hot shoe applied to the living tissues of a healthy foot, must, necessarily, contract the calibre of the porosities with which it is brought in contact, and impair the function of the same.

The reader is probably aware that moist heat does tend to relax all tissues of the animal economy, and that the reverse is the case when heat alone is applied; for example, a dry floor, or a stall floor, strewed with saw dust, a dry sandy beach, all abstract moisture from moist bodies; yet a heated shoe is a more direet absorber of moisture than either of the above, and must, necessarily, communicate an undue amount of caloric to the parts. By this method, the foot is not only carbonized, but a febrile or inflammatory condition is inaugurated.

In view of sustaining the latter proposition, I introduce the following evidence from a report on the subject made by a distinguisher professor of the veterinary art, a resident of France. By a series of experiments he discovered that the hoof and the sole were conductors of caloric; that the conductile power of the crust was inferior to that of the sole, (yet the latter often gets a pretty essential burning whenever a horse is brought to be shod), the very part that ought not to be burned. He found, also, that it is not before the lapse of four or five minutes after combustion that the thermometer indicates the highest degree of heat to the foot. Also, that the 
thinner the crust is, the more heat becomes transmitted to the internal parts.

Having thus assured himself of the hoof's conducting power, his next object was to ascertain the amount of heat transmitted to the sensitive tissues. The facts are as follows:

From twelve experiments made on feet, in view of throwing light on a subject hitherto considered as dark, the following are the results :

First. That the ordinary shoe, heated to cherry redness, and applied to a horny sole of an inch in thickness, and kept burning for one minute, the carbonized portion not being obliterated in "paring out the foot," has transmitted from three to four degrees of caloric to the villo-papillary and reticular tissue.

Second. That the greatest amount of caloric transmitted in these experiments, was felt, according to the thermometer, between the fourth and sixth minute from the application of the heated shoe.

Thircl. That the sole, pared to the thickness of one-third of an inch, giving under the pressure of the thumb, and the iron kept burning upon it for half a minute, exhibited the villo-papillæ destroyed by the caloric.

Fourth. That when the sole had but one-eighth of an inch in thickness, and readily bent under the thumb, when the heated shoe was held upon it, burning for half a minute, both its villo-papillæ and the surface of the reticular tissues were destroyed by the caloric.

From other twelve experiments, performed with the shoe heated to black redness, the following facts were gleaned:

First. The shoe being applied to the sole upon which the burnt mark still remained, it was found to transmit in the same time more caloric to the living tissues than the iron at a cherry red heat.

Second. The dull heated iron, the thickness of the sole being the same, caused a more lively and deeper burn than the bright heated one.

Thircl. These experiments confirm what was said by the elder Lafosse, in 1858, viz., that it was not the bright heated iron which oftenest occasioned the burning of the fleshy sole, but rather the iron brought to a dull or obscure heat.

"A notion has generally passed current among persons engaged in the art of shoeing, that if the burnt part of the sole be pared away, by means of the ordinary tools (knife and butteris), immediately after the application of the hot shoe, the burn is obliterated, with its effects at the same time. I found this, however, by placing my hand upon the burnt spot, and by testing it with a thermometer, not to be correct; and I further demonstrated its fallacy by direct experiment."

The reader will now perceive that the danger apprehended as the result of hot shoeing, is not entirely groundless; neither do the effects of the same exist only in a fertile imagination, as some writers have asserted, but there is often more truth than poetry in the matter.

Unfortunately we have a vast amount of book knowledge on shoeing, which often passes current as the result of scientific investigation; yet, in my opinion, the horse and its owner would have been better off had such works never been written.

Some smiths contend that it is necessary to apply hot shoes in 
order to "ascertain the bearings," or rather to discover the uneven parts which necessarily occur as the result of faulty paring. Now I contend that a good workman, with proper tools at command, can make an even surface; hence, a good workman has no reasonable excuse for the unnecessary application of red-hot shoes. In fact the application of the same either shows that the smith is wedded to the errors of our forefathers, or else is deficient in skill. Now, if this be true, every honest smith who understands his business, should try to dispense with hot shoeing, and consider the practice as one of the barbarisms of the ancients, whose policy it was "never to forget what they had learned, and never to learn anything new.""

Some smiths, I am informed, merely apply the heated shoe for the purpose of carbonizing, and thus softening the sole and crust of the hoof so that it can be easily pared. This, I think, is a very lame excuse, for in most cases too much of the same is removed, and thus the horse has "tender feet."

If the above is true, then it appears that the intelligent and progressive smith of the present day has no rational excuse for the application of heated shoes; and he who acts according to the dictates of reason and humanity, is sure to secure a good business, and the thanks of an intelligent community will be his reward.

In offering the above remarks on the practice and principles of shoeing, I have no desire to scold or fiad fault with the honest smith,

"Whose brow is often wet with honest sweat,"

for it is a well known fact that lameness in horses is often attributed to faulty shoeing, when such is not the case. For example, a horse has recently been shod and become suddenly lame; this lameness may be obscure, so that its owner cannot determine its location, and he jumps at the conclusion that the lameness has its origin in faulty shoeing, when the reverse is the case-the animal being lame in the shoulder instead of the foot.

\section{QUARTER-CRACKS.}

The best plan for shoeing horses with quarter-crack and toe-crack, is as follows: Before operating on the foot or applying the shoe, the foot should be poulticed with linseed or slippery elm; the poultice to remain on the parts for a period of at least twelve hours. The object in applying a poultice is to soften the hoof and abate any irritation or lameness which may exist; then by means of a crooked end of a drawing knife, all extraneous matter is to be removed from the crack or fissure; a fine gimlet, corresponding to the size of the clinch (which is a round shoe nail), is then to be sent through the hoof directly across the crack, taking care not to get too deep a hold, for fear of wounding the sensitive tissues which lie in contact with the inner part of the hoof; the nail or rivet is now to be sent through the gimlet hole-across the crack-and by means of hammer and pincers it must be well clinched; then the projecting heads are to be rasped off. The hoof is now to be cut through across the crack, close up to the coronet, and thereby all communication between the new growth and the fissure, or crack, is effectually cut of.

When the crack is quite extensive it may be necessary to insert 
more than one rivet. So soon as the process of riveting is completed, the crack or fissure may be dressed with a small quantity of strong spirits of hartshorn, then bind a piece of tape firmly around the foot, and keep the latter cool by frequent spongings of cold water. A bar-shoe, affording equal pressure around the crust and frog, is to be applied; two nails on the inside and three on the outside, as remote from the heels as possible. This form of shoe is, under the above circumstances, the best that can be applied; yet, in case of quarter-crack, perhaps a plain shoe, applied so as to bear upon the heel under the crack, may answer better than the bar-shoe.

The reader will perceive that I recommend the use of a gimlet for perforating the walls of the hoof. It may be proper, however, for me to remark, that in case the walls be thin, such an instrument cannot be used; therefore the smith must either use an awl or a bradawl, for if he drive the nail, or clinch, without first perforating the hoof, the fibres of the latter are unnecessarily separated.

From what I have already written in reference to the art of shoeing, the reader will probably infer that there is no great difficulty in shoeing a strong, well formed foot; and all that is necessary in the preparation of such a foot, is to level the crust and sole, and scrape off any loose portions of horny substance that may be found on the sole, frog, or bars. The nails-two on the inside and three on the outside-should be placed as near the toe as is consistent with the security of the shoe; the heads of the nails should be "sunk, or counter-sunk," so that when traveling on the road or en paved streets, the nails remain immovable, and thus the shoe is not likely to get loose; and the same will be held firmer to the foot if torsion be practiced. Torsion signifies twisting, and is performed in the following manner: after the nail has been carefully driven home, and before it is cut or broken off prior to clinching, it must be seized or inclosed in the fangs of a pair of pincers, and then twisted several times so as to give it a sort of cork-screw end; the screw thus formed is extended to the upper part of the nail, within the fibres of the hoof, and of course requires much more force to draw it than when a nail remains untwisted. The nail being thus twisted, it is cut off and clinched. It appears to me that this method is far superior to that heretofore practiced.

The surface of the shoe which bears on the ground should be hollowed-concave-for by this means the horse is enabled to get a secure foothold; and such a formation corresponds with the natural form of well formed feet, which are, in the undomesticated state ot the animal, always concave.

When the bottom or sole of a horse's foot is flat or convex, instead of concave, it is at the same time much thinner and less capable of bearing pressure. The shoe for such a foot should be broader than the ordinary one, and must have a good flat seat at the region of the junction of crust and sole. This form of foot being naturally weak, in consequence, perhaps, of some hereditary predisposition, great care is required in nailing the same, otherwise the nail is apt, it driven too far in an upward direction, to enter the sensitive tissues, and thus the horse is pricked, as the saying is.

Finally, the feet of horses are often variously deformed, in consequence of predisposition lurking in breed, from bad management, 
and accidental causes; therefore, it is the business of all persons engaged in the art of shoeing horses to make themselves acquainted with the structure and function of a horse's foot; for in the present progressive era, when improvements are treading on the heels of improvement, a blacksmith cannot afford to plead ignorance on such important subjects, which are vital to his success as a practical shoeing smith.

I cannot conscientiously close this article without offering a few remarks in favor of that much-abused class of men known as "blacksmiths." It is my firm belief that they are often, very often, blamed without any rational excuse for censure. For example, a horse is recently shod, becomes suddenly lame, the lameness may be so obscure and unaccountable that the owner and his advisers caunot, by ordinary observation, determine the seat of lameness, and they come to the conclusion that the mysterious lameness a as its origin in faulty shoeing, which may not be the case, for very many horses are predisposed to various diseases of the feet and lameness of limbs, which, under the very bad system of shoeing, cannot be prevented.

In regard to bad shoeing, it is my opinion that many smiths do not obtain a fair compensation for their services, in the prosecution of their laborious and dangerous vocation; hence, they cannot afford to employ the best kind of help; and if, under the circumstances, a horse's shoes are merely tacked on to the feet, at the rate of the prevalent bread-and-butter price, the owner of the horse is more culpable than the smith.

If horse-owners have a desire to guard against the consequences of faulty shoeing, and wish to see their horses shod in a satisfactory manner, I advise them to pay the blacksmith a living price, so that he can afford to employ "good help"-men who know how to perform work in a workmanlike manner.

Taking a rational view of the whole art of shoeing, the greatest wonder is how so many horses used for draught purposes on our unyielding pavements, enjoy freedom from foot lameness.

\section{MECHANISM OF HORSES' HOOFS.}

The hoof of a horse is considered as an epidermic appendagesimilar to nails and claws of other animals, and scales of fishes. They are produced, in the first instance, by the growth of cells, the contents of which gradually evaporate, so that the walls of the same gradually approximate each other.

In the upper part of the hoof-near its matrix (mother)-these cells are to be observed; they are somewhat flattened against each other, but still retain a rounded form.

The hoof, nails and scales, are not traversed by nutriment vessels or absorbents, as is the case in regard to the sensitive tissues; and the flattened cells, when fully developed, undergo but little change.

The chemical analysis of the constituents of the hoof are as follows:

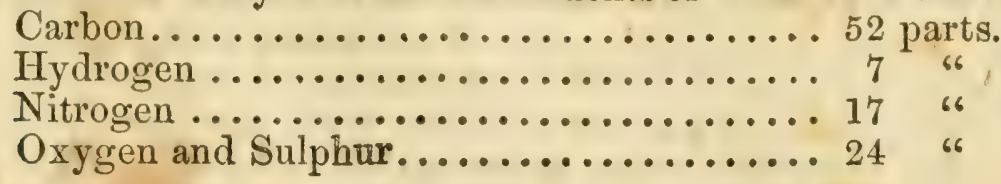

Total ........................100 


\section{PRESSURE ON THE FROG.}

Goodwin says, "It is an incontrovertible fact that unless the frog receives a certain degree of pressure, it will degenerate and become incapable of affording sufficient protection to the sensitive frog, which it covers ; that the heels will gradually contract; that the bars alone are not sufficient to prevent the same, though they certainly oppose it with considerable force. But it does not follow from this that it is necessary for the pressure to be constant, nor is it believed that a shoe which allows the frog to bear on the ground, when the horse stands upon a plane, hard surface, can be always applied even to sound feet without inconvenience. There is no doubt that a horse in a state of nature has his frog almost always in contact with the ground, and then of course he feels no inconvenience from it; but when burthens are placed upon his back, and he is driven about on hard roads, he is certainly in very different circumstances, and if the frog in such cases was constantly exposed to this severe pressure, it would no doubt occasion lameness." Still, a certain amount of pressure is absolutely necessary, for unless that be the case, descent of the sole and disease of the laminæ is apt to occur.

\section{SHOEING OF CAVALRY HORSES.}

The following circular has just been issued by the Adjutant General, British army, from the Horse Guards :

Sir:-It being very desirable that a uniform system of shoeing should be established in the cavalry, and the whole of that important subject having been recently referred to the consideration of a Board composed of officers of great experience in that branch of the service, assisted by two old and experienced professional men, the General Commanding in Chief has been pleased to direct that the following instructions, extracted from their Report, and which embody the whole of their recommendations, be circulated throughout the cavalry, accompanied by duplicates of the pattern shoes, which have been sealed and deposited at the office of Military Boards for general reference and guidance.

1. The shoe is to be beveled off, so as to leave a space and prevent pressure to the sole.

2. It is not to be grooved or fettered; but simply punched, and the nails counter-sunk.

3. Calkin is to be applied to the hind shoe only, and is to be confined to the outside heel. The inside heel is to be thickened in proportion.

4. The weight of the shoe is to be from twelve to fifteen ounces, according to the size of the horse.

5. As a general principle, horses are to be shod with not less than six nails in the fore and seven in the hind shoe; nor is the sole to be attached with not fewer than three nails on either side.

6. In preparing the foot for the shoe, as little as possible should be pared out, and the operation should be confined to the removal of the exfoliating parts of the sole only.

7. Both the fore and hind shoes are to be made with a single clip at the toes. 
Viscount Hardinge is aware that peculiarities in the form and nature of particular horses' feet will cause considerable deviations from these instructions in isolated cases; but, in making this communication, I am directed to express his Lordship's expectation, that in general, the shoeing of the horses of the regiment under your command may be executed in accordance with the principles herein recommended, without reference to previous regimental practice, or to the preconceived opinions of individuals on the subject. I am only further to desire that, at the end of three months, you will have the goodness to transmit to this department, for the General Commanding in Chief's consideration, a report of your opinion as to the advantages or inconveniences which may be found to attend the introduction of the system now recommended.

\section{To the officer commanding.}

In view of giving the reader some idea of the theory and art of shoeing horses in Scotland, I here introduce a selection from the "Scottish Farmer:"

"In preparing the horse's foot to be shod, the requirement in the skill of the operator above all is, that he shall know the right form and required bearing surface of that particular foot; he has, in fact, as much to give the bearing surface to the foot, as he will afterwards have to adapt the shoe to it; the foot-surface and that of the iron shoe to be applied are entirely dependent on the skill and understanding of the shoer, and on these mainly depends the success of the whole process. We will go a little further in explanation: when we have adjusted the foot, whether it be a sound or an unsound one, we proceed to adapt our shoe accordingly, and if the understanding and manual skill are efficient, the shoe will be brought to the foot in every way moulded to its requirements. In approximating the two surfaces, which is always done once or twice, and, if necessary, more frequently, till the adaptation is complete, we just as much review the foot as we do the shoe, and may in the critical process with as much propriety file away a little hoof as we may in another case bend the iron under the hammer. In either case, it is necessarily an adaptation of surfaces; the foot in the first part of the preparation being approximately finished, as the shoe when first tried is the same. In answer to the question, what parts of the hoof are to be removed? we should say none, only so far as is necessary to give the circumference and due proportion to the whole hoof. This we may say cannot always be effected; unfortunately, as horses' feet come to our hands, we find such deficiency, through destruction of parts, and not unfrequently a general debility throughout the whole hoof, that we can only make the best use of what remains.

"Among the most common deteriorations in form, under the present custom of shoeing, is a low, weak state of the hoof across the quarters-that is, taking a transverse line across the centre of the foot, immediately under the line of bearing. This low and weak state proceeds from two causes-first, from the method of preparing the feet; secondly, from the way they are shod, so that the iron gravitates, nay, is often converted into a lever, the fulcrum of which is in that centre, alike in both branches of the shoe, and the hoof is worn, or, as is said, ridden down by the pressure. Another com- 
mon defect is the foot being higher on one side than the other, and thus every part of the foot and limb is thrown out of its natural line of bearing. Then we have many disturbances in the line of obliquity which the foot in its natural state should bear to the limb; we find variations of half an inch or an inch in the depth of the heels, under different modes of preparing the foot, and a similar extreme at the point constituting what is called length or shortening of the toe; all these, which nature has ordained to be exact, are found to vary by the inch, and the defects are variously complicated in the same foot. To know how to prepare the foot implies an understanding of all these deviations. We may be asked, are there no parts of the foot to be removed and other's to be conserved besides that which comes under the general meaning of proportion in depth, breadth, and length of the whole? We say, no. In adjusting the foot we have to deal with the wall, and if that part is well done and the foot well shod, the other parts-viz., the sole and frog-are necessarily taken care of; though the horn is secreted constantly on those parts like that of the wall, to meet the wear, the process of detaching is different; the sole and frog detach their outer layers as they become superabundant. When, however, as is commonly the case, the foot is badly prepared and badly shod, the sole may become, as it does, imprisoned by an overlapping of the wall, and want of the general natural functions of the foot; then the process of exfoliation may be interrupted; the proper remedy in which case is not to hack and sink holes into the sole, but restore the balance in the whole foot by removal of disturbing causes. The instruments at present in use with us, for preparing the horse's foot, are of the most ill-adapted kind; and here we are prepared to be met by the observation that a good workman will effect his object with any tool; it would, perhaps, however, be more correct to say that an able artist will generally devise a proper instrument to effect his object. Two instruments are used for the reduction of the hoof, the drawing-knife and rasp; these are both of modern introduction for that purpose, and, as applies to the old world, they are confined to our country. These instruments are coeval with a doctrine of shoe. ing which has prevailed for between sixty and seventy years; previous to that time, an instrument similar to that in use up to the present time all over the Continent, called a butteris, was adopted in Great Britain. To the late Professor Coleman is mainly due the abolition of the butteris and substitution of the drawing-knife. The reason assigned was, that the old one was an ungainly, clumsy tool, and certainly, to perform what the new doctrine in shoeing was requiring, it was not the instrument. It was laid down as a rule that the sole was to be cut away; that it was to be pared thin every time the horse was shod; that there were certain parts called bar's that were to be preserved, which consisted in neither more nor less than a carving away of the sole almost to the blood, and leaving a small ridge at each angle, between which the hook of the drawing-knife was freely used to scoop out what was called the seat of corn. The little drawing-knife, bent so as to reach to every crevice and angle of the foot, was just the destructive instrument to do such work, but was in no way adapted to adjust a foot for the shoe; indeed no sne ever used it, or does so now, for that purpose. The rasp is used 
for lowering the wall. There is a point where the work of these two instruments meets ; the little crooked knife clears away and destroys the sole, leaving a thin edge of the wall, which the rasp sweeps away. A rasp or file was long in use with us, as it is now on the Continent; but little use is made of it there, since the butteris, a broad, cutting instrument, gives a much better bearing surface to the foot, and the file is used to a small extent only in finishing the work. We may give some notion of the adaptation of the old instrument, the butteris, and the thorough unfitness of the drawing-knife for the same office, by a few comparisons.

"Every one knows that if" he wants to form an exact surface or line, ne does not choose a very small instrument, but one of breadth and ength; a joiner does not use his chisel, but his long plane, to strike a plane, smooth surface; a man who carves handsomely and economcally a joint of meat does not take his pocket-knife, but one with a broad, well-adapted blade; a man who cuts leather uses a broad instrument, and he can do it with exactness. We may go further, and adduce the tailor's large shears as he divides his broadcloth. The fact is, the little instrument makes notches and holes, destroys and weakens; and this has been pre-eminently the case, in the application of the drawing-knife to the destruction of horses' feet.

"We will, in conclusion, say a few words as to how this change was affected. To abolish an instrument from the land, which was welladapted for the requirement, and to introduce into general application one which we hold to be ill-adapted, seems difficult to arcount for. The fact is, at the time the London Veterinary College was first established, nearly seventy years ago, and subsequently, its Principal was able to carry any point, almost at command; the power was displayed in the army, through which changes in the plan of shoeing were rapidly carried, and there the butteris was at once abolished and the drawing-knife substituted; the same thing followed through all the principal forges, and since the scooping out of the foot was pronounced to be a requirement, and insisted on, compliance on the part of the workmen to use the drawing-knife was the more readily exacted. Subsequently, the rasp manufacturer adapted that instrument, so that instead of the little fine-cut rasp and file of the former times, a sharper, rougher, and bigger instrument was introduced, with which a strong man could reduce the hoof, and even destroy it with a very few sweeping strokes. How we are to get back to a more rational system than now prevails, is the work to which we have put our shoulders." 


\section{CIRCUIAI OF TIIE}

\section{Academy of Veterinary Medicine and Surgery,}

CHICAGO,

ILIINOIS.

\section{[AN INCORPORATED INSTITUTION.]}

The object in establishing an Academy of Veterinary Medicine and Surgert in this city, is to educate percons by practical and clinical teaching for the practice of Veterinary Medicine and Surgery on all the inferior orders of creation, which are the subjects of derangements, maladies, and accidents.

The necessity for an institution of this kind is evident from the fact, that the husbandmen of this and other States are the owners of live stock to an immense amount of money; hence have great interests at stake in the welfare and treatment of diseases incidental to the same.

Hitherto the means for education in Veterinary art and science, have been very limited, and a vast number of the finest stock in the country die prematurely; many of them of unnecessary diseases, which might be prevented by proper attention to the laws of physiology, and the rational practice of Veterinary science.

The Veterinary schools of Europe are quite numerous, and rank high in public estimation; they are fostered by governments, associations of husbandmen, and private individuals; and the professional attainments of the graduates of such schools command the respect and confidence of the world.

The study and pursuit of Veterinary science offers a new professional field of usefulness and emolument for the young men of this country, and it is probable that educated Veterinarians will soon find remunerative employment in the service of the Government.

\section{DEPARTMENTS OF TUITION.}

Anatomy and Physiology.-The Lectures on Avatomy and Physiology will be demonstrated and illustrated by Dissection, and by means of diagrams, skeletons, and prepared anaotmical specimens.

Theory and Practice of Veterinary Medicine and Surgery.-Ample meang for acquiring a thorough knowledge of the Theory and Practice of Veterinary Medicine and Surgery, occurs in the practice of the Principal of the Academy, and the same is also taught through the medium of daily Lectures and Recitations.

Text Books. - The Text Books used in the Academy are as follows: Anatomr and Physrology: Percival, Blaine, Dadd, Carpenter. Chemistri and Pharmact: Morton's Manual of Pharmacy, and the ordinaryT ext Books of the Schools of Medicine. Materia Medica: Findlay, Dunn, Eclectic and United States Dispensatories. Theory and Practice: Blaine's Outlines of the Veterinary Art, Dadd on the Treatment of the Diseases of Horses and Cattle, Youatt on the same subjects, and Percival's Hippopathology. Veterinary Jorisprudence: Oliphant, and the Revised Statutes of Illinois.

REGULATIONS.-The Regular Session of this Academy lasts during a period of one year ; each student is required to attend a full Session ere he can present himself before the Board of Examiners for a Diploma of Qualification.

GEORGE H, DADD, V. S., Chicago, Ill. 


\section{HORSD AND CATTLD MBDICINBS.}

THE Subscribers, believing that a great necessity exists for some reliable articles for the treatment of diseases peculiar to domestic animals, after many years of investigation and much expense, are now prepared to offer to the public a class of

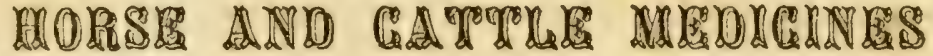

that may be relied upon as superior to any similar preparations ever before offered. They are prepared from

\section{CAREFULLY SELECTED MATERIALS,}

that many years of scientific research and practical experience have found to be most efficient and curative for the diseases and complaints for which they are recommended.

Whenever a Horse is out of condition, which may be known by the presence of worms, chronic congh, unthriftiness, loss of appetite, unhealthy appearance of the skin and hair, turbid urine, debility, and various other symptoms well known to horse men, the

\section{MAGNETIC EQUINE POWDERS}

are a sure and certain remedy ; and as an alterative in the treatment of the diseases of HORSES and CATTLE, these Powders stand unrivalled. The

\section{AMERICAN MAGNETIC EQUINE LINIMENT}

is an infallible remedy for the treatment of the various forms of lameness incidental to man and beast. It has been used a long time in view of mitigating the lameness accompanying Splint, Spavin, Ringbone, and other affections of like character to which domestic animals are liable, and in the treatment of rheumatic affections it has given universal satisfaction. It is also equally applicable to the treatment of all the various forms of lameness occurring among Cattle. The

\section{AMERICAN MAGNETIC EQUINE LOTION}

is a sovereign remedy for the treatment of all the various diseases of the Skin, Heels, and Hoofs, occurring among Horses or Cattle; also for Itch, Mange, Ringbone, FootRot, Grease, and various other affections of like character. It is also very useful in the treatment of wounds and galls.

In confirmation of the above facts, we would subjoin the following certificate of Doctor G. H. DADD, whose well-earned reputation and skill in his profession makes his opinion entitled to the confidence of horse owners, and those who have the care of Horses and Cattle.

\section{CERTIFICATE.}

Chicago, Jan. 1st, 1863.

0. I hereby certify that I have examined and thoroughly tested in my practice the articles known as "American Magnetic Equine Povoders," "American MFaynetic Equine Liviment," and "American Mfagnetic Equine Lotion," prepared by LoRD \& Surrn, of Chicago, Ill. I regard them as preparations of great merit, and would cordially recommend them as being prepared with special care, from reliable remedies, and more efficacious for the treatment of the various diseases for which they are designed, than any remedies of which I have knowledge.

GEO. H. DADD, Veterinary Surgeon,

Author of "Anatomy and Physiology of the Horse," "Modern Horse Doctor," \&c. Principal of the Chicago Veterinary School.

We would ask a fair trial for these remedies, believing them to be the best preparations of the kind ever before offered to the public.

The Trade supplied on most liberal terms by the Proprietors, to whom all orders ihould be addressed.

LORD \& SMITH,

Wholesale Druggists, 23 Lake Street, Chicago, Ill. 


\section{P. P. STEWART'S}

LARGE OVEN, AIR TIGHT,

SUMMIER AIND WIITER

COOXIG STOX

EVERY FAMILY SHOULD HAVE ONE.

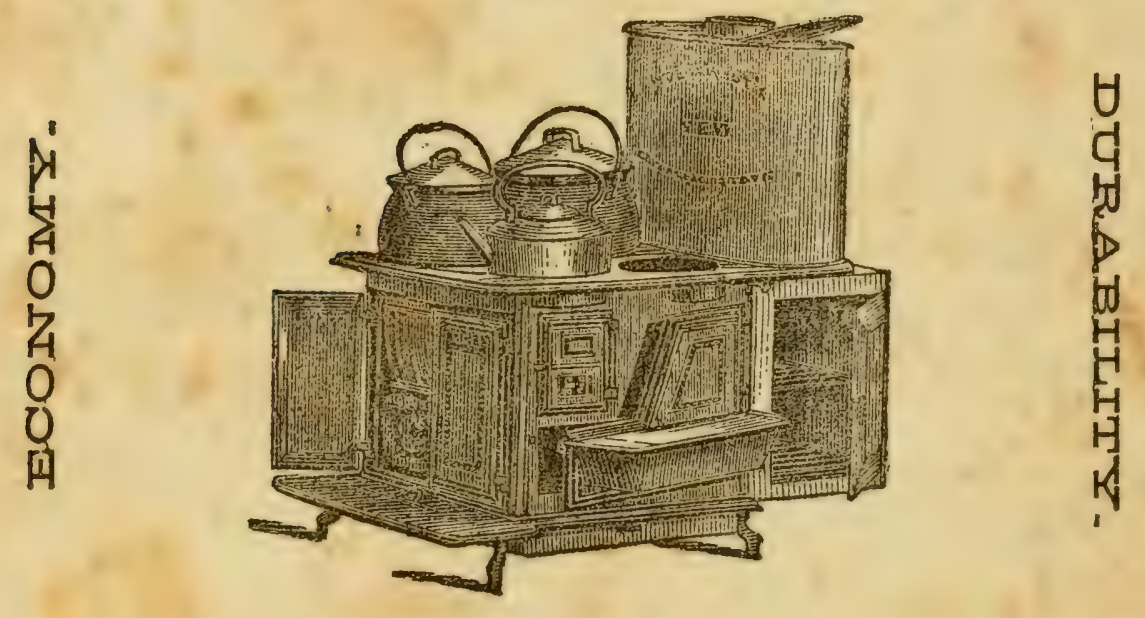

This stove has taken more First Premiums than any other ever manufactured.

\section{THRRE IRR OURR 70,000 OP THEM IN USR!}

For Sale in all the Principal Towns throughout the North-West.

ASK FOR THE GENUINE P. P. STEWART STOVE

FULLER, WARPEN \& CO.

53 State St., Chicago, III.

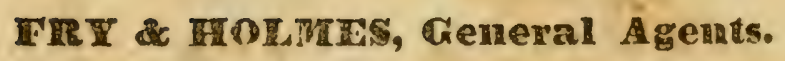


TWR 



